\title{
MHz-Rate NO PLIF Imaging in a Mach 10 Hypersonic Wind Tunnel
}

\author{
N. Jiang ${ }^{1}$, M. Webster ${ }^{2}$, and W.R. Lempert ${ }^{3}$ \\ Departments of Mechanical Engineering and Chemistry \\ The Ohio State University, $201 \mathrm{~W} .19^{\text {th }}$ Ave, Columbus, OH 43201 \\ J. D. Miller ${ }^{2}$ and T. R. Meyer ${ }^{3}$ \\ Department of Mechanical Engineering, Iowa State University, Ames, IA 50011 \\ P. M. Danehy ${ }^{4}$ \\ NASA Langley Research Center, Hampton VA, 23681
}

\begin{abstract}
NO PLIF imaging at repetition rates as high as $1 \mathrm{MHz}$ is demonstrated in the NASA Langley 31 inch Mach 10 hypersonic wind tunnel. Approximately two hundred time correlated image sequences, of between ten and twenty individual frames, were obtained over eight days of wind tunnel testing spanning two entries in March and September of 2009. The majority of the image sequences were obtained from the boundary layer of a $20^{\circ}$ flat plate model, in which transition was induced using a variety of cylindrical and triangular shaped protuberances. The high speed image sequences captured a variety of laminar and transitional flow phenomena, ranging from mostly laminar flow, typically at lower Reynolds number and/or in the near wall region of the model, to highly transitional flow in which the temporal evolution and progression of characteristic streak instabilities and/or corkscrew-shaped vortices could be clearly identified. A series of image sequences were also obtained from a $20^{\circ}$ compression ramp at a $10^{\circ}$ angle of attack in which the temporal dynamics of the characteristic separated flow was captured in a time correlated manner.
\end{abstract}

\footnotetext{
${ }^{1}$ Post-Doctoral Researcher, Member AIAA

${ }^{2}$ Graduate Research Assistant, Student Member AIAA

${ }^{3}$ Professor, Associate Fellow AIAA

${ }^{4}$ NASA Research Scientist, Associate Fellow AIAA
} 


\section{INTRODUCTION}

Many critical hypersonic flow phenomena, such as flow transition, turbulence, shock-wave flapping and vortex shedding, occur at frequencies of 10's or 100's of $\mathrm{kHz}$ and cannot be temporally resolved by conventional measurement techniques such as force and moment, phosphor thermography, and schlieren imaging. While some advanced Schlieren systems and intrusive probes (e.g., hot wire) can obtain flow data in this frequency range, non-intrusive, spatially and temporally resolved measurement techniques are required to provide benchmark data for comparison with CFD codes. Since its inception more than twenty-five years ago [1,2] Planar Laser-Induced Fluorescence (PLIF) imaging has been developed into a powerful technique for qualitative and quantitative visualization in a wide variety of flow and combustion environments. However the ability to capture unsteady flow dynamics at high speed is severely constrained by the relatively low repetition rates (order $10 \mathrm{~Hz}$ ) of typical PLIF systems. More recently, solid-state diode-pumped/dye laser technology appears capable of achieving up to 10 $\mathrm{kHz}$ of continuous PLIF imaging, but this is still much lower than the bandwidth required for tracking flow phenomena in hypersonic flows [3]. To address this diagnostic need we have been developing, over the last several years, an ultra-high frame rate PLIF imaging system which combines a "burst mode" Nd:YAG-based tunable OPO system [4-6], with a framing ICCD camera. In this paper we will demonstrate the utility of the system for obtaining time correlated PLIF movie sequences in a large scale flow facility, the NASA Langley 31" Mach 10 Hypersonic Wind Tunnel [7]. Results will be presented for facility test 463 in which approximately 150 image sequences were acquired over four days of wind tunnel testing.

This paper builds upon the recent results of Danehy, et al. [8-10] by demonstrating, for the first time, the ability to capture sequences of $10-20$ NO PLIF visualization images at frame rates as high as $1 \mathrm{MHz}$. Such a system provides the potential to visualize and quantify highspeed hypersonic flow phenomena to reduce error margins of codes used to design the hypersonic vehicles. Improved predictive capability is critical to optimizing the design of heat shields, for example, which ensure the survival and affect the overall weight of high performance hypersonic vehicles.

\section{EXPERIMENTAL}

\subsection{Laser System Description}

The burst mode pump laser, illustrated in Fig. 1, has been described in detail previously [1113]. Briefly, a continuous wave diode pumped $\mathrm{Nd}$ :YAG ring laser serves as the primary oscillator, the output of which is pre-amplified in a double-pass variable pulse width (from $0.3-$ $2.0 \mathrm{msec}$ ) flashlamp-pumped pulsed amplifier. The amplifier rod is $10 \mathrm{~cm}$ in length by $6.4 \mathrm{~mm}$ in diameter, and is wedged at a few degrees to mitigate self lasing. The resulting smooth pulse is formed into a "burst" train using a custom, dual Pockels cell "slicer," the output of which is further amplified in a series of six additional flashlamp pumped amplifiers, with $6.4 \mathrm{~mm}, 6.4$ $\mathrm{mm}, 9 \mathrm{~mm}, 9 \mathrm{~mm}, 12.7 \mathrm{~mm}$ and $12.7 \mathrm{~mm}$ diameter $\mathrm{x} 10 \mathrm{~cm}$ long rods, respectively. Note that the slicer produces burst sequences of $\sim 20-30$ pulses at $1064 \mathrm{~nm}$, each with duration of $\sim 10 \mathrm{nsec}$, and pulse energy of $\sim 10^{-9}$ Joules ( 1 nanoJoule). The remaining amplifier stages increase the individual average pulse energy to $\sim 100 \mathrm{~mJ}$ per pulse $\left(10^{8}\right.$ gain), or more, at $1064 \mathrm{~nm}$. 
The generation of such high energy $(\sim 100 \mathrm{~mJ} /$ pulse $)$ burst sequences at repetition rates exceeding $\sim 100-250 \mathrm{kHz}$ is extremely challenging, due to the inherent dynamics of achieving population inversion (i.e., gain) in the Nd:YAG medium. More specifically, maximum optical gain in an Nd:YAG amplifier occurs at a time delay of $\sim 180 \mu \mathrm{sec}$ after initiation of the flashlamp pumping pulse. In some senses the solid state Nd:YAG medium can be thought of an as "optical capacitor" in which flashlamp photons are stored, and subsequently "discharged" as laser pulse energy. Optical discharge, which is due to stimulated emission, can occur on extremely rapid (psec, or less) time scales, but the time scale for "re-charging" is determined by internal energy conversion processes related to the detailed material internal electronic structure. In the burst mode laser system the flashlamps provide a quasi-continuous "charging" pulse, over time scales of between 0.3 and $2.0 \mathrm{msec}$ (in the current configuration). If only relatively modest individual pulse energies are required ( a few mJs) such that the "capacitor" is insignificantly "discharged" by each pulse, then achieving high repetition rate is relatively straight-forward. For example, low $(2.5 \mathrm{~mJ} /$ pulse at $532 \mathrm{~nm})$ energy sequences of twenty pulses at $250 \mathrm{kHz}$ repetition rate, suitable for scattering-based diagnostics such as Planar Doppler Velocimetry (PDV), have been obtained several years ago [13]. As pulse energy requirements are increased, however, there is significant "gain depletion" that occurs in the amplifier chain after each pulse of the burst. At relatively long interpulse spacing ( $\sim 20$ microseconds, or greater), this is less of an issue in that there is sufficient time between the pulses for a non-negligible fraction of the initial gain to be "refilled." For example, 20-pulse burst sequences at $50 \mathrm{kHz}$ with individual pulse energy in excess of $400 \mathrm{~mJ}$ (at $1064 \mathrm{~nm}$ ) have previously been demonstrated [11].

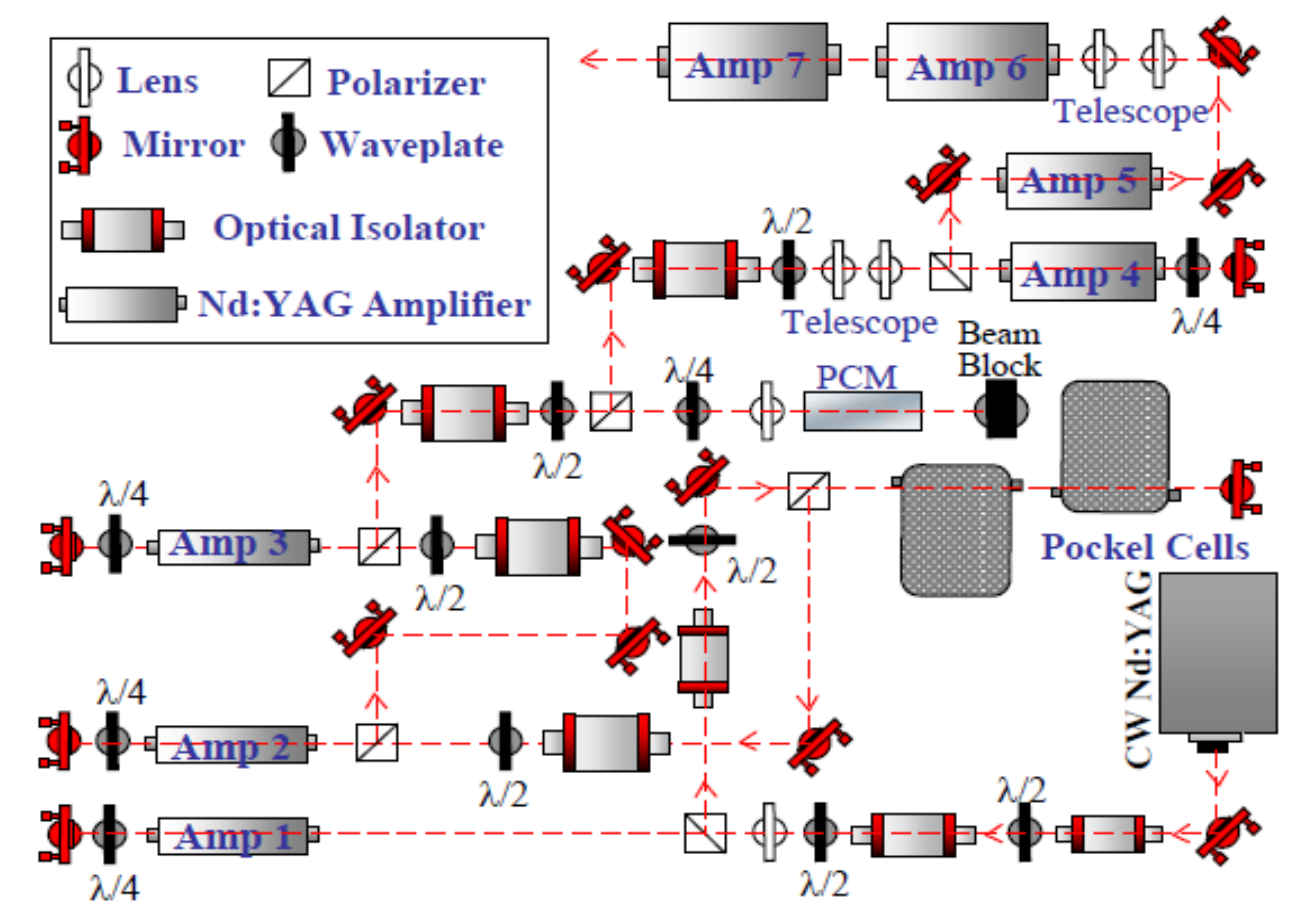

Figure 1: Schematic diagram of pulse burst Nd:YAG laser. 
At the required interpulse repetition rates $(500 \mathrm{kHz}$ to $1 \mathrm{MHz})$ and individual pulse energies ( 100 mJ@1064 nm) for imaging in large scale hypersonic facilities the lack of gain refilling was observed to be a very significant factor, limiting achievable pulse energy, pulses per burst, and burst-to-burst uniformity. To address these limitations a seven-amplifier pulse burst laser system has been assembled, as shown in Fig. 1. Note that amplifiers cannot simply be added arbitrarily, as system performance is ultimately limited by the growth of Amplified Spontaneous Emission (ASE) in the forward direction. As will be discussed in more detail directly below, breaking the ASE chain is one of the functions of the Stimulated Brillouin Scattering (SBS) Phase Conjugate Mirror (PCM) which is located between the third and the fourth amplifier.

Inclusion of an SBS PCM is a well known approach for improving the spectral characteristics of a pulsed laser beam [14]. For this work, the purpose of the PCM is two-fold. First, since it acts as a highly non-linear intensity dependent mirror, it essentially eliminates the low intensity pedestal which is superimposed upon the desired pulse burst sequence due to the finite on/off contrast of the pulse slicer. In addition placement of the PCM approximately halfway through the amplifier chain greatly suppresses ASE growth in the forward direction, which ultimately dictates the limit of achievable pulse energy. ASE, which grows exponentially (from "noise) with the number of passes through the Nd:YAG gain medium, does not attain sufficient energy to achieve SBS threshold when the PCM is located at this point in the amplifier chain. Downstream of the PCM ASE growth restarts, from noise, at the fourth amplifier. Interruption of the ASE exponential growth "chain" in this manner results in negligible ASE growth, even after a total of seven amplifiers.

Fluorinert FC-75, which has been used extensively as an SBS fluid [13] was previously found to perform well when operating the burst mode laser at less than $\sim 250 \mathrm{kHz}$ [4]. However, it was found that operation at frequencies of $500 \mathrm{kHz}$ or higher resulted in poor stability and burst uniformity, indicating, presumably, that the system was being operated at, or near, the SBS threshold [12]. To mitigate this problem, $\mathrm{CS}_{2}$, which is commonly used for SBS phase conjugation [15-17], and which has an SBS gain coefficient which is a factor of approximately fourteen higher than that of FC-75 [16], was used as the PCM working fluid in this work. When the pulse burst laser is operated at $500 \mathrm{kHz}$, average individual pulse energy input to the PCM is $\sim 4 \mathrm{~mJ} /$ pulse. At this pulse energy, the measured SBS reflection efficiency is approximately $70 \%$ and $35 \%$, respectively, for $\mathrm{CS}_{2}$ and $\mathrm{FC}-75$, a significant difference that impacts system performance. Perhaps more importantly, as shown in [12], the SBS reflectivity of $\mathrm{CS}_{2}$ is approximately constant for input pulse energy in the range $\sim 1.8-4 \mathrm{~mJ}$ (or more), whereas the reflectivity of FC-75 increases approximately linearly from zero (threshold) to $\sim 33 \%$ in the range. The use of $\mathrm{CS}_{2}$ as the SBS fluid therefore results in greatly improved burst uniformity for burst rates of $500 \mathrm{kHz}$ or greater.

As in our previous work, the fundamental output at 1.06 microns is converted to second (532 $\mathrm{nm})$ and third $(355 \mathrm{~nm})$ harmonic wavelengths using a pair of non-critically phase matched Type I LBO crystals. The third harmonic is then used as the pump for a home-built injection-seeded OPO system. OPO output is sum-frequency mixed with residual $355 \mathrm{~nm}$ pump, creating high frequency bursts of tunable output in the vicinity of $226 \mathrm{~nm}$, which are used for NO PLIF imaging. The repetition rate of the burst sequence can be as high as $10 \mathrm{~Hz}$, but is typically limited to $1-4 \mathrm{~Hz}$ when operating with burst envelopes exceeding $\sim 0.5 \mathrm{msec}$, due to thermal 
loading of the amplifier rods. Figure 2 shows a typical set of 8-10 pulse oscilloscope traces obtained at $1 \mathrm{MHz}$ burst rate at $1064 \mathrm{~nm}$ (top left), $355 \mathrm{~nm}$ (top right), $622 \mathrm{~nm}$ (bottom left), and 226 (bottom right). Note that the $1064 \mathrm{~nm}$ trace was obtained with a relatively low sampling rate oscilloscope that required the detector output to be deliberately broadened in time (using a load resistor and the intrinsic cable capacitance).

For spectrally narrowed imaging the OPO was operated with injection seeding [4], using an external cavity diode laser (ECDL) manufactured by Sacher, Inc. The OPO "idler" beam is seeded, which results in line-narrowed output for both the idler and signal waves. For the seeded measurements performed in this work the seed laser was tuned to $827.456 \mathrm{~nm}$ (vacuum wavelength - measured with a HighFinesse WS-6 Fizeau interferometer wavemeter), which after mixing with the third harmonic beam produced UV output at $225.838 \mathrm{~nm}$, exciting the $\mathrm{R}_{1}(12)$ transition of the NO A-X $(0,0)$ band, which is a reasonable match to the NO Boltzmann distribution at the nominally $250 \mathrm{~K}$ static temperature at the outer edge of the Mach 10 boundary layer.

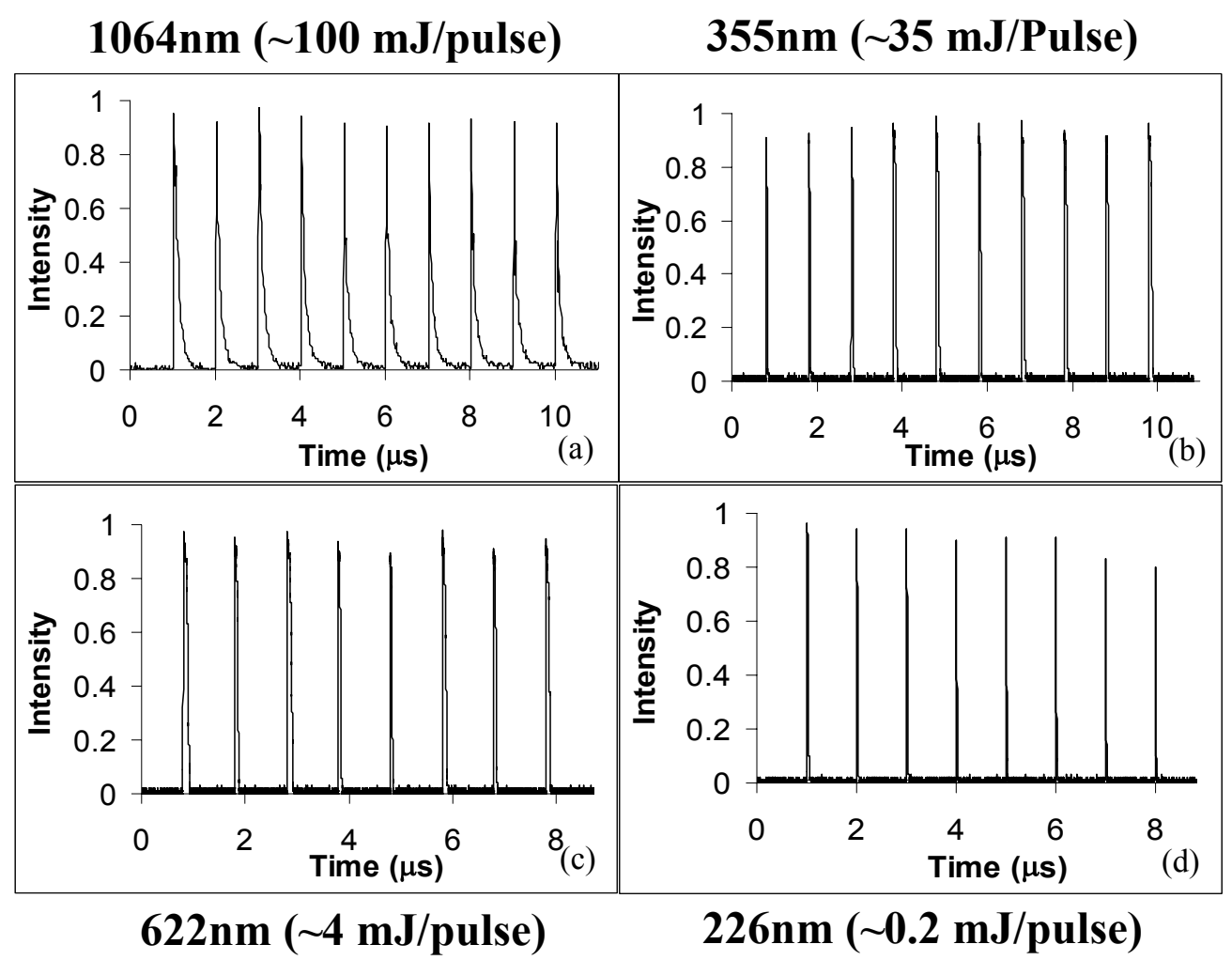

Figure 2: $1 \mathrm{MHz}$ pulse burst laser output traces (a) 1064nm; (b) $355 \mathrm{~nm}$; (c) $622 \mathrm{~nm}$; (d) $226 \mathrm{~nm}$.

\subsection{1" Mach 10 Facility and Pulse Burst Laser Facility Integration}

The 31-Inch Mach 10 Air wind tunnel, shown in Fig. 3 and described in detail in [7], is an electrically-heated blowdown facility located at NASA Langley Research Center in Hampton, Virginia, USA. The air flows from a high pressure heater, through a settling chamber and threedimensional contoured nozzle to the test section. Optical access is provided by top, bottom, and one side wall UV-grade fused silica windows. The facility is capable of approximately 1 test per 
hour, with duration of approximately 1-2 minutes. The nominal operating stagnation temperature is 1000 $\mathrm{K}$, with stagnation pressure in the range $2.4-10 \mathrm{MPa}$ (350 - 1450 psia), corresponding to free stream Reynolds numbers (Re) in the range $1.5-6.6$ million $/ \mathrm{m}$. Typical static temperature and pressure at the edge of the boundary layer, based on CFD computations for this model and conditions [18] are $250 \mathrm{~K}$ and $2.9 \mathrm{kPa}$ ( $\sim 22 \mathrm{Torr}$ ), corresponding to a local Mach number of 3.8. For the images in this paper transition is induced on a model consisting of a flat plate which was $127.0 \mathrm{~mm}$ (5 in.) wide and 162.5 $\mathrm{mm}\left(6.4 \mathrm{in}\right.$.) long and oriented at a $20^{\circ}$ angle to the oncoming flow. A variety of different shaped

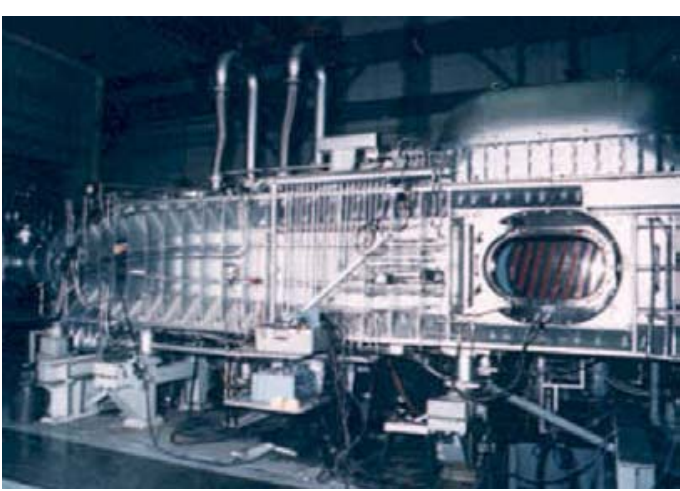

Figure 3: Photograph of NASA Langley 31" Mach 10 Hypersonic Wind Tunnel nozzle and test section. protuberances, including cylinders of varying heights (typically 1-4 mm in height), and a triangle were tested. As illustrated in Fig. 4, pure NO was injected through an $11 \mathrm{~mm}$ wide slot near the leading edge of the model. The NO was injected at a low flow rate, resulting in local seed mole fraction of $\sim 1-2 \%$, assuming the gas mixes uniformly with the boundary layer fluid. More details about the NO seeding can be found in references [8-10].

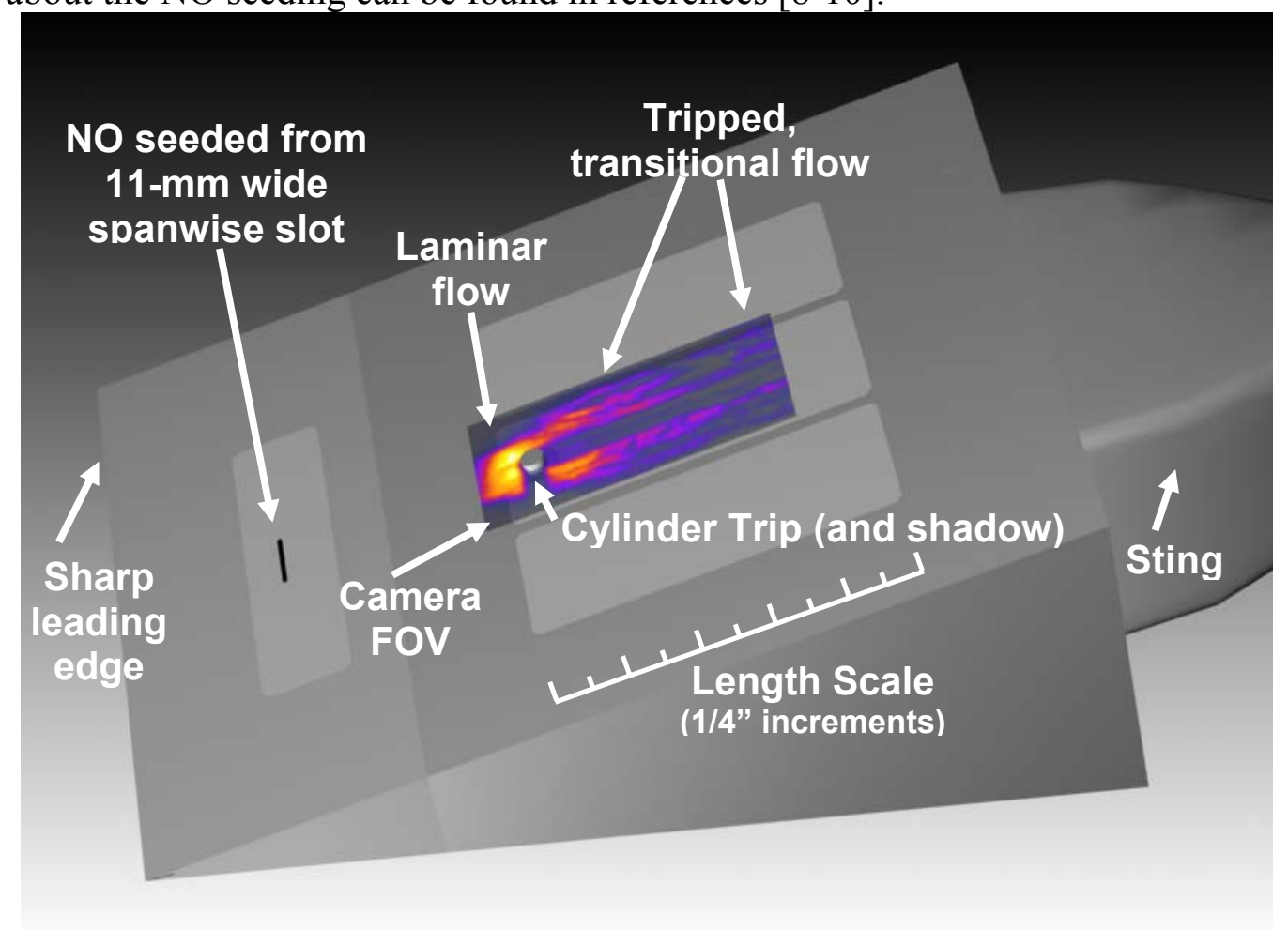

Figure 4: ViDI (Virtual Diagnostics Interface) rendering of the flat plate model tested, showing the $2 \mathrm{~mm}$ tall by $4 \mathrm{~mm}$ wide cylindrical trip at the center and the slot on the model centerline that was used to seed NO. Flow is from left to right and the top surface of the model is oriented at a $20^{\circ}$ angle with respect to the oncoming flow. 
To facilitate measurement in the 31 " wind tunnel, the laser/OPO optical system was mounted on a portable, 3' $\times 8^{\prime}$ ' optical table. A separate portable cart was assembled for the flashlamp power supplies and other electrical driver components. The power supplies were individually fused to three standard 30-amp breaker boxes, one three-phase $208 \mathrm{~V}$ and two single-phase 208 V. Fig. 5 (left) shows a three-dimensional rendering of the portable pulse burst laser and imaging system installed in the 31 " facility. The UV output (shown in purple in Fig. 5) was directed upwards, using a series of telescopes and lenses, to the top of the facility, where it was then formed into a $\sim 50 \mathrm{~mm}$ wide sheet, and directed downward into the test section. The total distance the UV laser beam travelled to the test section was $\sim 15$ meters. The downward propagating laser sheet is aligned approximately parallel to the surface of the model. During a tunnel run the laser sheet was swept through the flow using a stepper motor so that the image location varied between 0 and $5 \mathrm{~mm}$ above the surface. A framing ICCD camera (described below), along with an ordinary "dual-frame" ICCD for $10 \mathrm{~Hz}$ imaging, was placed close $(\sim 30$ $\mathrm{mm})$ to the test section imaging window, resulting in the object plane being about a half meter from the camera lens.

Burst mode NO PLIF image sequences are captured using a Princeton Scientific Instruments PSI-IV framing ICCD camera and $110 \mathrm{~mm} \mathrm{~F} / 2 \mathrm{UV}$ lens. The basic PSI-IV image sensor consists of an $80 \times 160$ array of $115 \times 115$ micron pixels, each of which has its own integrated 28 element memory buffer. Charge is shifted from the photo active area, which constitutes approximately $50 \%$ of the total pixel area, to memory at a maximum frame rate of $1 \mathrm{MHz}$. After acquisition of the desired sequence, the image set is transferred to a PC. The PSI-IV is designed to enable up to four $80 \times 160$ image sensors to be incorporated into a single camera for a maximum resolution of $160 \times 320$. The version used for this work consisted of a pair of sensors with total available resolution of $160 \times 160$. A lens-coupled UV sensitive microchannel plate intensifier, with fast decaying phosphor ( $160 \mathrm{nsec}$ according to manufacturer's specification), provides time gating capability with minimum exposure time of approximately $10 \mathrm{nsec}$.

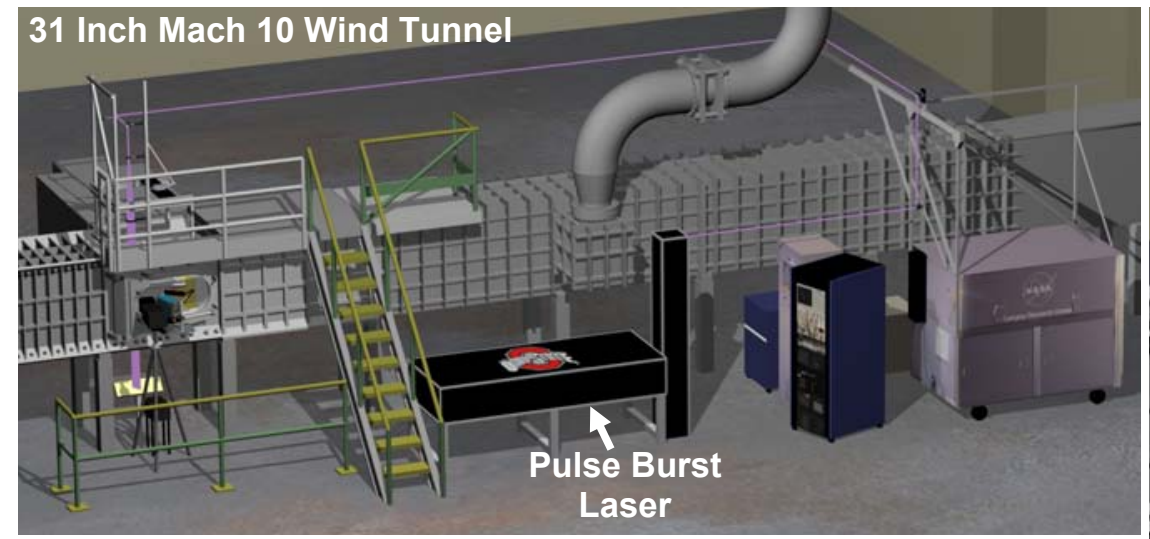

Figure 5: (left) 3-dimensional rendering of pulse burst and $10 \mathrm{~Hz}$ imaging systems installed in the NASA Langley 31" Mach 10 Hypersonic Wind Tunnel. (right) Close up view of model and framing and $10 \mathrm{~Hz}$ ICCD cameras, and sheet profiling optics.

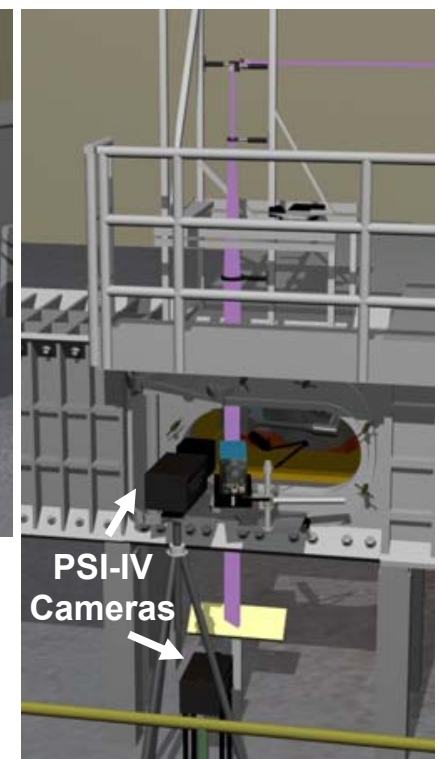

A new method for monitoring the spatial variation in the intensity of laser sheet (i.e. sheet profiling), described in more detail in [19], was utilized for these measurements. As can be seen in Fig. 5 (right) the laser sheet was allowed to pass through the bottom window of the test section and onto a flat surface oriented at $45^{\circ}$ with respect to the horizontal. The flat surface was coated with a fluorescent paint that absorbed in the ultraviolet and emitted in the visible. An 
unintensified PSI-IV CCD framing camera was used to capture the resulting line image which, with careful registration, was used for sheet non-uniformity correction.

Image sequence acquisition requires approximately 5 seconds, limited by the download time to the PC, resulting in acquisition of $\sim 10-15$ frames in each movie sequence during the $\sim 60$ second tunnel runs. Test 463 resulted in the acquisition of approximately 150 usable image sequences, obtained over four days of testing in early March of 2009. This paper reports some of these results, with more cylindrical trip data presented in Reference [20]. In addition, results from a second facility entry, test 467, which focused on measurements simulating 2009 space shuttle orbiter Boundary Layer Transition Detailed Test Objective (BLT DTO) flight experiments (STS-119 and STS-128), are presented in a separate paper [19].

\section{ILLUSTRATIVE IMAGING RESULTS}

In this section a limited sampling of illustrative ultra high frame rate imaging results obtained, predominantly, at $500 \mathrm{kHz}$ and $1 \mathrm{MHz}$, are presented. A more extensive set of 24 image sequences, are presented in the Appendix. Note that in this section, raw, grey scale image sequences are presented, whereas the appendix displays images which have been sheet corrected and processed in false color.

\subsection{NO PLIF images at $1 \mathrm{MHz}$}

As alluded to in section 2, obtaining NO PLIF images at repetition rates exceeding $250 \mathrm{kHz}$ is challenging due to the gain dynamics of the Nd:YAG laser. Figure 6 shows an eight-frame image sequence (top left to bottom right) obtained at $1 \mathrm{MHz}$ frame rate, using a 2-mm tall, x 4 $\mathrm{mm}$ diameter cylindrical trip with the laser sheet located approximately $0.7 \mathrm{~mm}$ above the $20^{\circ}$ flat plate model surface. The field of view is $\sim 2.2 \mathrm{~cm} \times 5 \mathrm{~cm}$ and the nominal free stream flow velocity is $\sim 1400 \mathrm{~m} / \mathrm{s}$, though the velocity at the edge of the laminar boundary layer just upstream of the trip is $1220 \mathrm{~m} / \mathrm{s}$. The stagnation pressure for this run is $5.0 \mathrm{MPa}$, corresponding to $\operatorname{Re} \sim 3.3 \mathrm{million} / \mathrm{meter}$. The "shadow" cast by the hemi-spherical trip on the downward propagating laser sheet can clearly be seen on the left side each image. The flow is from left to right. The transitional nature of the flow can be clearly seen from the image sequence. In particular, the laminar flow upstream of the trip clearly exhibits a transition within approximately $1 \mathrm{~cm}$ downstream, as evidenced by the elongated, somewhat cylindrical "streaks" of fluid which rapidly develop. The continued evolution of these large "cylindrical" structures as the flow progresses downstream is also evident, developing into distinct, coherent large scale vortical type structures which can be tracked in time through the image sequence, as indicated by the red box in the figure. 


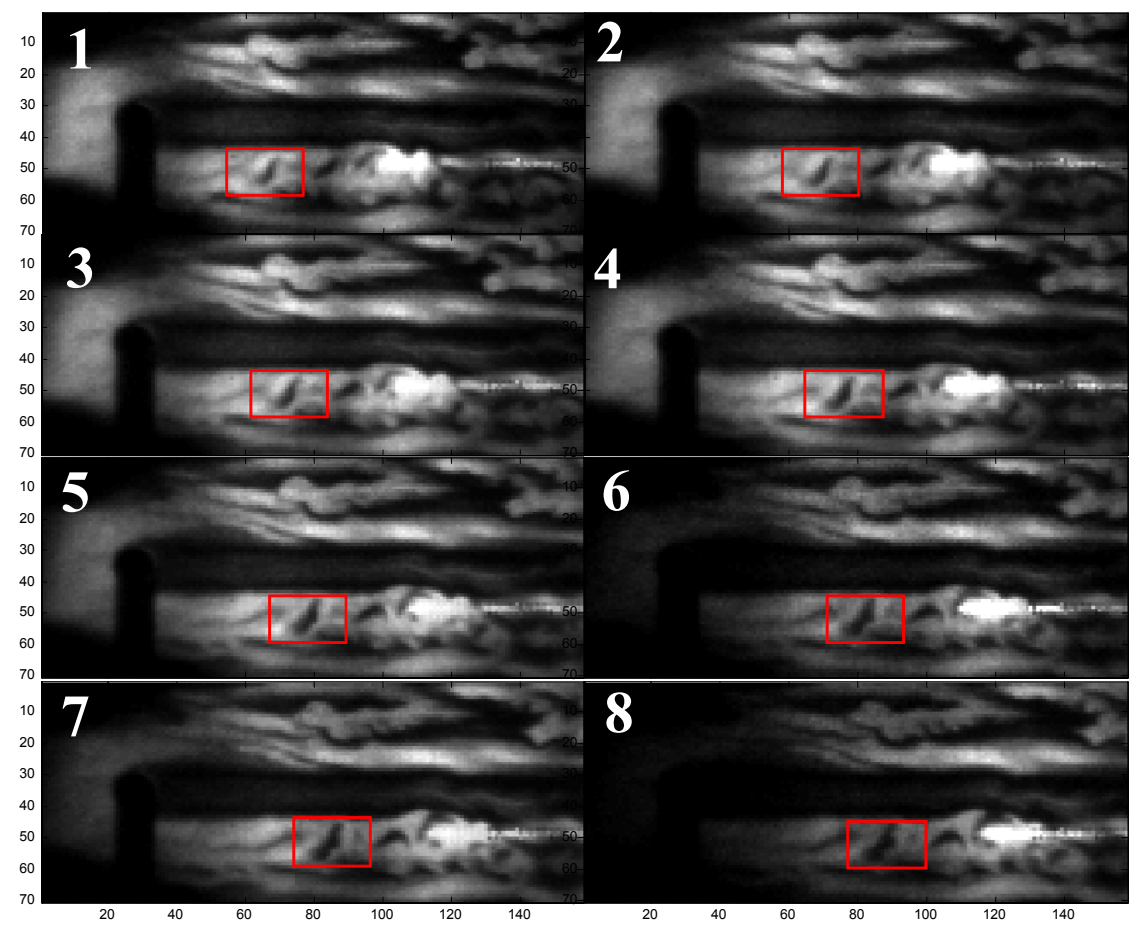

Figure 6: $1 \mathrm{MHz}$ NO PLIF images of flow over a $2 \mathrm{~mm}$ tall, $4 \mathrm{~mm}$ diameter cylindrical trip. Laser sheet is located $\sim 0.7 \mathrm{~mm}$ above the $20^{\circ}$ flat plate model surface.

Figures 7 and 8 illustrate additional $1 \mathrm{MHz}$ image sequences obtained under the same flow and optical conditions as that of Fig 6, except that the laser sheet is higher above the model surface, $\sim 1 \mathrm{~mm}$ and $\sim 1.7 \mathrm{~mm}$, respectively. At the $1 \mathrm{~mm}$ location the development and growth of large scale structures is similar to that observed at $0.7 \mathrm{~mm}$, although the structures, on average, are somewhat more distinct and, perhaps, more elongated At the $1.7 \mathrm{~mm}$ location the structures are far more compact, more vortical, and quite periodic. There is also a relative sparseness of visualized structures, some of which is attributed to lack of penetration of the NO seed to this location above the model surface. 


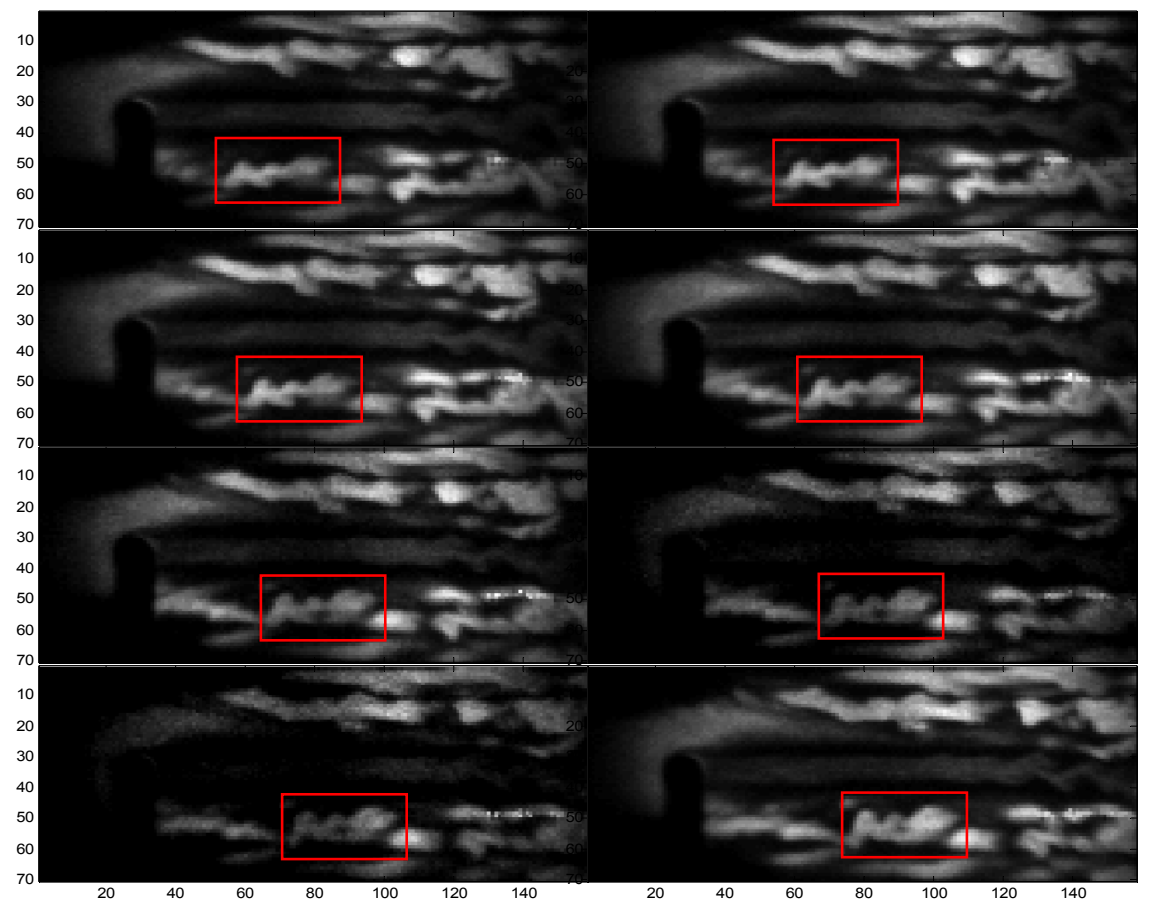

Figure 7: $1 \mathrm{MHz}$ NO PLIF images of flow over a $2 \mathrm{~mm}$ tall by $4 \mathrm{~mm}$ diameter cylindrical trip. Laser sheet is $\sim 1 \mathrm{~mm}$ above the $20^{\circ}$ flat plate surface.

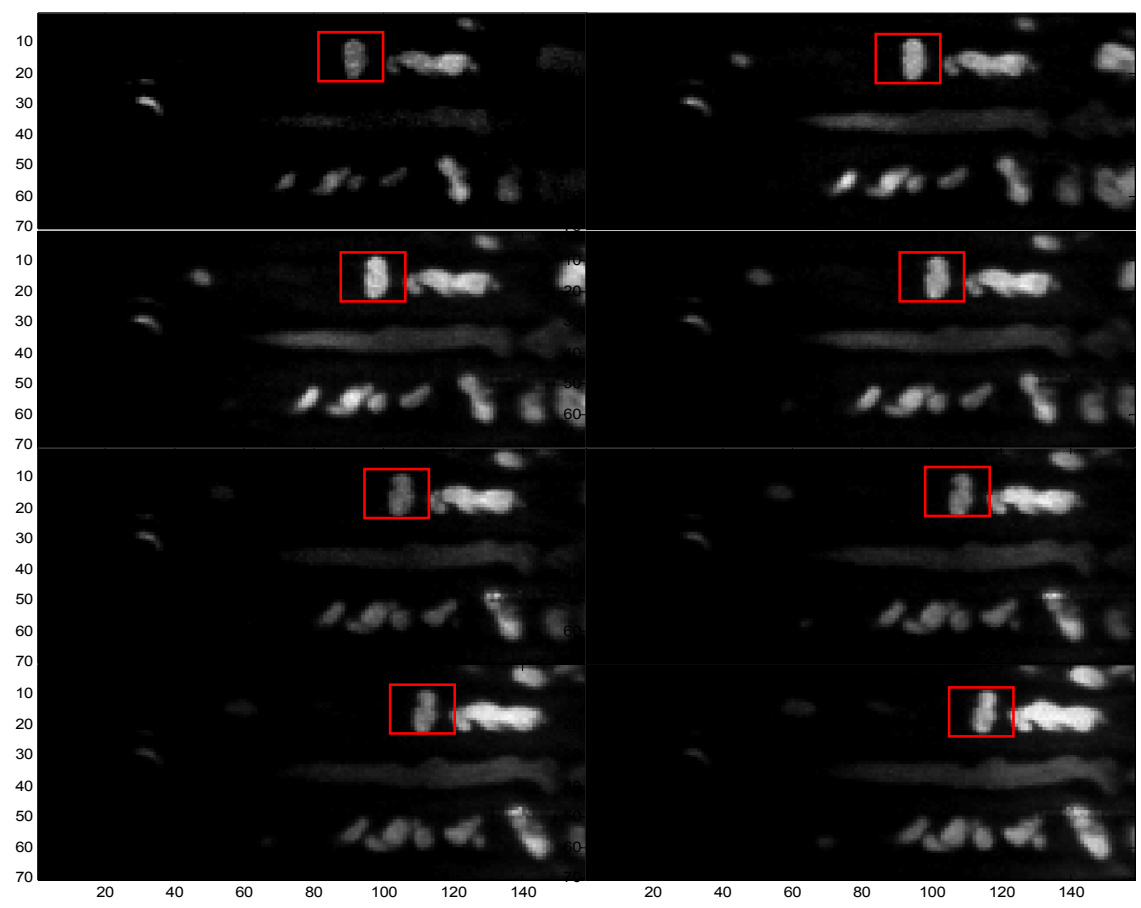

Figure 8: $1 \mathrm{MHz}$ NO PLIF images of flow over a $2 \mathrm{~mm}$ tall by $4 \mathrm{~mm}$ diameter cylindrical trip. Laser sheet is $1.7 \mathrm{~mm}$ above the model surface. 


\subsection{NO PLIF images at $500 \mathrm{KHz}$}

At two microseconds pulse spacing $(500 \mathrm{kHz})$ achieving longer burst sequences is significantly easier than at 1 microsecond $(1 \mathrm{MHz})$. Specifically, during the present studies, bursts of 16-20 pulses were typically achieved at $500 \mathrm{kHz}$ whereas at $1 \mathrm{MHz} 8-10$ pulse sequences were more typical. As examples of data obtained at $500 \mathrm{kHz}$, Fig. 9 shows a pair of twelve (of a total of 20 obtained) frame image sequences from a single tunnel run utilizing a 2 $\mathrm{mm}$ tall $\times 8 \mathrm{~mm}$ wide triangular trip (visible near the lower left side of each image) oriented at 45 degrees with respect to the principal flow direction (left to right). For this case the imaged field of view, which utilized both of the two available PSI-IV image sensors, is $\sim 5 \mathrm{~cm} \times 5 \mathrm{~cm}$. For this run the facility stagnation pressure was $9.3 \mathrm{MPa}(1350 \mathrm{psi})$, corresponding to $\mathrm{Re} \sim 6$ million/meter. The image sequence on the left was obtained with the sheet located very close to the model surface (approximately $0.9 \mathrm{~mm}$ ), whereas that on the right corresponds to a sheet location approximately $1.9 \mathrm{~mm}$ above the model surface. Note that the nominal boundary layer thickness directly upstream of the trip location is approximately $0.7 \mathrm{~mm}$ (as compared to the trip height of $2 \mathrm{~mm}$ ).
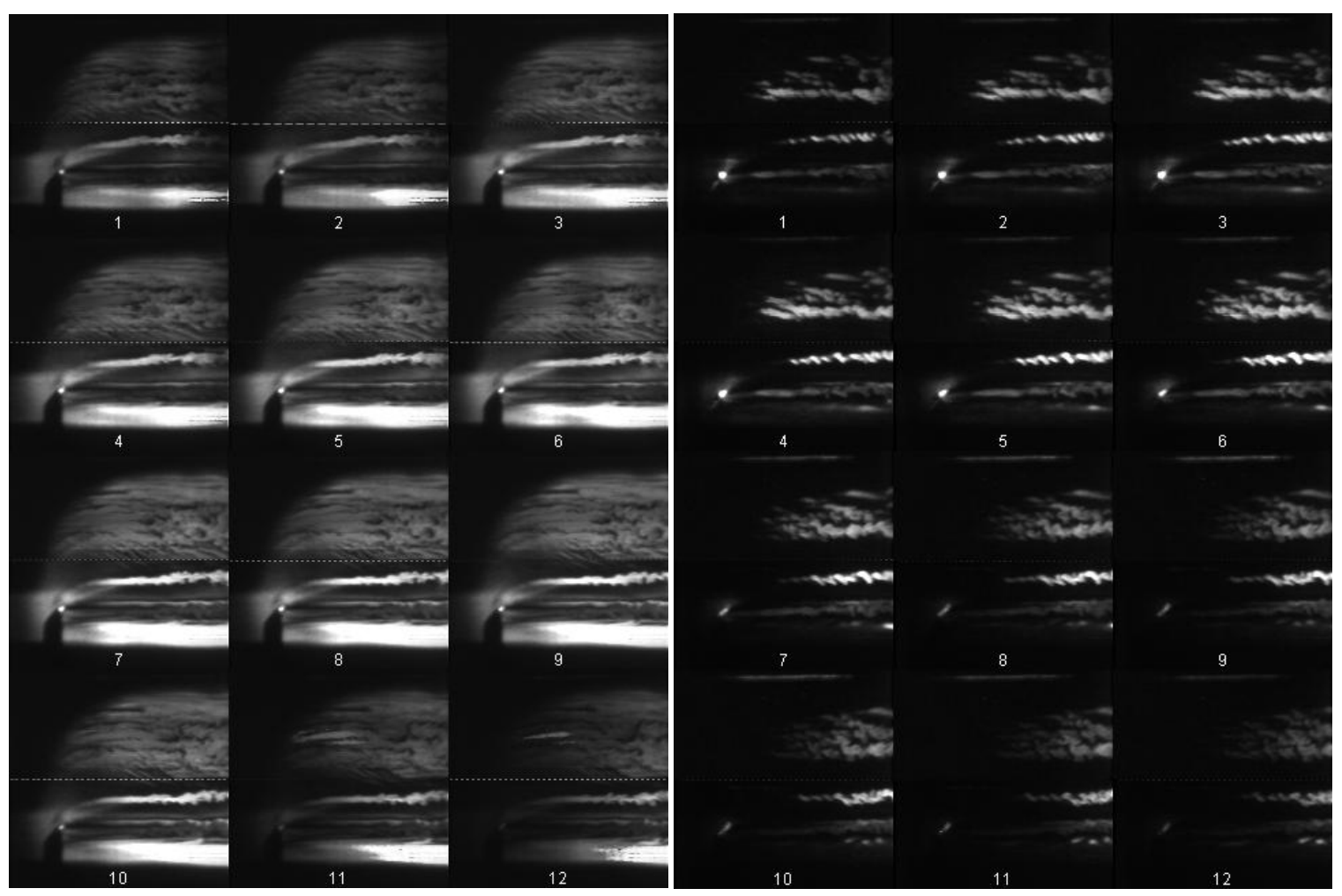

Figure 9: $500-\mathrm{kHz}$ image sequences obtained from triangular trip on $20^{\circ}$ flat plate model. Image sequence on left obtained close to model surface $(\sim 0.9 \mathrm{~mm})$. Image sequence on right obtained 1.9 $\mathrm{mm}$ above the model surface. Flow direction is left to right.

Since the trip was oriented at a 45 degree angle with respect to the main boundary layer flow, the seeded NO gas is deflected towards the top of the image. This triangular trip generates strong vortices, as seen in the images. The image acquired closer to the surface shows a mostly laminar flow along the bottom of the image, an irregular transitional flow directly downstream of 
the trip, and various streamwise and 45 degree oriented streak instabilities near the top of the images. Further above the surface of the boundary layer (Fig. 9 - right), the temporal evolution and progression of characteristic "corkscrew-shaped" vortices can be seen in each image sequence. Broadly speaking, these corkscrew-shaped vortices are seen to develop in the first few images, propagate downstream coherently in the middle three to five images, and finally, begin to breakdown to irregular shaped structures in the final three to four images.

\subsection{NO PLIF images of a compression corner}

As a final example we briefly illustrate the results of a few facility runs using the $20^{\circ}$ compression corner model shown schematically on the left side of Fig. 10. This geometry is known to produce a separated flow region in the vicinity of the $20^{\circ}$ corner, which results in unsteady, clockwise rotating flow with characteristic time scales that are approximately one order of magnitude slower than those of the vortical structures illustrated in Figs. 6-9.
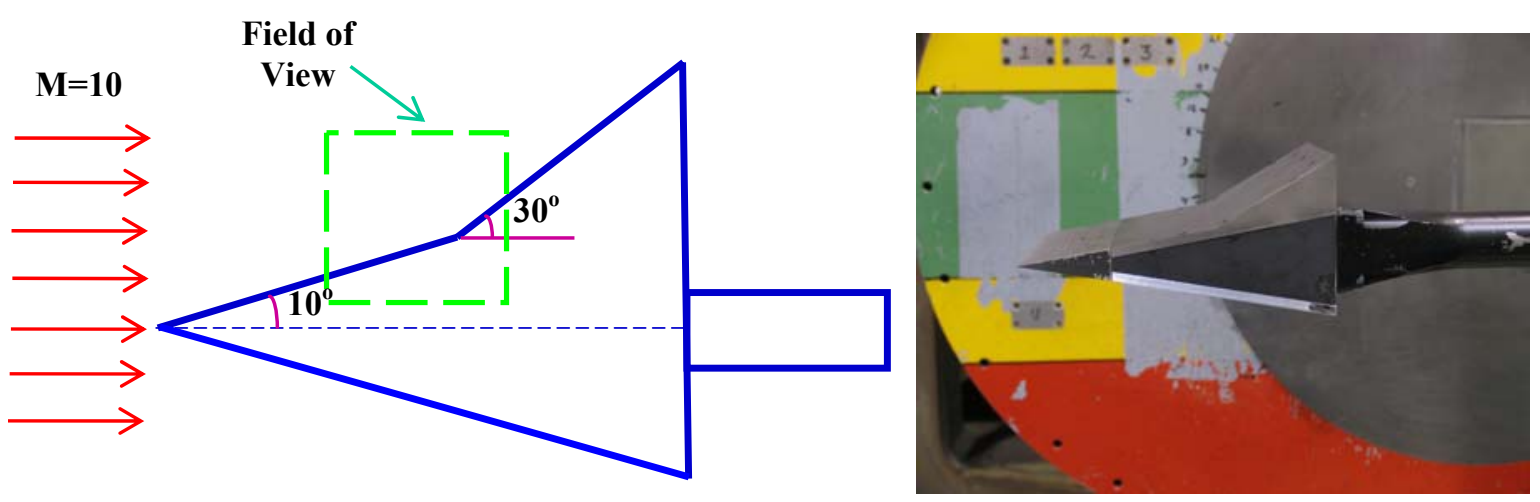

Figure 10: (Left) Schematic diagram of Mach 10 flow over a $20^{\circ}$ compression corner. Note that $30^{\circ}$ is total angle with respect to incident flow. (Right) Photograph of model.

These measurements serve to illustrate the flexibility of the burst mode imaging system to obtain time correlated data over a wide range of turbulent and/or unsteady flow time scales, and to do this in large scale flow facilities. Since the current burst mode laser system can operate at pulse repetition rates between 1 and 200 microseconds, it enables flow features with characteristic frequencies in the range $\sim$ ten to several hundred $\mathrm{kHz}$ to be captured in a time correlated manner. As an example, Fig. 11 shows an illustrative image sequence obtained at 10 microsecond pulse spacing $(100 \mathrm{kHz})$, which is a good match to the temporal dynamics of the flow produced by the compression corner model. Otherwise these measurements were performed with identical geometry and NO seeding as that used for Figs. 6-9. The stagnation pressure is $\sim 5 \mathrm{MPa}(\operatorname{Re} \sim 3.3 \mathrm{M} /$ meter) and, again, the main flow direction is from left to right. It can be seen that this image sequence has captured an unsteady event (see boxed region) in which a well defined fluid structure is formed, in frames $\mathrm{c}-\mathrm{e}$, and then propagates against the principal flow direction in the remaining eight images. The observed average speed of the left-ward propagating structure is $\sim 40$ meter/second ( $\sim 3 \mathrm{~mm}$ in 70 microseconds), more than one order of magnitude slower than the convective velocity of the large vortical structures observed in Figs. 6-9. 
(a)

(b)

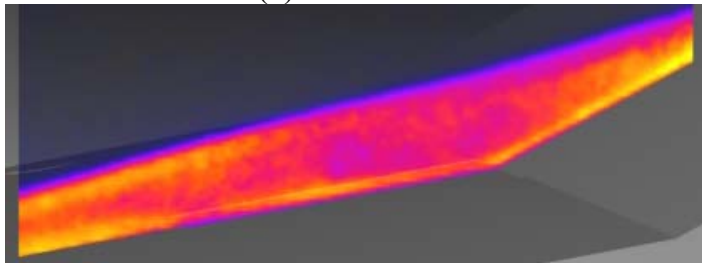

(d)

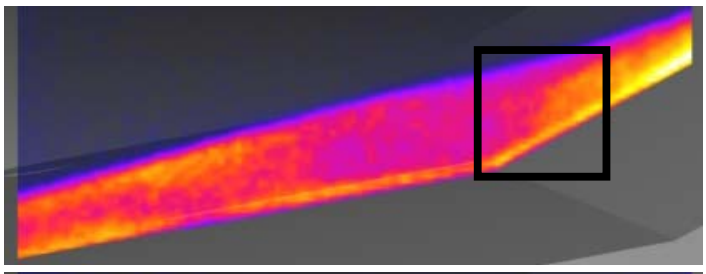

(f)

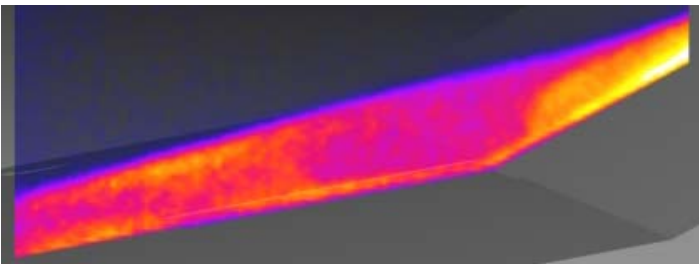

(h)

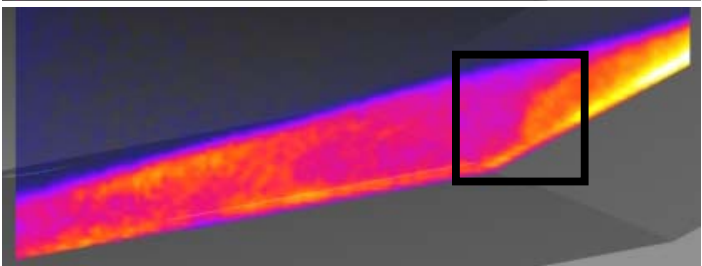

(j)
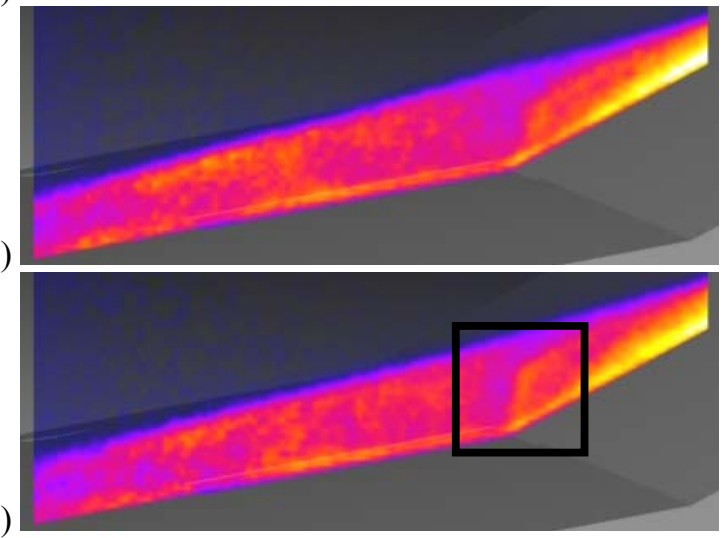

(c)

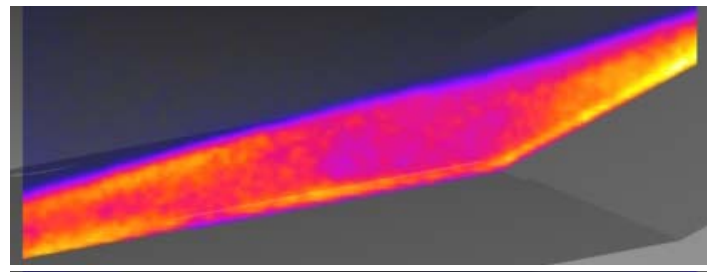

(e)

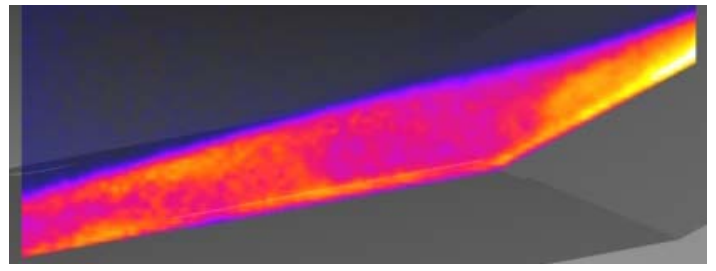

(g)

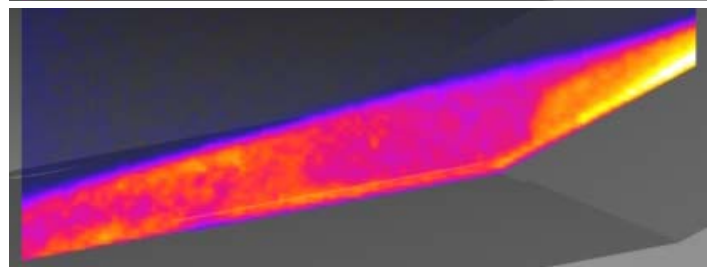

(i)

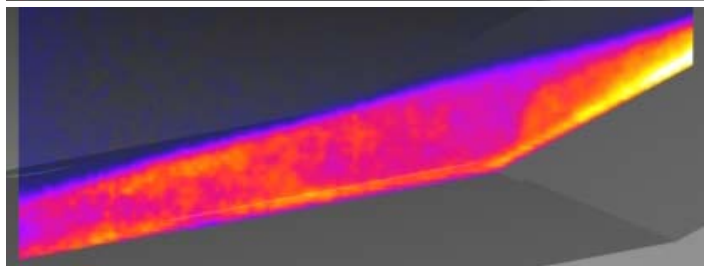

(k)

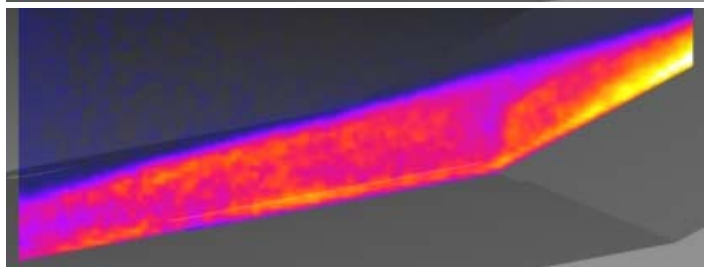

(m)

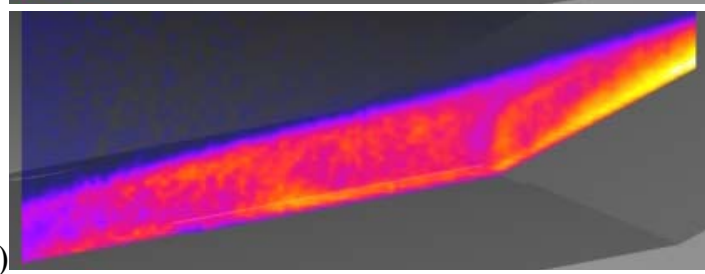

Figure 11: Image sequence from $20^{\circ}$ compression corner. $\mathrm{P}_{0}=4.97 \mathrm{MPa}$. Fame rate $=100 \mathrm{kHz}$. Top image shows sheet location with respect to NO injection slot. The boxed structure is discussed in the text. 


\section{CONCLUSIONS}

We have demonstrated high repetition rate NO PLIF imaging in NASA Langley's 31 inch Mach 10 wind tunnel with emphasis on demonstrating the ability to capture the dynamics of laminar-to-turbulent transition in hypersonic flows. Approximately two hundred time correlated image sequences, of between ten and twenty individual frames, at $500 \mathrm{kHz}$ and $1 \mathrm{MHz}$ repetition rate, were obtained over eight days of wind tunnel testing spanning two entries in March and September of 2009. The majority of the image sequences were obtained from the boundary layer of a flat plate model oriented at $20^{\circ}$ with respect to the freestream flow, in which transition was induced using a variety of cylindrical and triangular shaped protuberances. Images were captured from a laser sheet oriented parallel to the flat plate model, at a location above the model surface which was swept from approximately 0.5 to $2.0 \mathrm{~mm}$. Typical static temperature and pressure conditions at the outer edge of the nominally $1 \mathrm{~mm}$ thick boundary layer are $250 \mathrm{~K}$ and $2.9 \mathrm{kPa}$ ( $22 \mathrm{Torr}$ ), respectively, although this is a function of both the flow stagnation conditions and the trip geometry. The test gas is ordinary facility dried air, in which the boundary layer is seeded with a low mass flow rate of pure NO, to a local mole fraction of approximately 1-2 percent assuming complete and uniform mixing.

The high speed image sequences captured a variety of laminar and transitional flow phenomena, ranging from mostly laminar flow, typically at lower Reynolds number and/or in the near wall region of the model, to highly transitional flow in which the temporal evolution and progression of characteristic streak instabilities and/or corkscrew-shaped vortices could be identified. A limited number of image sequences were also obtained from a $20^{\circ}$ compression corner, illustrating the ability to capture unsteady flow phenomena over a wide range of temporal scales.

\section{Acknowledgements}

The authors would like to acknowledge the NASA Fundamental Aeronautics Program, Experimental Capabilities Discipline through a NASA Research Opportunities in Aeronautics (ROA) program as the primary supporter of this work. The authors would like to thank Brett Bathel from the University of Virginia, as well as Jennifer Inman and Stephen Jones from NASA Langley Research Center for assistance in installing the MHz system in the 31" Mach 10 wind tunnel facility. Also the efforts of the 31" Mach 10 wind tunnel staff are appreciated. Many useful discussions and comments of Dr. James Gord, as well as previous financial support for the development of the ultra-high frame rate imaging system from the U.S. Air Force Research Laboratory - Propulsion Directorate, the Air Force Office of Scientific Research - Program in Unsteady Aerodynamics and Hypersonics (J. Schmisseur - program monitor), and Princeton Scientific Instruments, Inc are also acknowledged. 


\section{References}

1. M.J. Dyer and D.R. Crosley, Opt. Lett., 7, 382-384 (1982)

2. G. Kychakoff, K. Knapp, R.D. Howe, and R.K. Hanson, AIAA J. 22, 153-154 (1984).

3. J.D. Smith and V. Sick, Appl. Phys. B. 81:579-584 (2005).

4. N. Jiang, W. Lempert, G. Switzer, T. Meyer and J. Gord, Appl. Opt. 47, 64-71 (2008).

5. N. Jiang, and W. Lempert, Optics Letters, 33, (19), 2236-2238, 2008.

6. N. Jiang, W. Lempert, M. Slipchenko, J. Miller, T. Meyer and J. Gord, Laser Focus World, 44, (8), 2008.

7. J. R. Micol, AIAA Paper 98-0147, 36th AIAA Aerospace Sciences Meeting \& Exhibit, January 12-15, Reno, NV, (1998).

8. P. M. Danehy, J. A. Inman, G. Brauckmann, D. W. Alderfer, S. B. Jones, and D. Patry, Journal of Spacecraft and Rockets, 46 no.1 p. 93-102 (2009).

9. P.M. Danehy, D.W. Alderfer, J.A. Inman , K.T. Berger, G.M. Buck and R. J. Schwartz, Proc. IMechE, Part G: J. Aerospace Engineering, 222(G5), 637-651 (2008).

10. J. A. Inman, P. M. Danehy, D. W. Alderfer, and G. M. Buck, and A. McCrea, AIAA Journal, 47, No. 4, April (2009).

11. N Jiang, M. Webster and W. Lempert, Applied Optics, 48, (4), B23-B31, 2009.

12. N. Jiang, M. Webster, M. Nishihara, and W.R. Lempert, AIAA-2009-1448, 47th AIAA Aerospace Sciences Meeting, Orlando, FL, January, 2009.

13. B. Thurow, N. Jiang, M. Samimy, and W.R. Lempert, Applied Optics, 43, (26), 50645073, 2004.

14. C. K. Ni and A. H. Kung, Optics Letters,21, 1673-1675 (1996).

15. S.K. Lee, D.W. Lee, and H.J. Kong, Journal of the Korean Physical Society, 46 (2), 443447, 2005.

16. J. Auyeung, D. Fekete, D. Pepper and A. Yariv, IEEE Journal of Quantum Electronics, 15 (10), 1180-1188, 1979.

17. R.W. Boyd and K. Rzaewski, Phys. Rev. A, 42, 5514 - 5521, 1990.

18. P.M. Danehy, A.P. Garcia, S. Borg, A.A. Dyakonov, S.A. Berry, J.A. Wilkes Inman, D.W. Alderfer, AIAA-2007-0536, 45th AIAA Aerospace Sciences Meeting, Reno Nevada, January 8-11 (2007).

19. P. M. Danehy, C.B. Ivey, B.F. Bathel, J. A. Inman, S. B. Jones, A. N. Watkins, K. Goodman, B, D. Leighty, W. K. Lipford, N. Jiang, M. Webster, W. Lempert, J. Miller, and T. Meyer, AIAA-2010-1571, 48th AIAA Aerospace Sciences Meeting, Orlando, FL, January, 2010.

20. P.M. Danehy, C. Ivey, J.A. Inman, B. Bathel, S.B. Jones, N. Jiang, M. Webster, W. Lempert, J. Miller, T. Meyer, AIAA-2010-0703 48th AIAA Aerospace Sciences Meeting, Fluid Dynamics TC, Orlando FL, January 2010. 


\section{Appendix}

This appendix contains selected ViDI-processed image sequences from runs 17-21 of Test 463 in the 31 Inch Mach 10 Wind Tunnel at NASA Langley Research Center. Additional image sequences for Tests 463 and 467 can be found in References [19] and [20]. The table below summarizes the data contained in this appendix.

\begin{tabular}{|c|c|c|c|c|c|c|c|c|c|c|c|c|}
\hline $\begin{array}{c}\text { Figure } \\
\text { Number }\end{array}$ & Test & Run & $\begin{array}{c}\text { Framing } \\
\text { Rate }\end{array}$ & Trip Type & $\begin{array}{c}\text { Trip } \\
\text { Height }\end{array}$ & $\begin{array}{c}\text { Trip } \\
\text { Width }\end{array}$ & \begin{tabular}{|c|} 
Height \\
above \\
plate \\
\end{tabular} & $\begin{array}{c}\text { Stagnation } \\
\text { Pressure }\end{array}$ & $\begin{array}{l}\text { Stagnation } \\
\text { Temperature }\end{array}$ & \begin{tabular}{|c|} 
Unit \\
Reynolds \\
Number \\
\end{tabular} & $\begin{array}{l}\text { Plate } \\
\text { Angle }\end{array}$ & $\begin{array}{l}\text { Sting } \\
\text { AoA }\end{array}$ \\
\hline & & & & & $(\mathrm{mm})$ & $(\mathrm{mm})$ & $(\mathrm{mm})$ & (MPa) & $(\mathrm{K})$ & $(1 / \mathrm{m})$ & (degrees) & (degrees) \\
\hline$\overline{\mathrm{A} 1}$ & 463 & 17 & $1 \mathrm{MHz}$ & cylinder & 2 & 4 & 0.1 & 4.98 & 1003 & 3.35 & 20 & -10 \\
\hline A2 & 463 & 17 & $1 \mathrm{MHz}$ & cylinder & 2 & 4 & 0.7 & 4.98 & 1003 & 3.35 & 20 & -10 \\
\hline A3 & 463 & 17 & $1 \mathrm{MHz}$ & cylinder & 2 & 4 & 0.6 & 4.98 & 1003 & 3.35 & 20 & -10 \\
\hline A4 & 463 & 17 & $1 \mathrm{MHz}$ & cylinder & 2 & 4 & 1.1 & 4.98 & 1003 & 3.35 & 20 & -10 \\
\hline A5 & 463 & 17 & $1 \mathrm{MHz}$ & cylinder & 2 & 4 & 1.0 & 4.98 & 1003 & 3.35 & 20 & -10 \\
\hline A6 & 463 & 17 & $1 \mathrm{MHz}$ & cylinder & 2 & 4 & 1.8 & 4.98 & 1003 & 3.35 & 20 & -10 \\
\hline A7 & 463 & 17 & $1 \mathrm{MHz}$ & cylinder & 2 & 4 & 1.7 & 4.98 & 1003 & 3.35 & 20 & -10 \\
\hline A8 & 463 & 17 & $1 \mathrm{MHz}$ & cylinder & 2 & 4 & 1.7 & 4.98 & 1003 & 3.35 & 20 & -10 \\
\hline A9 & 463 & 18 & $500 \mathrm{kHz}$ & triangle trip @ 45 deg & 2 & 8 & 0.1 & 9.34 & 999 & 6.15 & 20 & -10 \\
\hline A10 & 463 & 18 & $500 \mathrm{kHz}$ & triangle trip @ 45 deg & 2 & 8 & 0.1 & 9.34 & 999 & 6.15 & 20 & -10 \\
\hline A11 & 463 & 18 & $500 \mathrm{kHz}$ & triangle trip @ 45 deg & 2 & 8 & 0.9 & 9.34 & 999 & 6.15 & 20 & -10 \\
\hline A12 & 463 & 18 & $500 \mathrm{kHz}$ & triangle trip @ 45 deg & 2 & 8 & 0.9 & 9.34 & 999 & 6.15 & 20 & -10 \\
\hline A13 & 463 & 18 & $500 \mathrm{kHz}$ & triangle trip @ 45 deg & 2 & 8 & 1.5 & 9.34 & 999 & 6.15 & 20 & -10 \\
\hline A14 & 463 & 18 & $500 \mathrm{kHz}$ & triangle trip@ @ 45 deg & 2 & 8 & 1.9 & 9.34 & 999 & 6.15 & 20 & -10 \\
\hline A15 & 463 & 18 & $500 \mathrm{kHz}$ & triangle trip @ 45 deg & 2 & 8 & 3 & 9.34 & 999 & 6.15 & 20 & -10 \\
\hline A16 & 463 & 19 & $100 \mathrm{kHz}$ & 20 deg compression corner & -- & -- & -- & 4.97 & 1000 & 3.36 & 10 & 0 \\
\hline A17 & 463 & 19 & $100 \mathrm{kHz}$ & 20 deg compression corner & -- & -- & -- & 4.97 & 1000 & 3.36 & 10 & 0 \\
\hline A18 & 463 & 19 & $100 \mathrm{kHz}$ & 20 deg compression corner & -- & -- & -- & 4.97 & 1000 & 3.36 & 10 & 0 \\
\hline A19 & 463 & 19 & $100 \mathrm{kHz}$ & 20 deg compression corner & -- & -- & -- & 4.97 & 1000 & 3.36 & 10 & 0 \\
\hline $\mathrm{A} 20$ & 463 & 20 & $100 \mathrm{kHz}$ & 20 deg compression corner & -- & -- & -- & 4.97 & 999 & 3.37 & 10 & 0 \\
\hline A21 & 463 & 20 & $100 \mathrm{kHz}$ & 20 deg compression corner & -- & -- & -- & 4.97 & 999 & 3.37 & 10 & 0 \\
\hline A22 & 463 & 21 & $100 \mathrm{kHz}$ & 20 deg compression corner & -- & -- & -- & 9.34 & 1009 & 6.05 & 10 & 0 \\
\hline A23 & 463 & 21 & $100 \mathrm{kHz}$ & 20 deg compression corner & -- & -- & -- & 9.34 & 1009 & 6.05 & 10 & 0 \\
\hline A24 & 463 & 21 & $100 \mathrm{kHz}$ & 20 deg compression corner & -- & -- & -- & 9.34 & 1009 & 6.05 & 10 & 0 \\
\hline
\end{tabular}

Table A1: Test matrix and figure summary. 


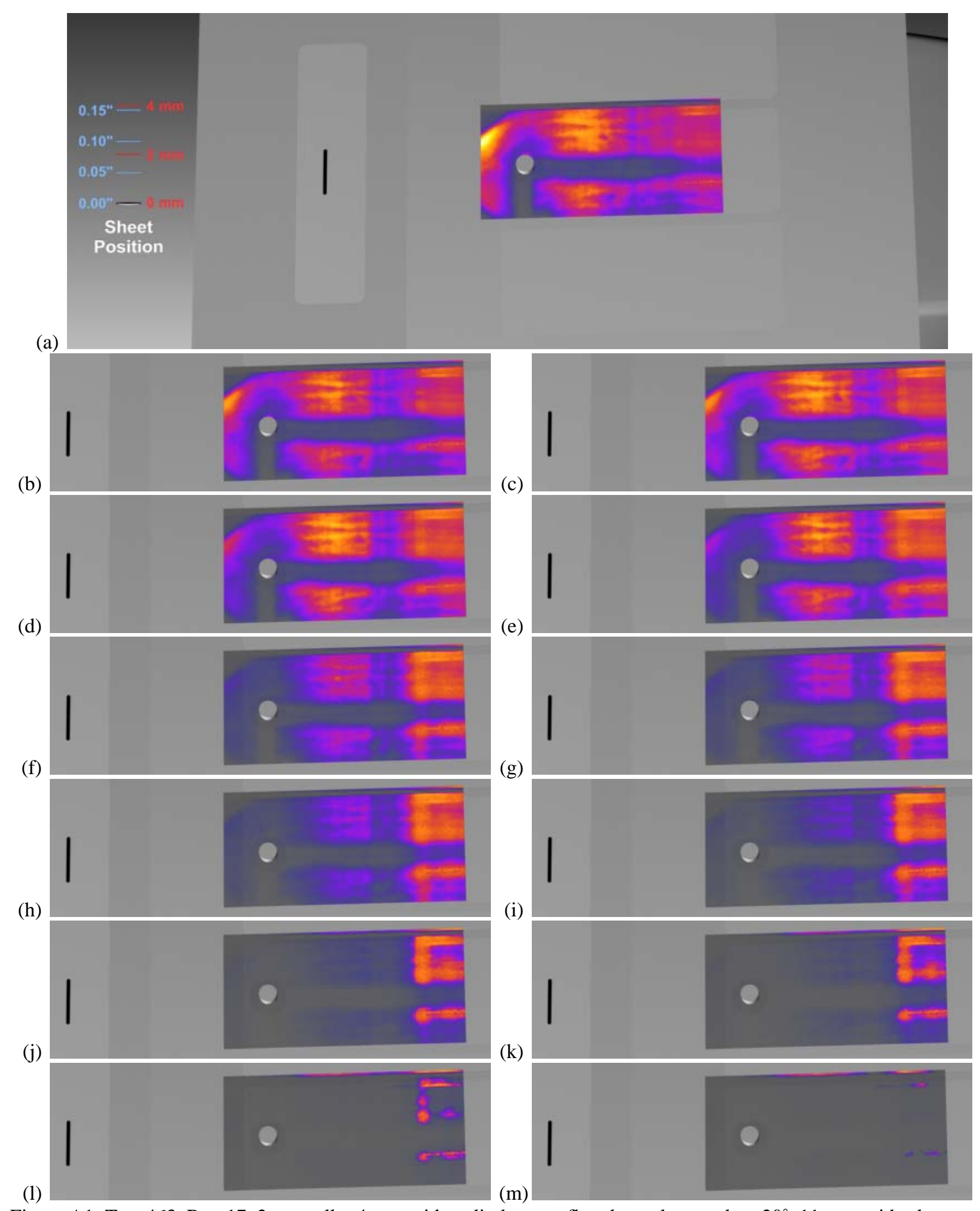

Figure A1: Test 463, Run 17, $2 \mathrm{~mm}$ tall x $4 \mathrm{~mm}$ wide cylinder on a flat plate, plate angle $=20^{\circ}$, 11-mm wide slot seeding, $\dot{m}=300 \mathrm{sccm}, \mathrm{P}_{0}=4.97 \mathrm{MPa}$, sheet position $=0.1 \mathrm{~mm}$ above surface, framing rate $=1 \mathrm{MHz}$. 


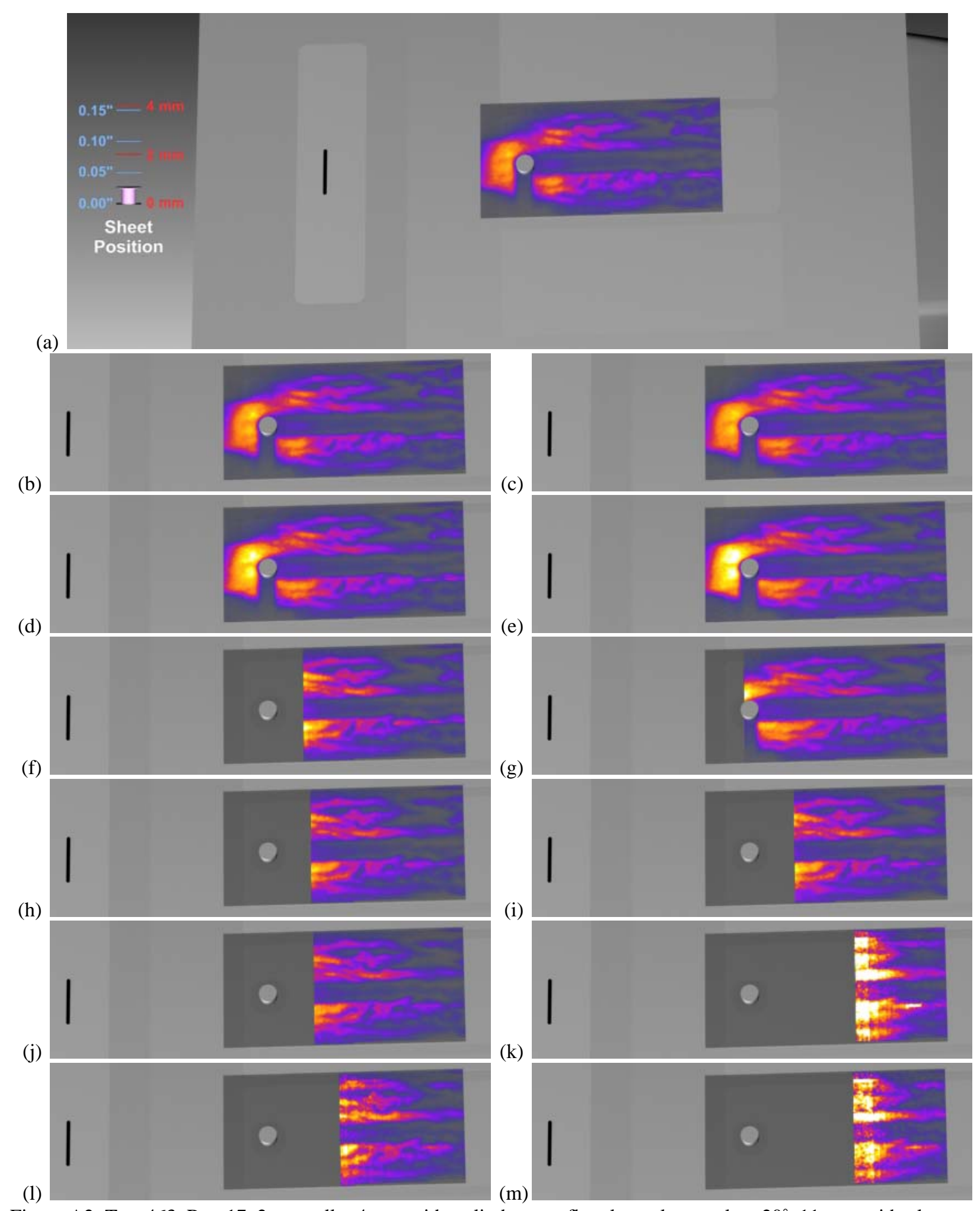

Figure A2: Test 463, Run 17, $2 \mathrm{~mm}$ tall x $4 \mathrm{~mm}$ wide cylinder on a flat plate, plate angle $=20^{\circ}$, 11-mm wide slot seeding, $\dot{m}=300 \mathrm{sccm}, \mathrm{P}_{0}=4.97 \mathrm{MPa}$, sheet position $=0.7 \mathrm{~mm}$ above surface, framing rate $=1 \mathrm{MHz}$. 


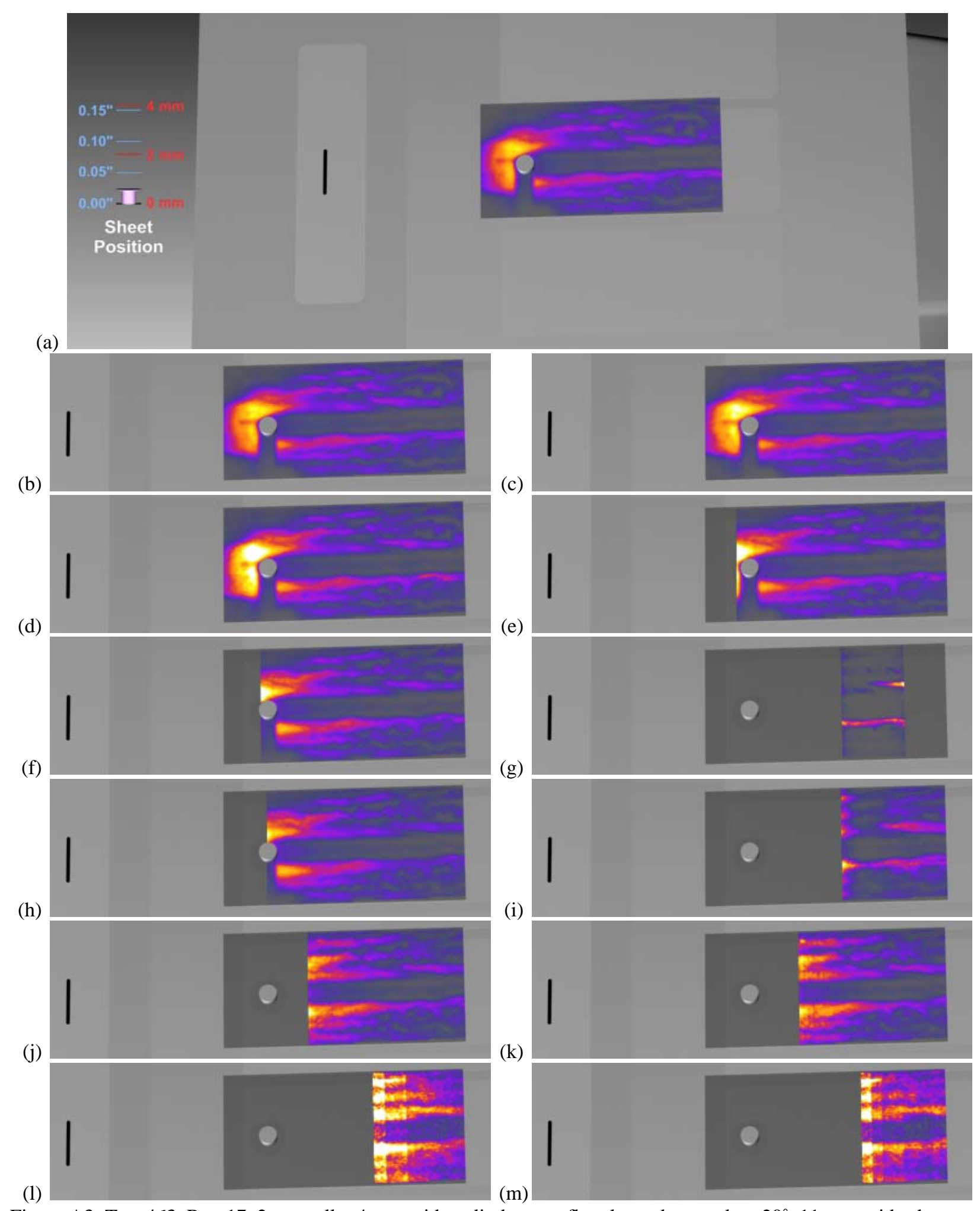

Figure A3: Test 463, Run 17, $2 \mathrm{~mm}$ tall x $4 \mathrm{~mm}$ wide cylinder on a flat plate, plate angle $=20^{\circ}$, 11-mm wide slot seeding, $\dot{m}=300 \mathrm{sccm}, \mathrm{P}_{0}=4.97 \mathrm{MPa}$, sheet position $=0.6 \mathrm{~mm}$ above surface, framing rate $=1 \mathrm{MHz}$. 


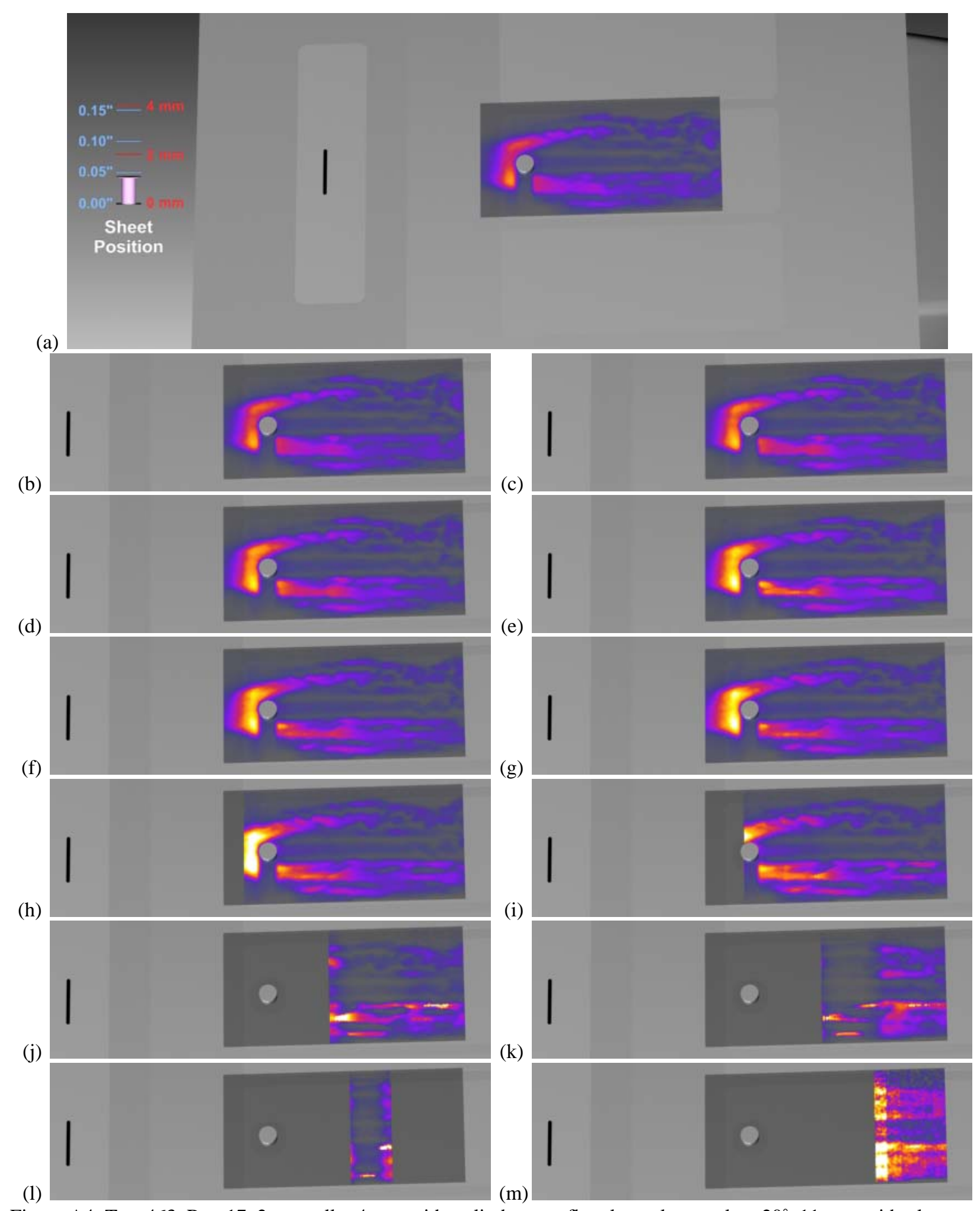

Figure A4: Test 463, Run 17, $2 \mathrm{~mm}$ tall x $4 \mathrm{~mm}$ wide cylinder on a flat plate, plate angle $=20^{\circ}$, 11-mm wide slot seeding, $\dot{m}=300 \mathrm{sccm}, \mathrm{P}_{0}=4.97 \mathrm{MPa}$, sheet position $=1.1 \mathrm{~mm}$ above surface, framing rate $=1 \mathrm{MHz}$. 


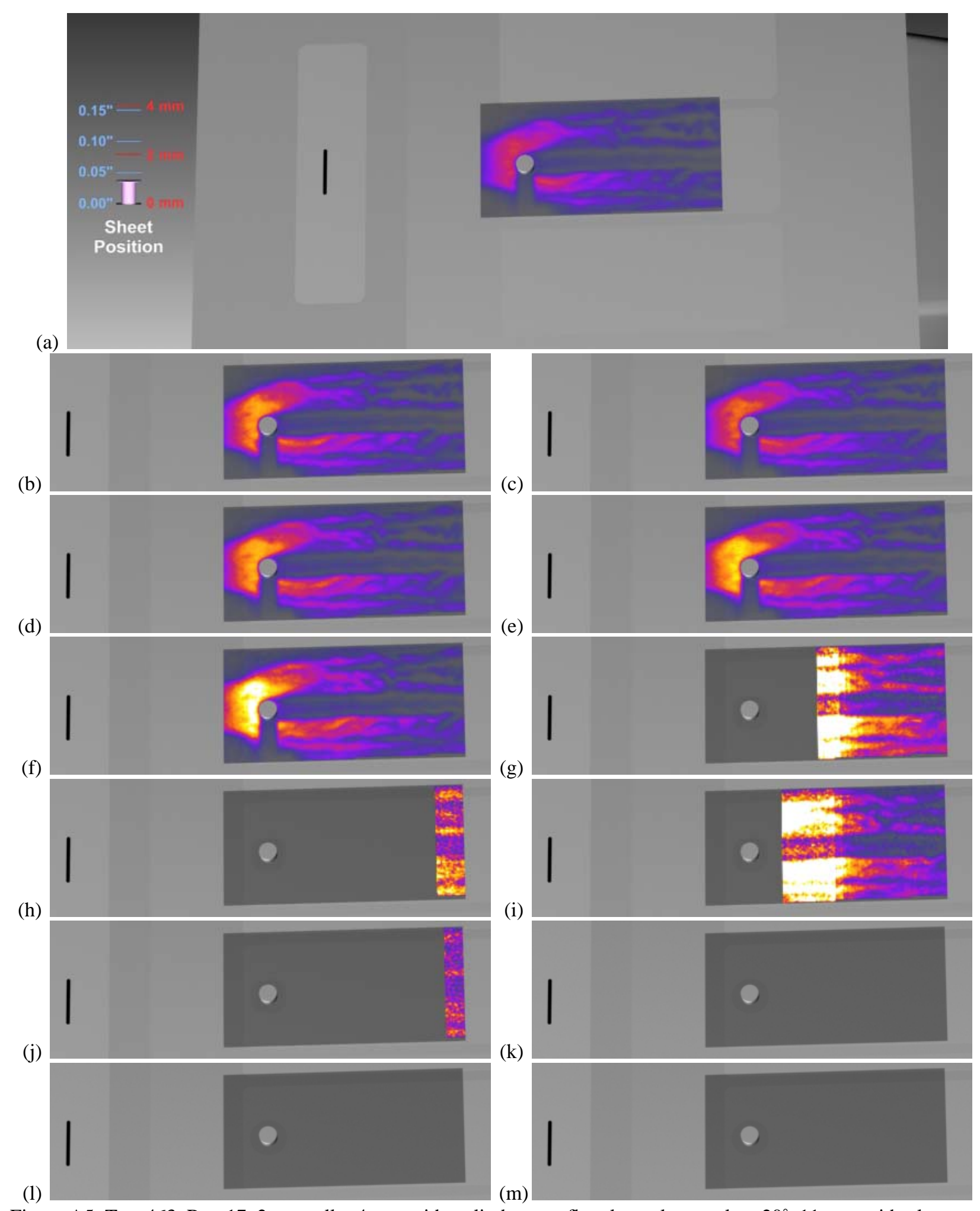

Figure A5: Test 463, Run 17, $2 \mathrm{~mm}$ tall x $4 \mathrm{~mm}$ wide cylinder on a flat plate, plate angle $=20^{\circ}$, 11-mm wide slot seeding, $\dot{m}=300 \mathrm{sccm}, \mathrm{P}_{0}=4.97 \mathrm{MPa}$, sheet position $=1.0 \mathrm{~mm}$ above surface, framing rate $=1 \mathrm{MHz}$. 


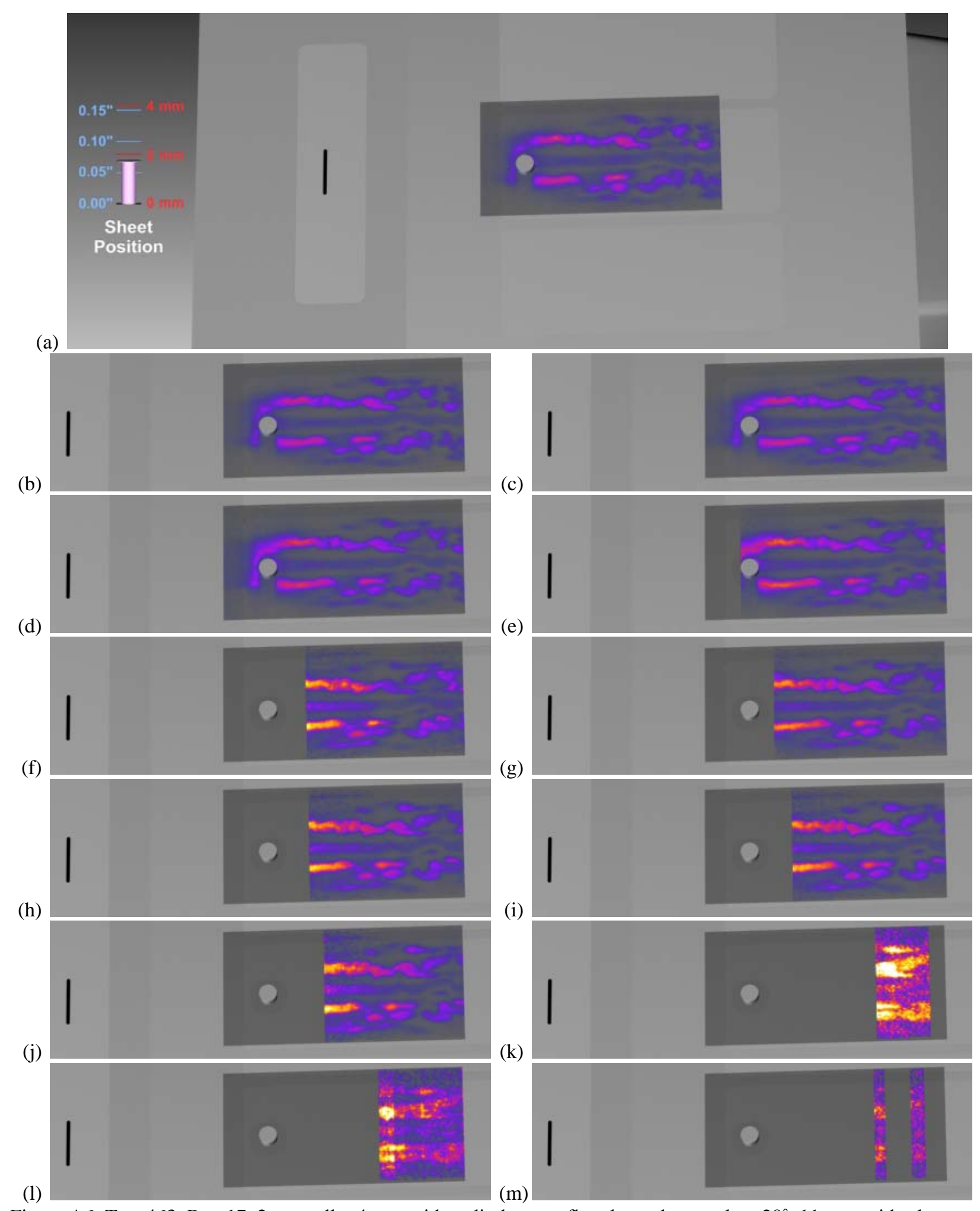

Figure A6: Test 463, Run 17, $2 \mathrm{~mm}$ tall x $4 \mathrm{~mm}$ wide cylinder on a flat plate, plate angle $=20^{\circ}$, 11-mm wide slot seeding, $\dot{m}=300 \mathrm{sccm}, \mathrm{P}_{0}=4.97 \mathrm{MPa}$, sheet position $=1.8 \mathrm{~mm}$ above surface, framing rate $=1 \mathrm{MHz}$. 


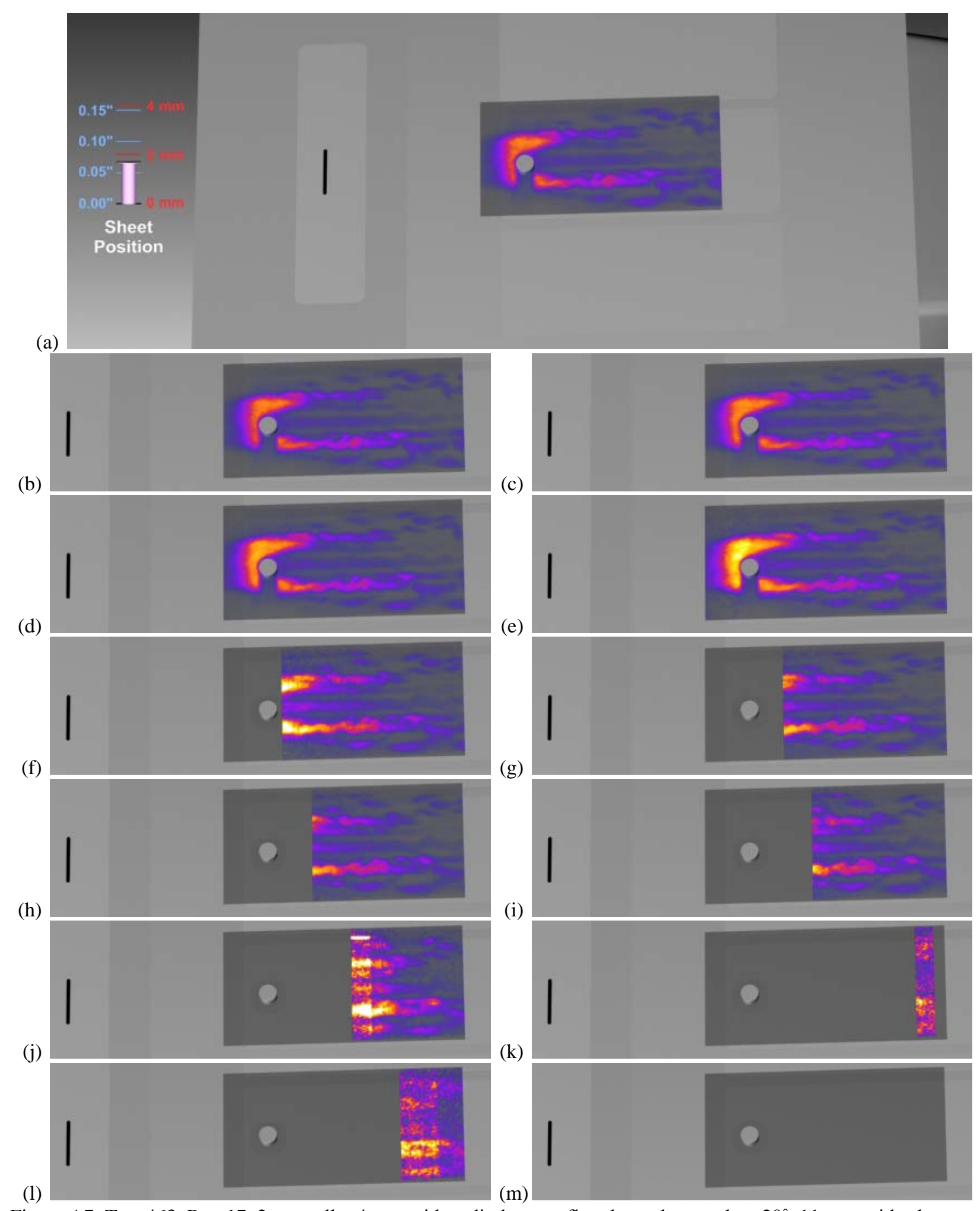

Figure A7: Test 463, Run 17, $2 \mathrm{~mm}$ tall x $4 \mathrm{~mm}$ wide cylinder on a flat plate, plate angle $=20^{\circ}$, 11-mm wide slot seeding, $\dot{m}=300 \mathrm{sccm}, \mathrm{P}_{0}=4.97 \mathrm{MPa}$, sheet position $=1.7 \mathrm{~mm}$ above surface, framing rate $=1 \mathrm{MHz}$. 


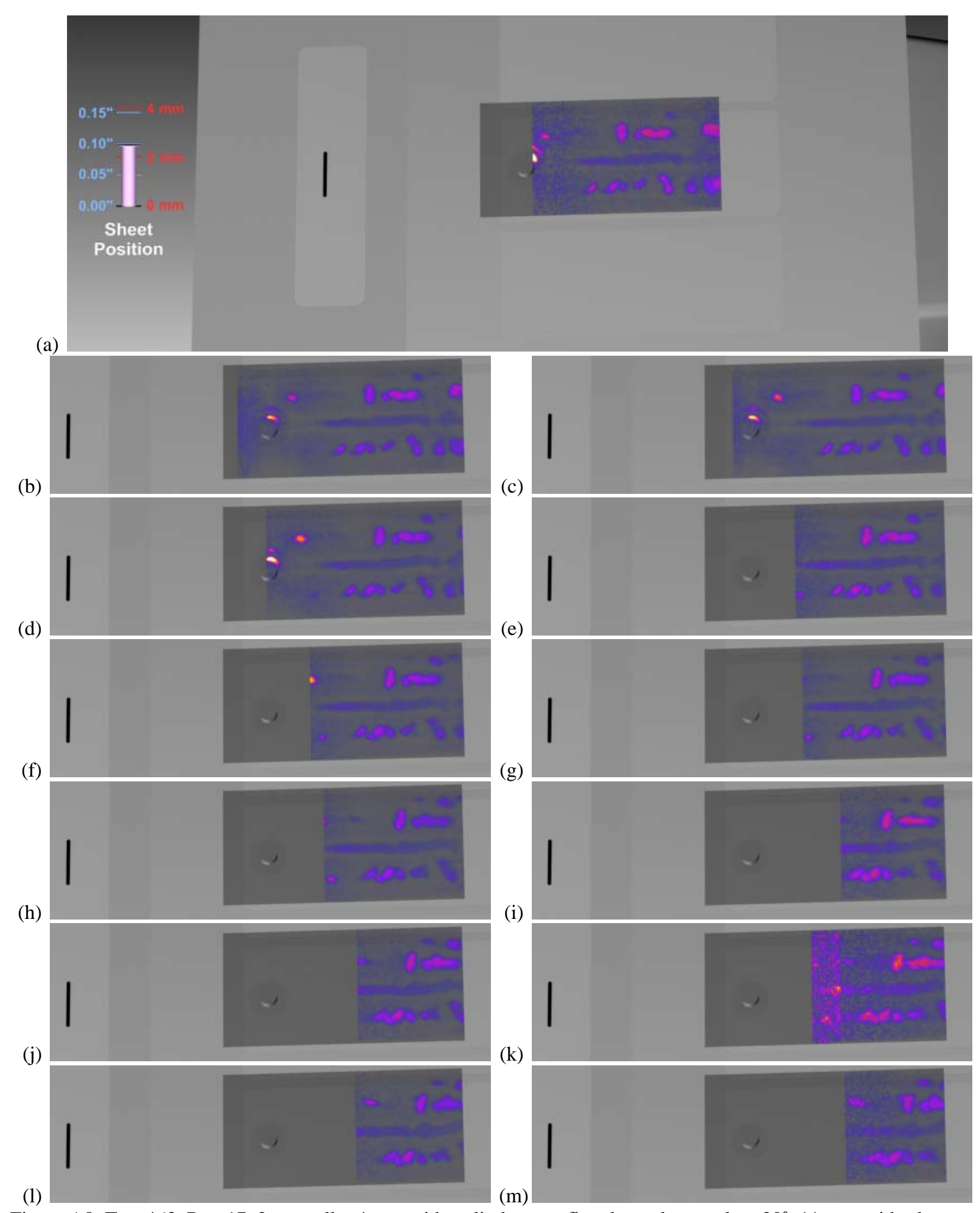

Figure A8: Test 463, Run 17, $2 \mathrm{~mm}$ tall x $4 \mathrm{~mm}$ wide cylinder on a flat plate, plate angle $=20^{\circ}$, 11-mm wide slot seeding, $\dot{m}=300 \mathrm{sccm}, \mathrm{P}_{0}=4.97 \mathrm{MPa}$, sheet position $=1.7 \mathrm{~mm}$ above surface, framing rate $=1 \mathrm{MHz}$. 
(a)

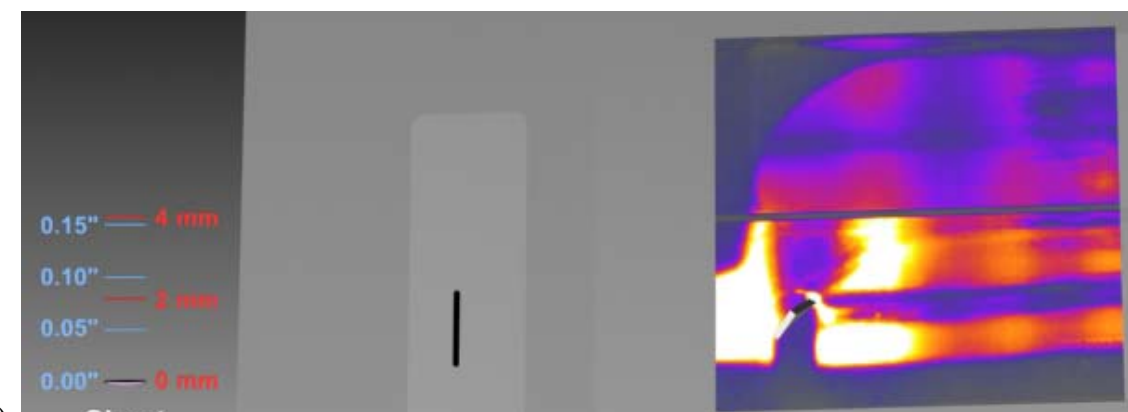

(b)

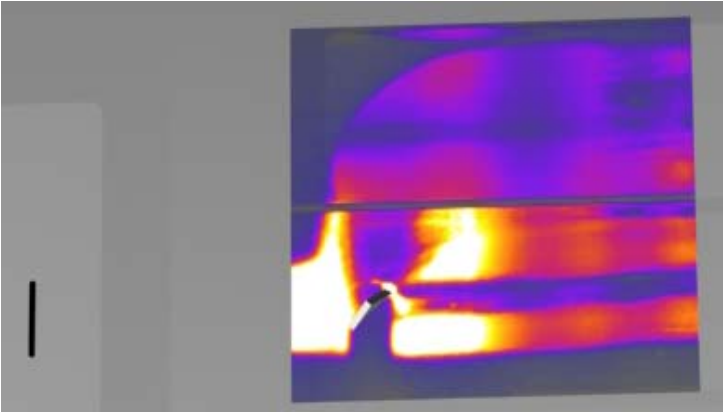

(d)

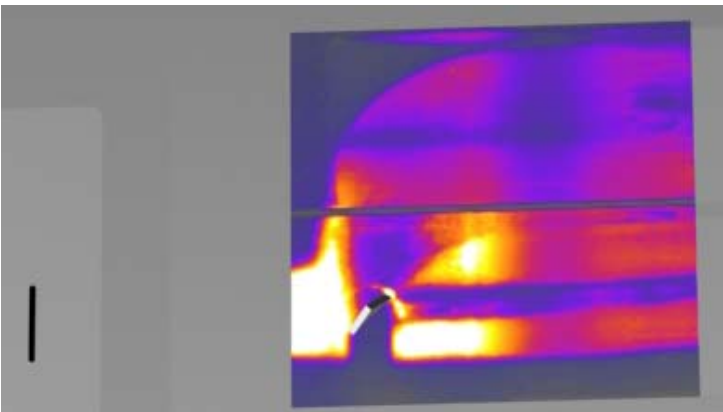

(f)
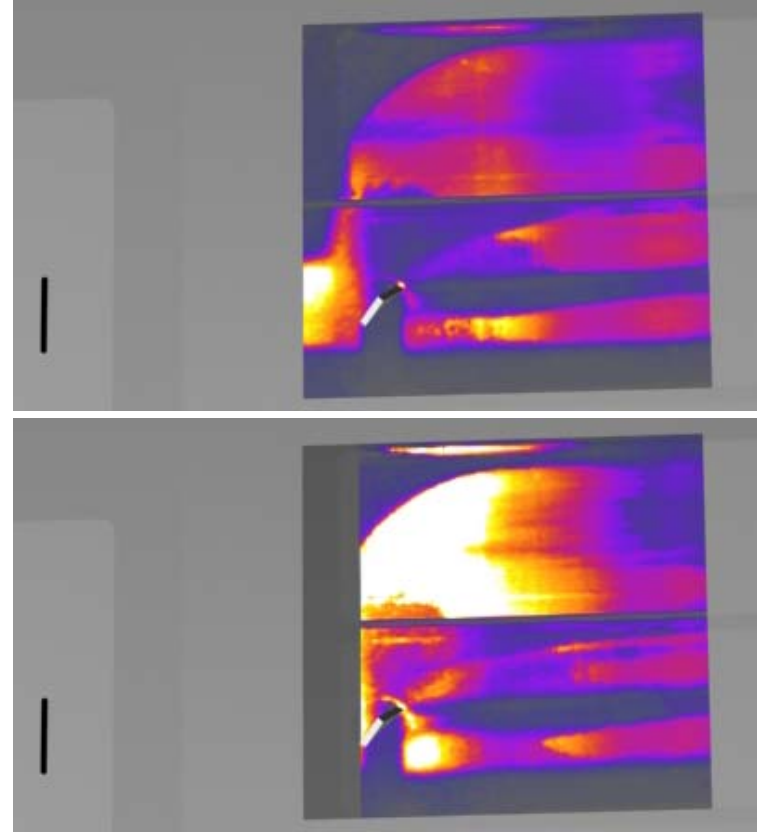

(c)

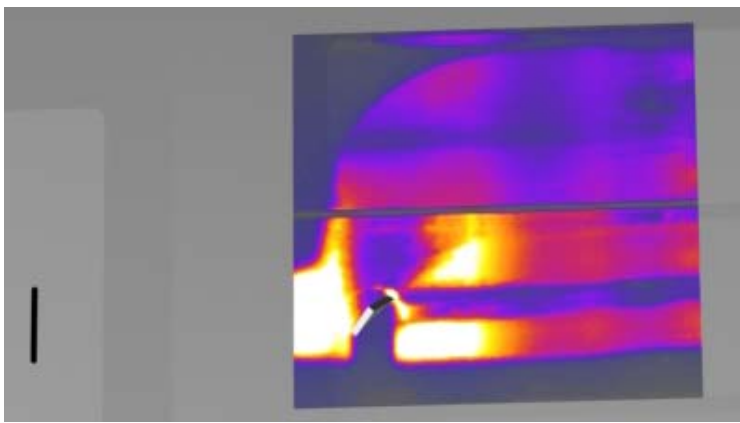

(e)

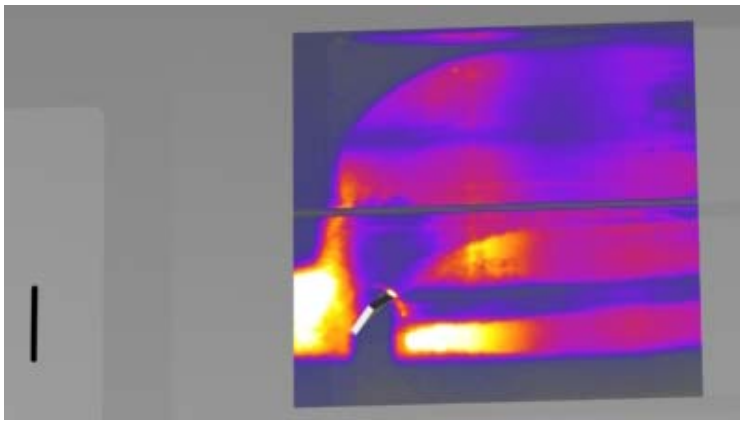

(g)

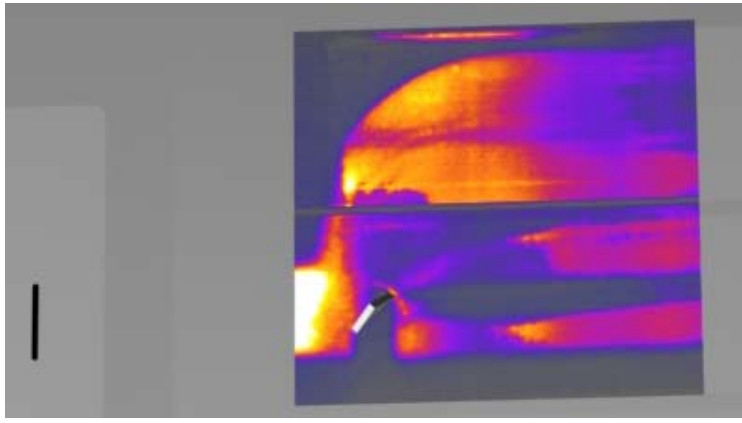

(i)

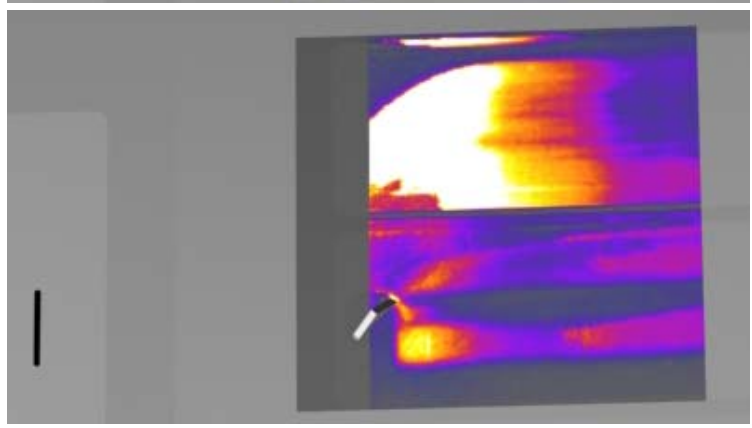

Figure A9: Test 463, Run 18, $2 \mathrm{~mm}$ tall x $8 \mathrm{~mm}$ wide triangular trip at $45^{\circ}$, plate angle $=20^{\circ}$, 11-mm wide slot seeding, $\dot{m}=300 \mathrm{sccm}, \mathrm{P}_{0}=9.33 \mathrm{MPa}$, sheet position $=0.1 \mathrm{~mm}$ above surface, framing rate $=500 \mathrm{kHz}$. 
(a)

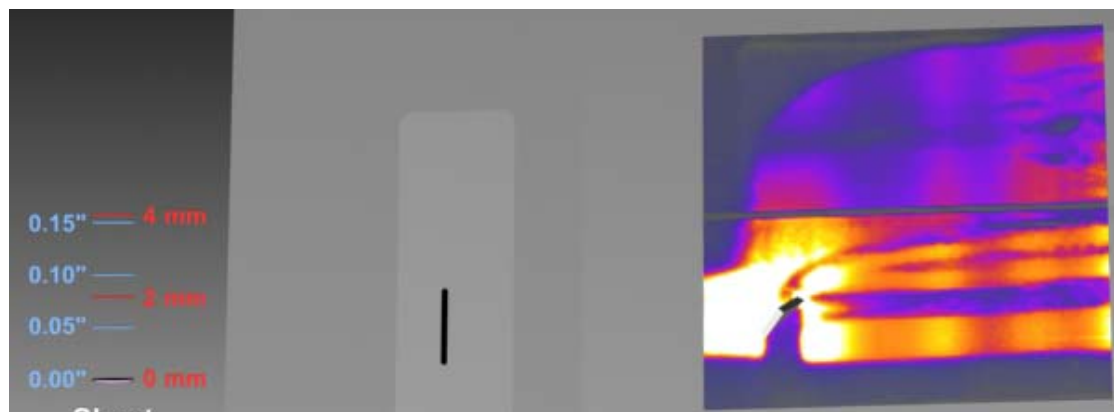

(b)

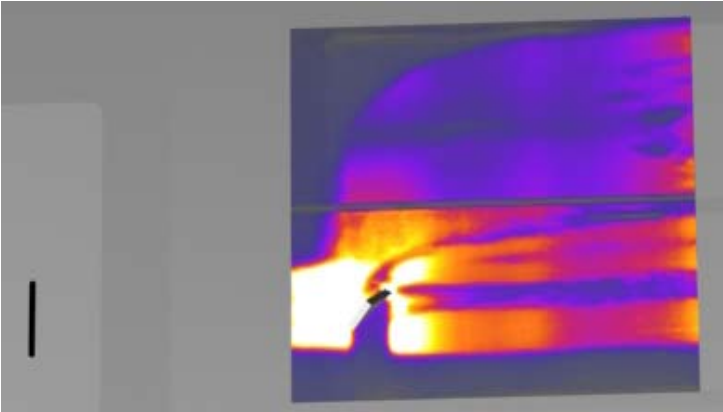

(d)

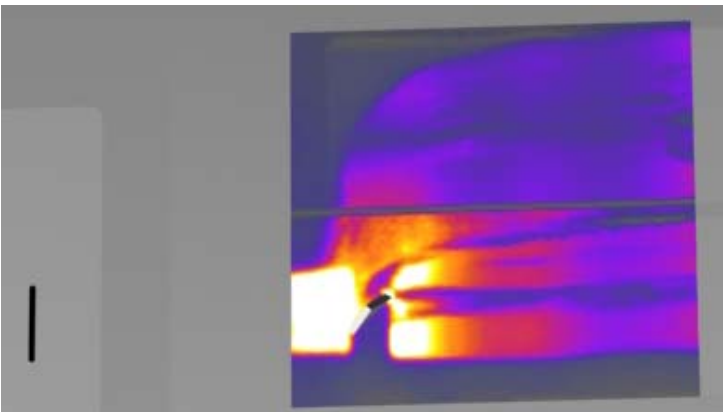

(f)
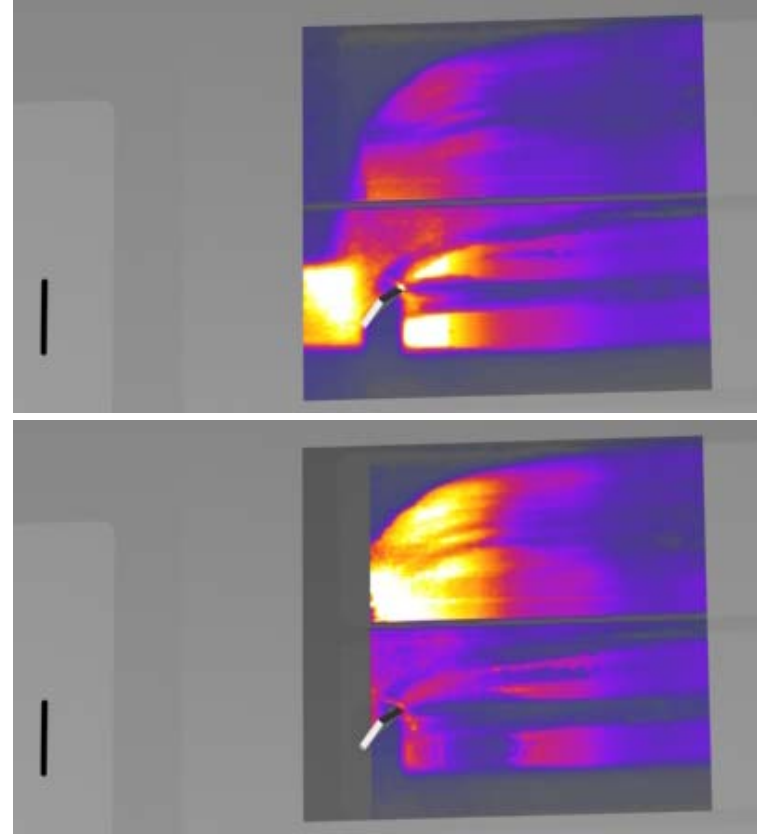

(c)

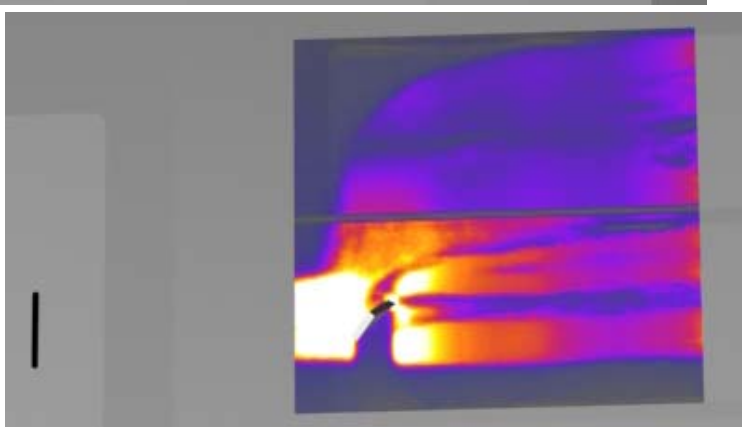

(e)

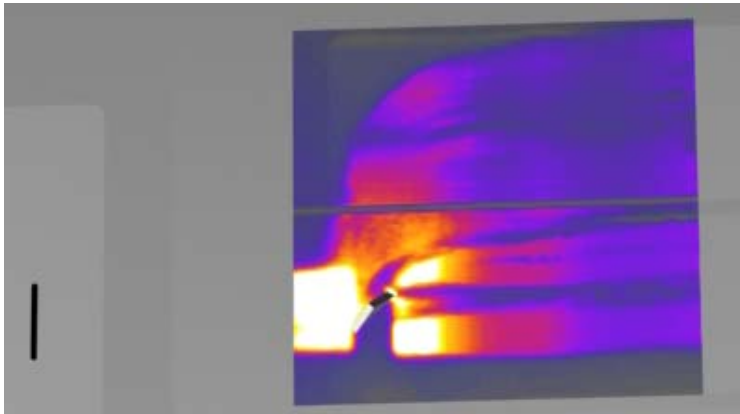

(g)

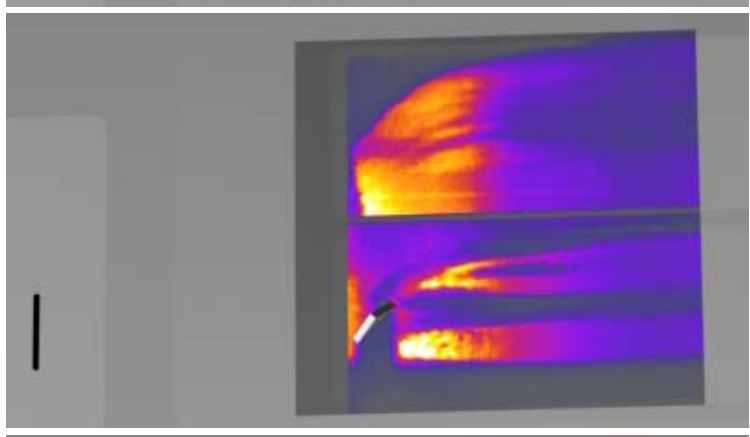

(i)

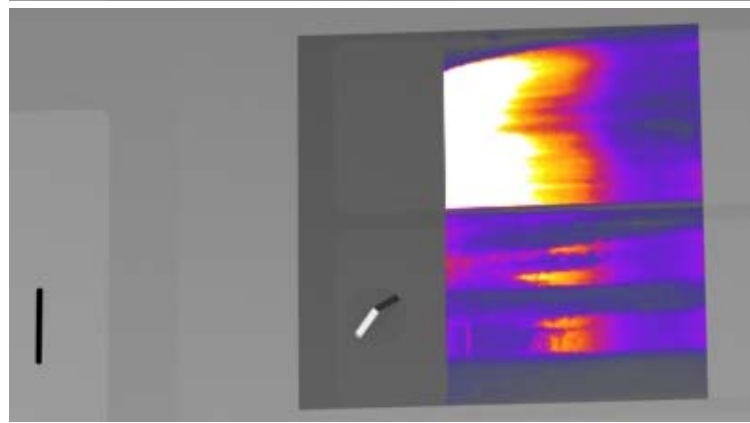

Figure A10: Test 463, Run 18, $2 \mathrm{~mm}$ tall x $8 \mathrm{~mm}$ wide triangular trip at $45^{\circ}$ on a flat plate, plate angle $=20^{\circ}, 11-\mathrm{mm}$ wide slot seeding, $\dot{m}=300 \mathrm{sccm}, \mathrm{P}_{0}=9.33 \mathrm{MPa}$, sheet position $=0.1 \mathrm{~mm}$ above surface, framing rate $=500 \mathrm{kHz}$. 
(a)

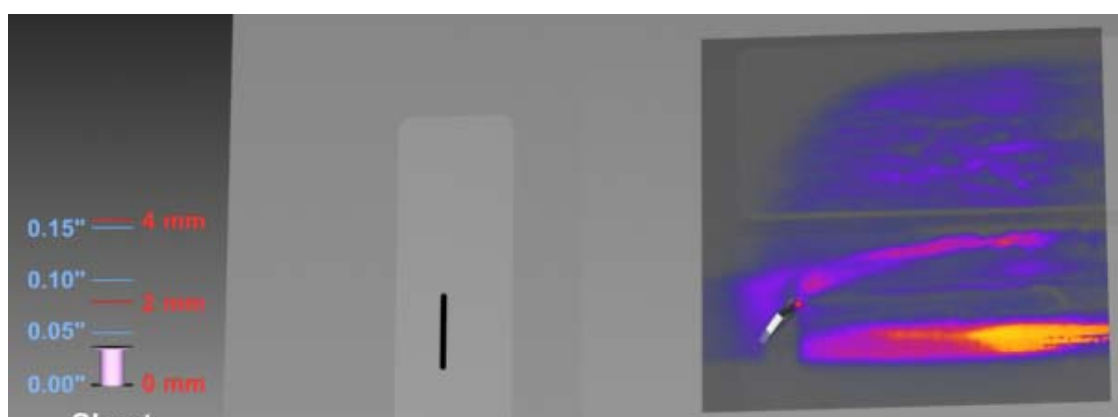

(b)

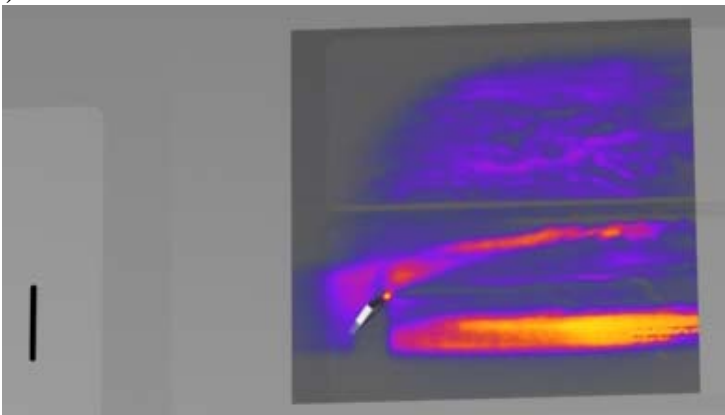

(d)

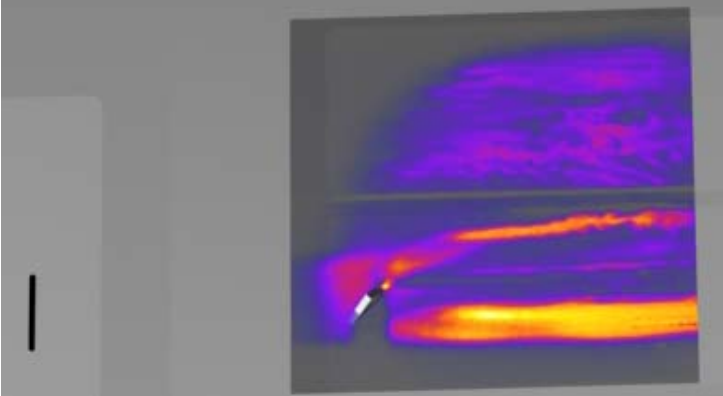

(f)
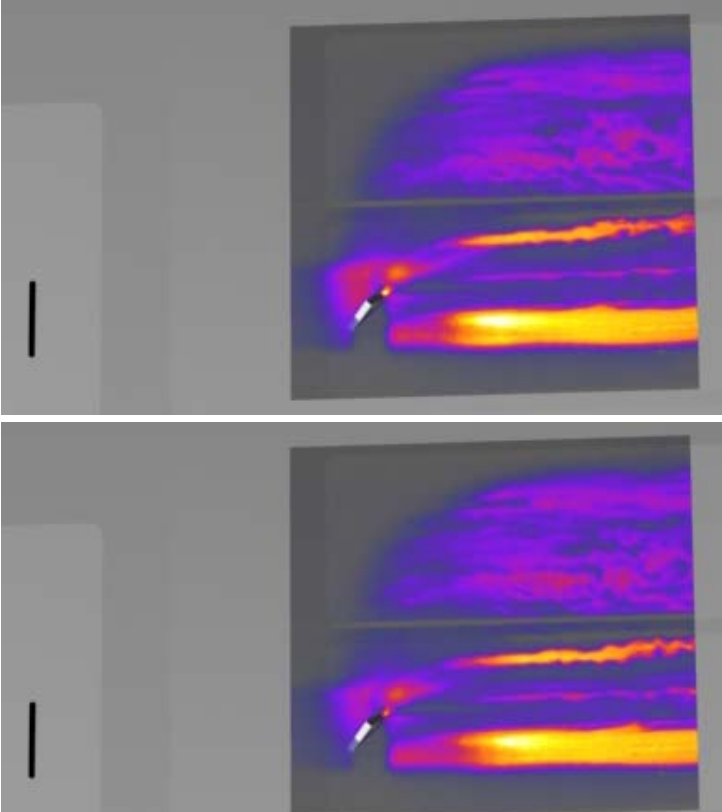

(h)

Figure A11: Test 463, Run 18, $2 \mathrm{~mm}$ tall x $8 \mathrm{~mm}$ wide triangular trip at $45^{\circ}$ on a flat plate, plate angle $=20^{\circ}, 11-\mathrm{mm}$ wide slot seeding, $\dot{m}=300 \mathrm{sccm}, \mathrm{P}_{0}=9.33 \mathrm{MPa}$, sheet position $=0.9 \mathrm{~mm}$ above surface, framing rate $=500 \mathrm{kHz}$. (c)

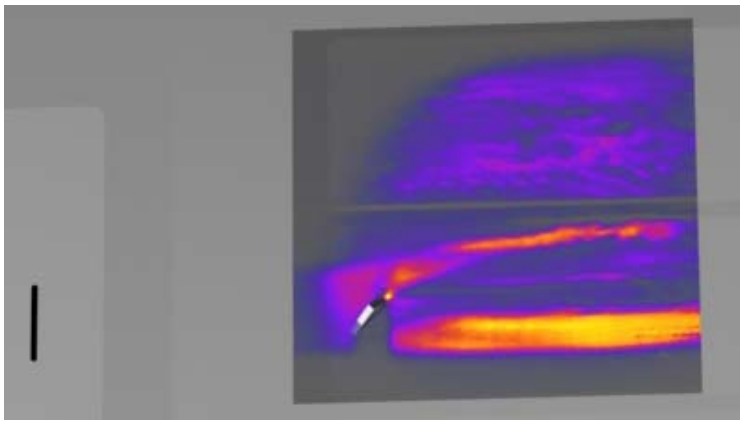

(e)

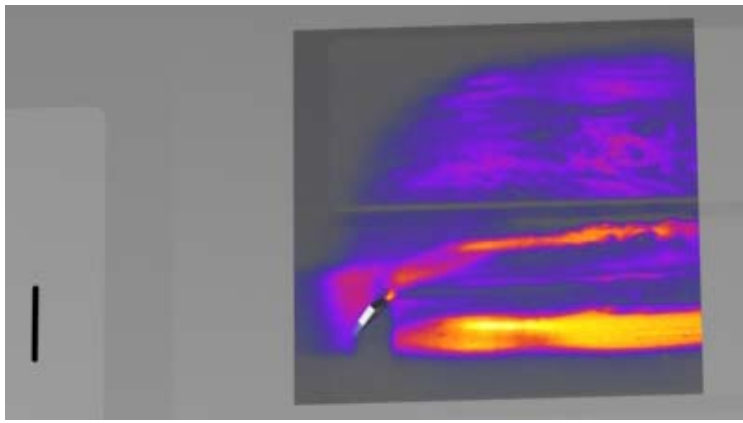

(g)
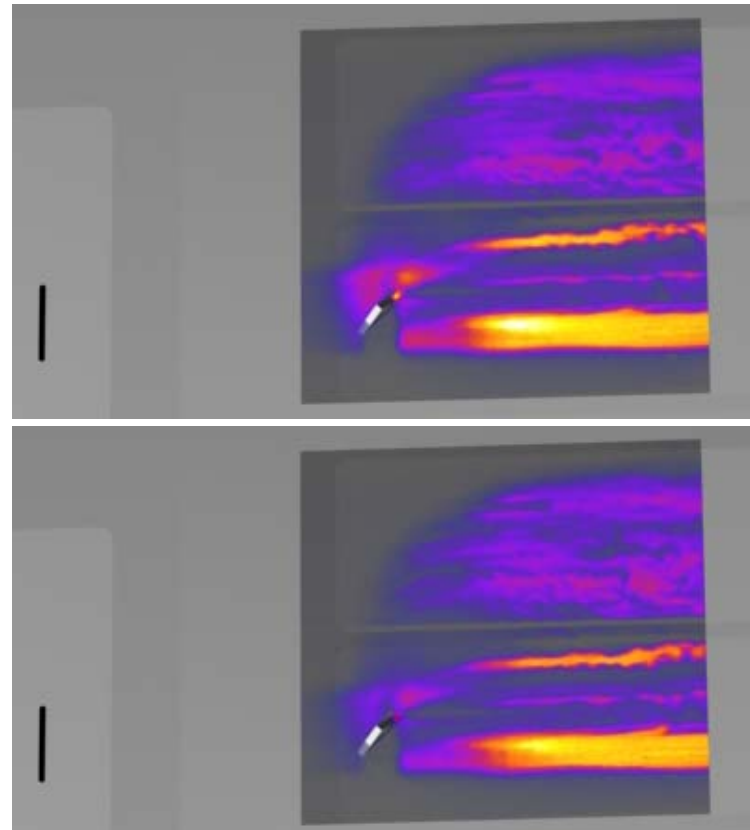

(i) 
(a)

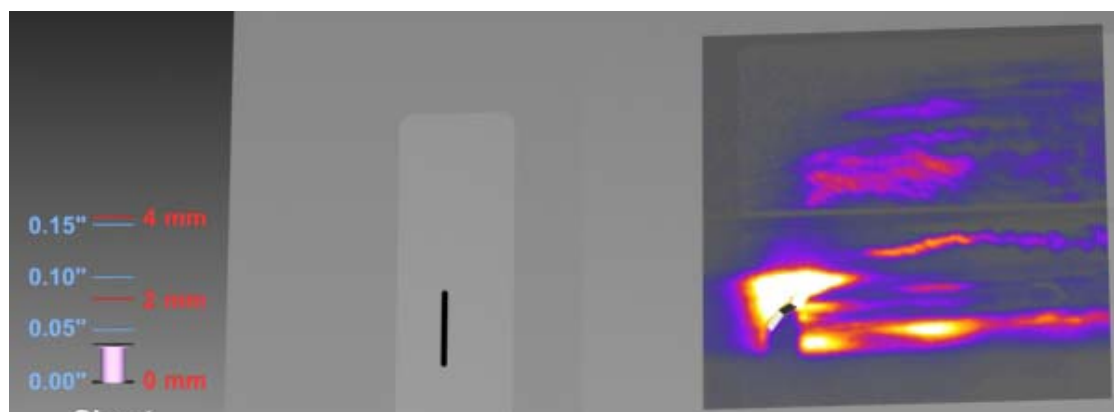

(b)

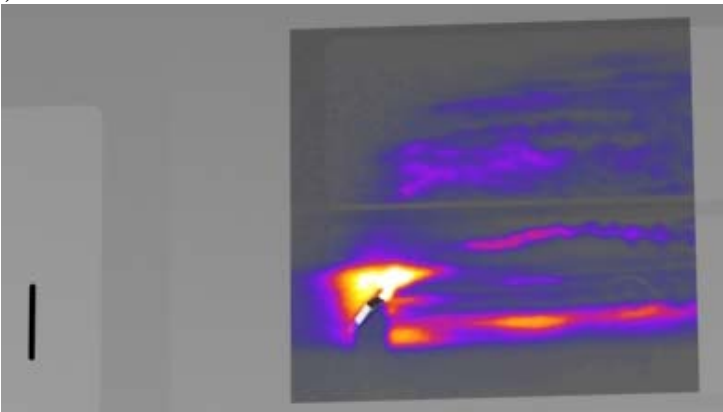

(d)

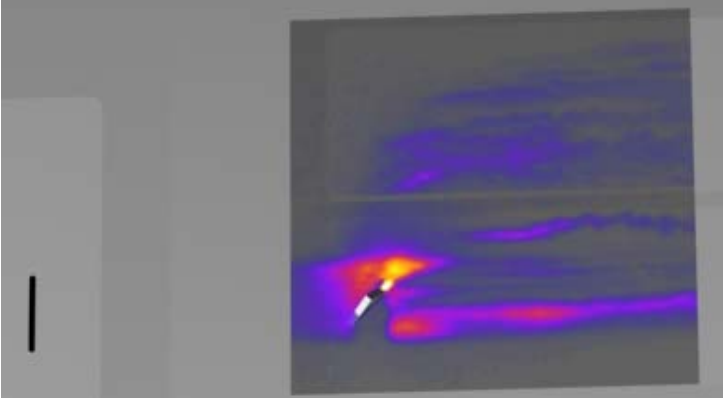

(f)
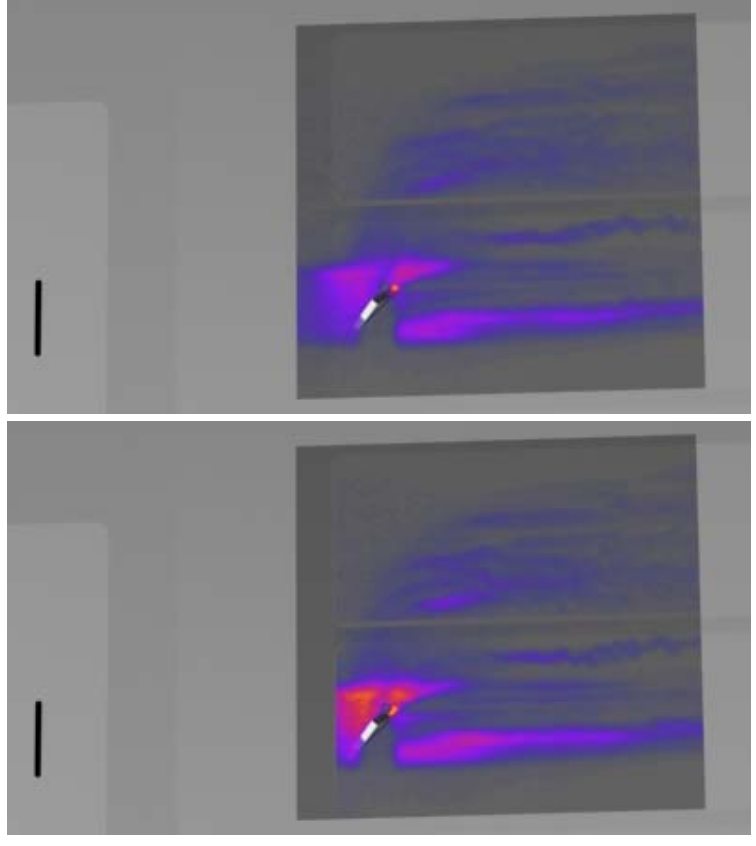

(c)

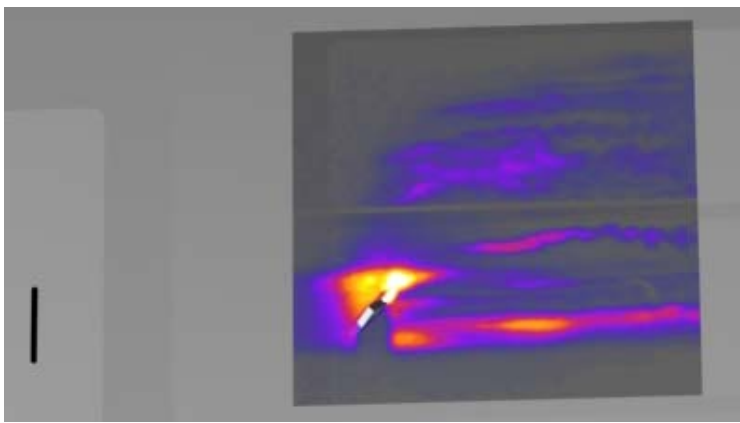

(e)

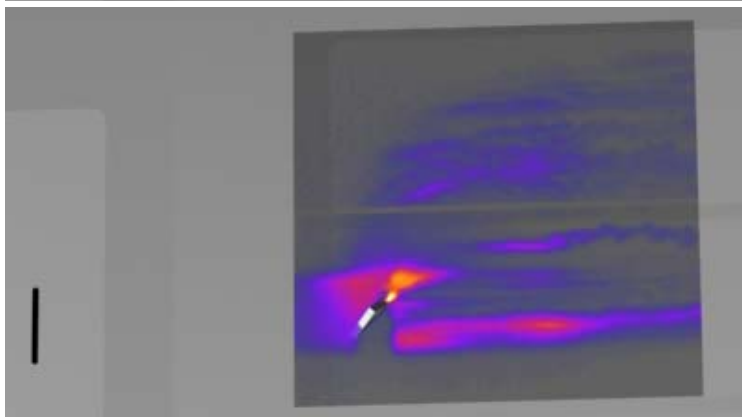

(g)

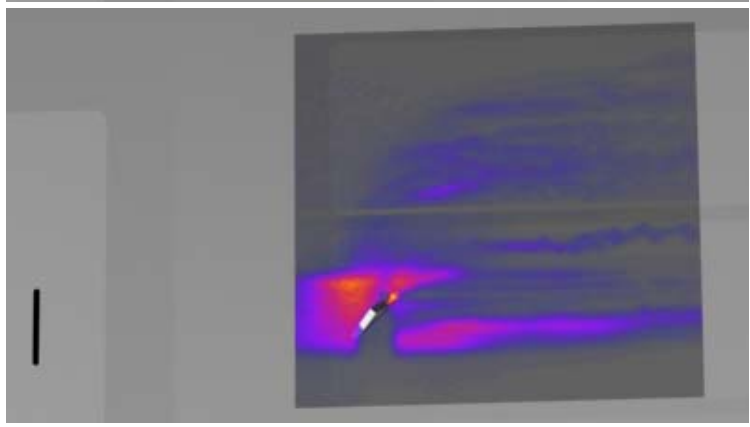

(i)

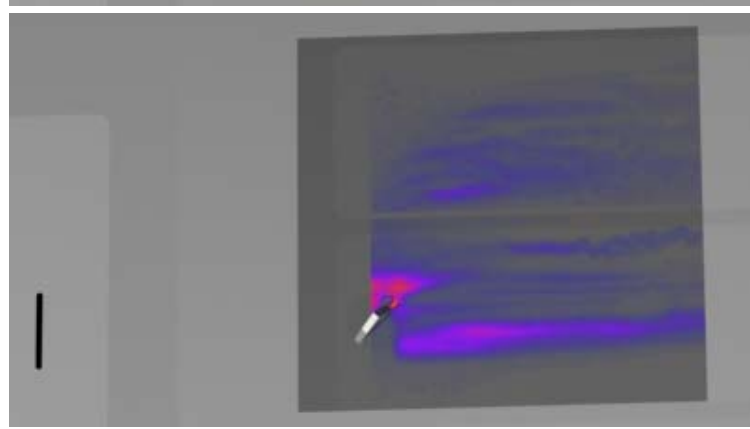

Figure A12: Test 463, Run 18, $2 \mathrm{~mm}$ tall x $8 \mathrm{~mm}$ wide triangular trip at $45^{\circ}$ on a flat plate, plate angle $=20^{\circ}, 11-\mathrm{mm}$ wide slot seeding, $\dot{m}=300 \mathrm{sccm}, \mathrm{P}_{0}=9.33 \mathrm{MPa}$, sheet position $=0.9 \mathrm{~mm}$ above surface, framing rate $=500 \mathrm{kHz}$. 
(a)

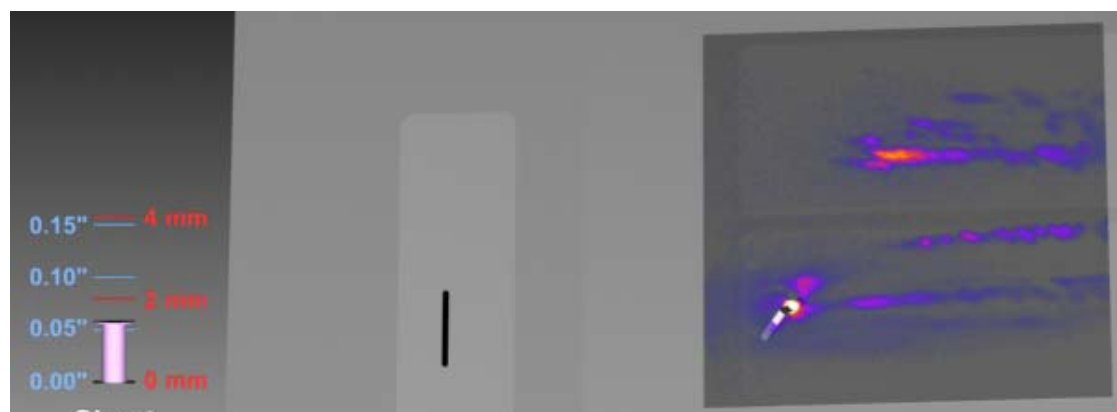

(b)

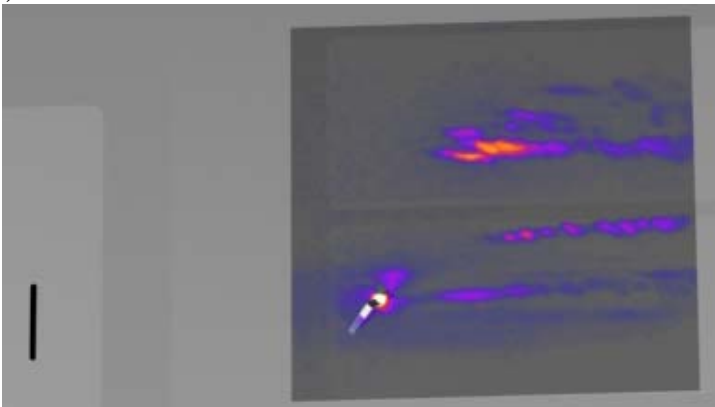

(d)
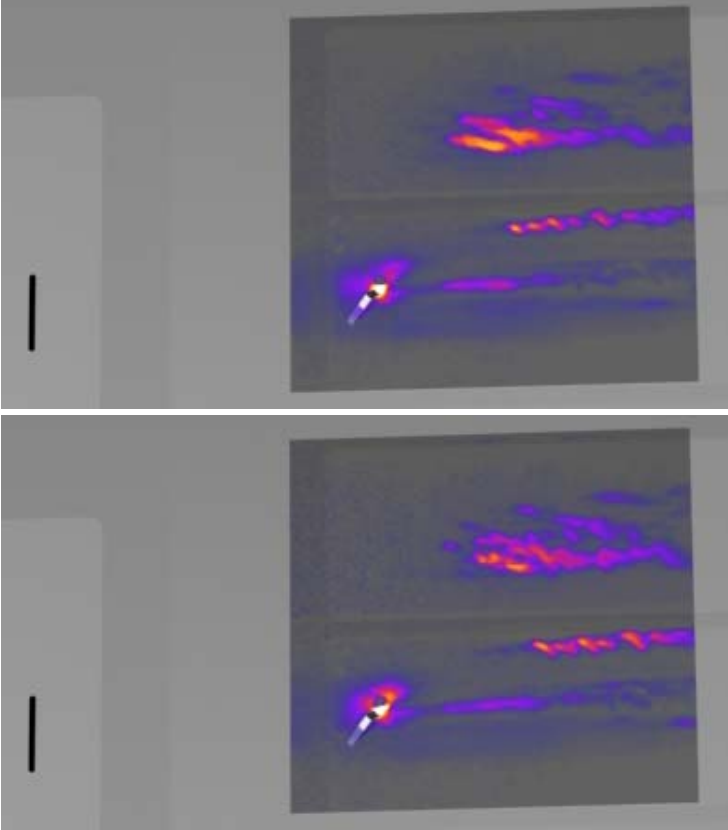

(f)

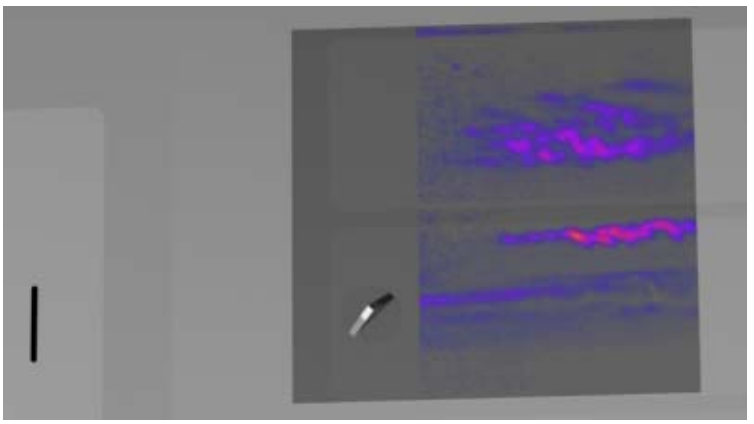

(g)

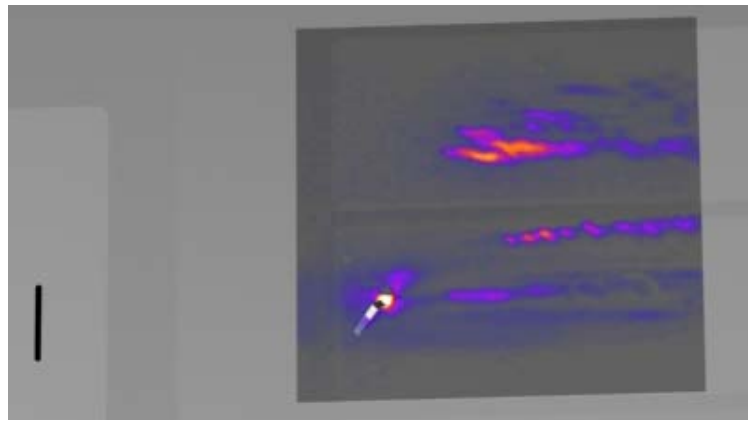

(e)
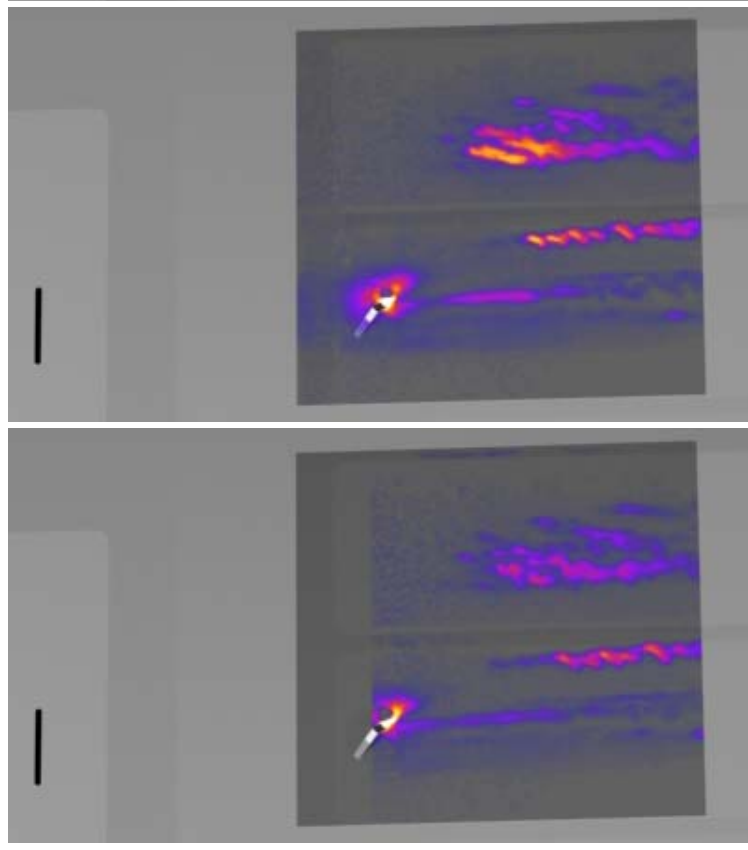

(h)

(i)

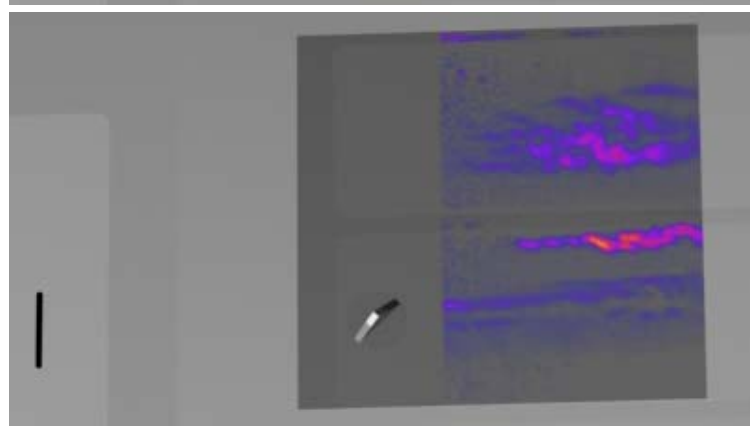

Figure A13: Test 463, Run 18, $2 \mathrm{~mm}$ tall x $8 \mathrm{~mm}$ wide triangular trip at $45^{\circ}$ on a flat plate, plate angle $=20^{\circ}, 11-\mathrm{mm}$ wide slot seeding, $\dot{m}=300 \mathrm{sccm}, \mathrm{P}_{0}=9.33 \mathrm{MPa}$, sheet position $=1.5 \mathrm{~mm}$ above surface, framing rate $=500 \mathrm{kHz}$. 
(a)

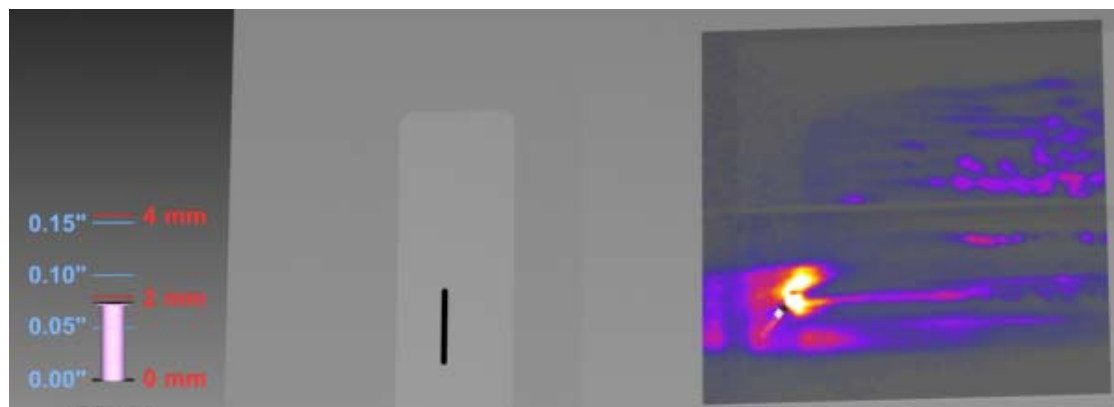

(b)

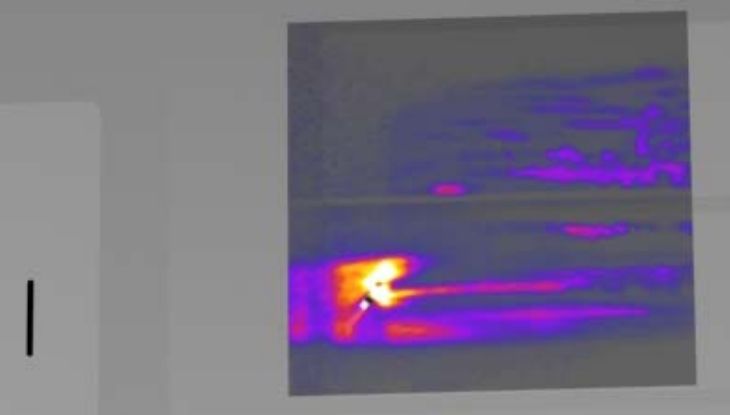

(d)
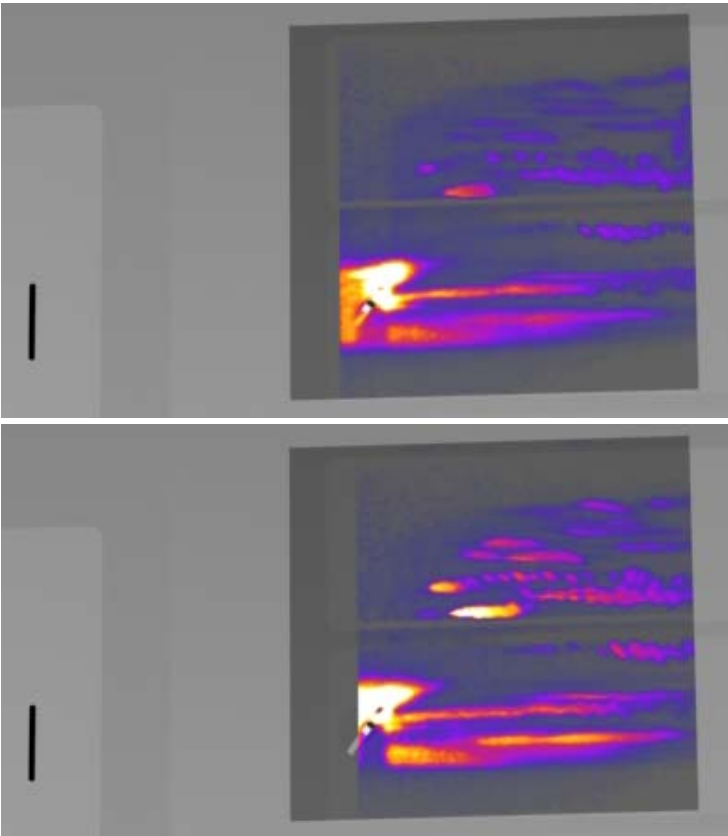

(f)

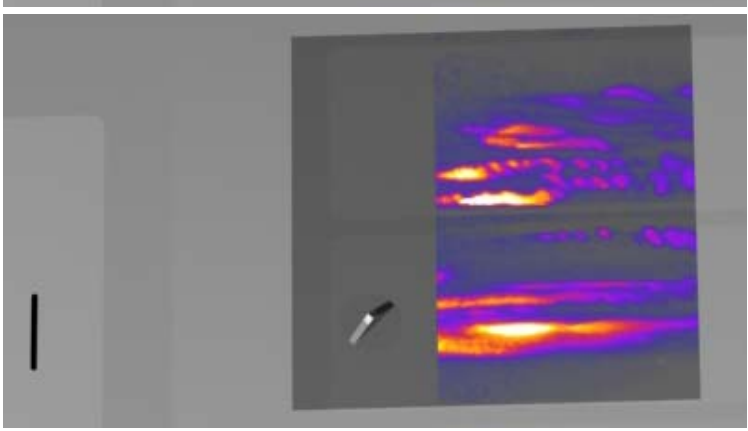

(c)

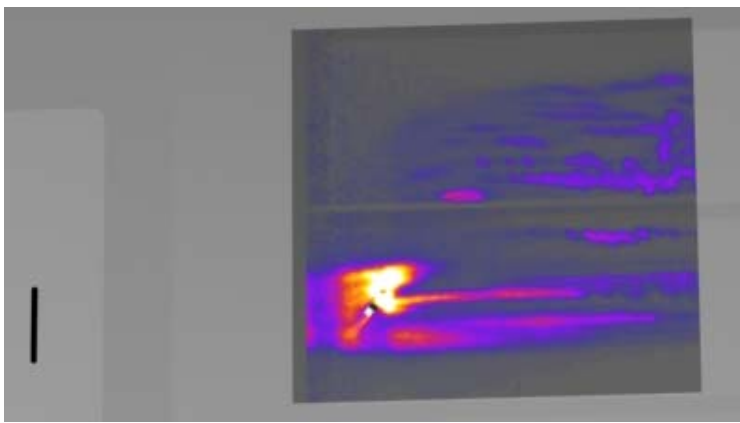

(e)

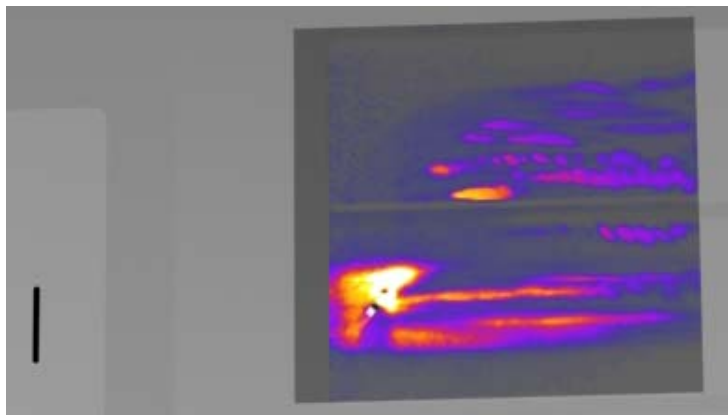

(g)

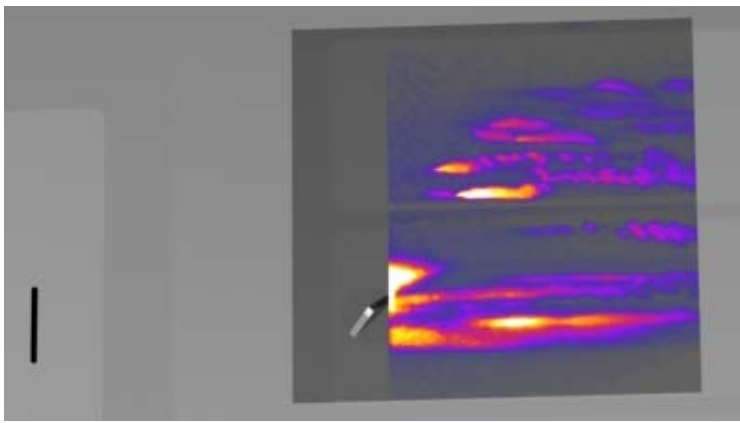

(i)

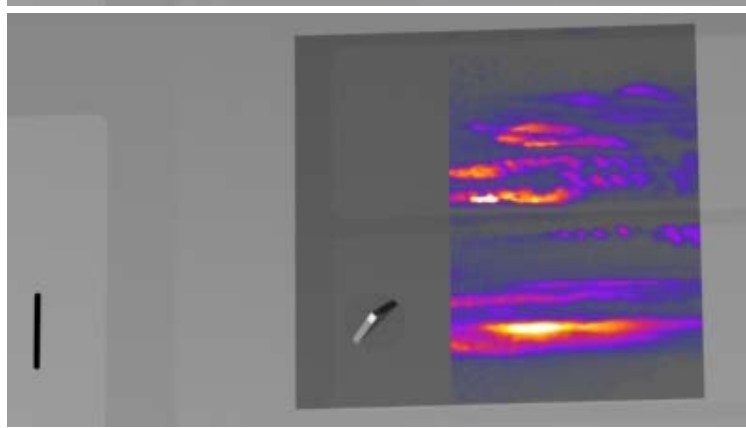

Figure A14: Test 463, Run 18, $2 \mathrm{~mm}$ tall x $8 \mathrm{~mm}$ wide triangular trip at $45^{\circ}$ on a flat plate, plate angle $=20^{\circ}$, 11-mm wide slot seeding, $\dot{m}=300 \mathrm{sccm}, \mathrm{P}_{0}=9.33 \mathrm{MPa}$, sheet position $=1.9 \mathrm{~mm}$ above surface, framing rate $=500 \mathrm{kHz}$. 
(a)

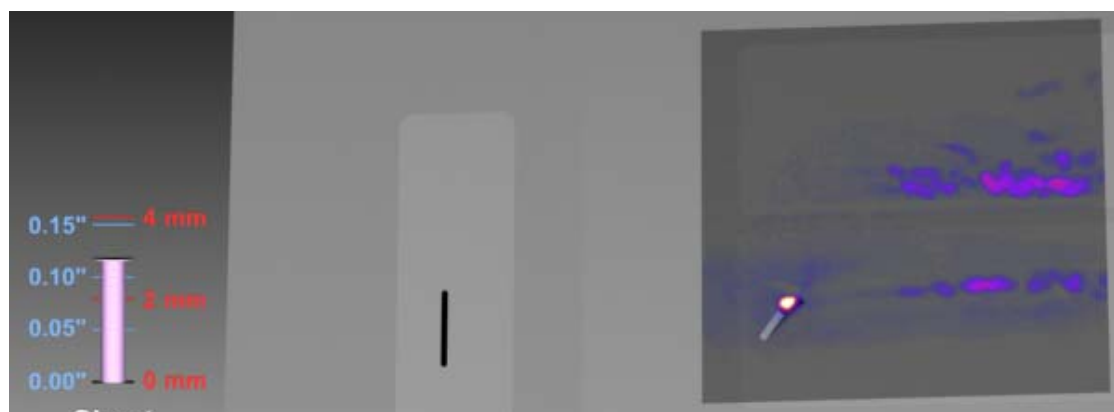

(b)
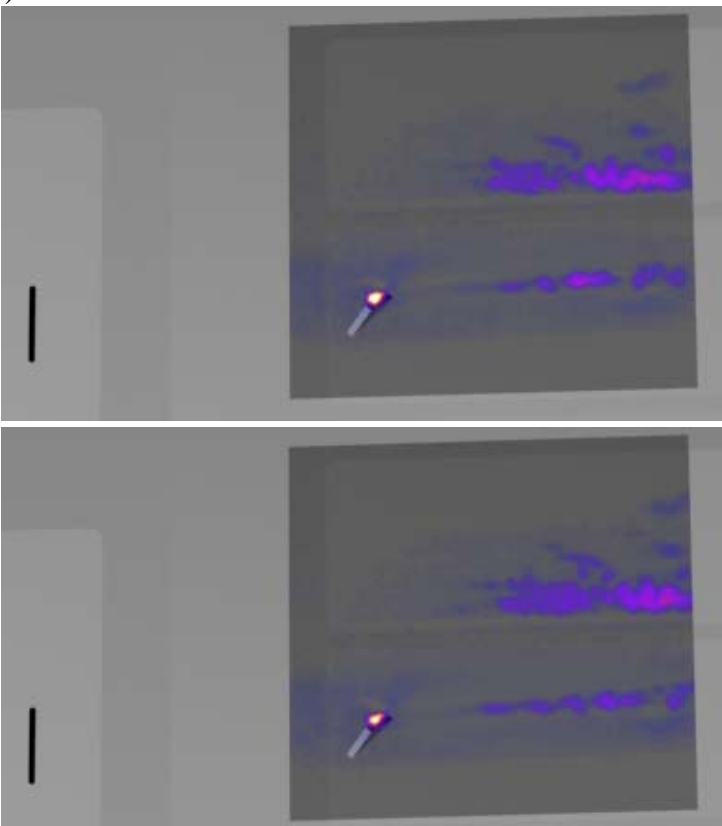

(d)

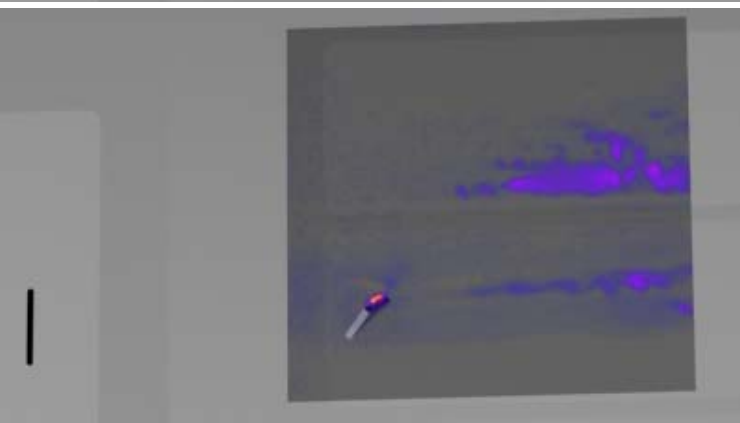

(f)

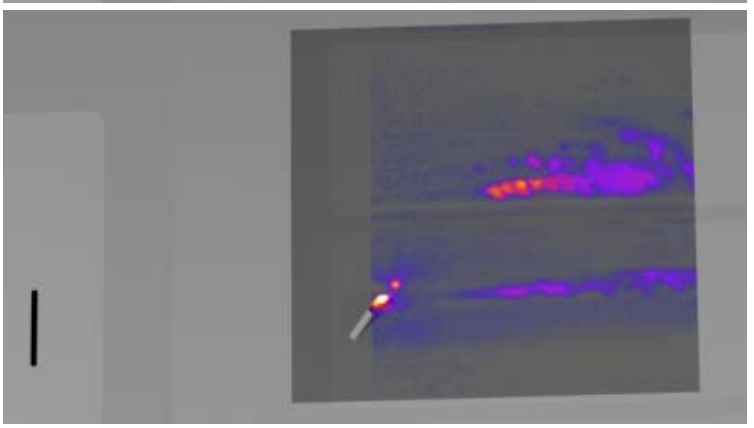

(h)

(g)

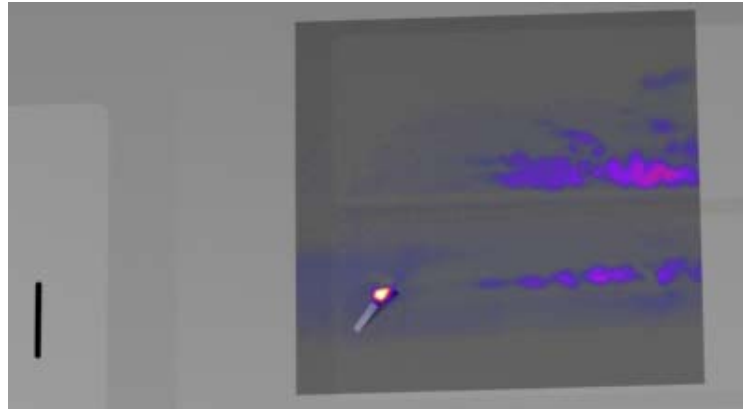

(e)
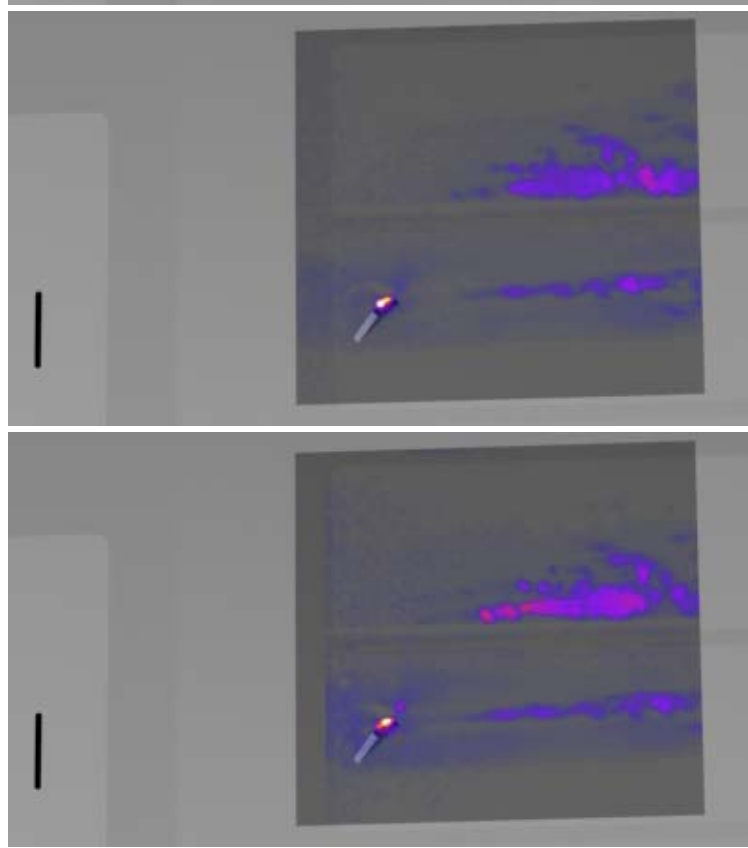

(i)

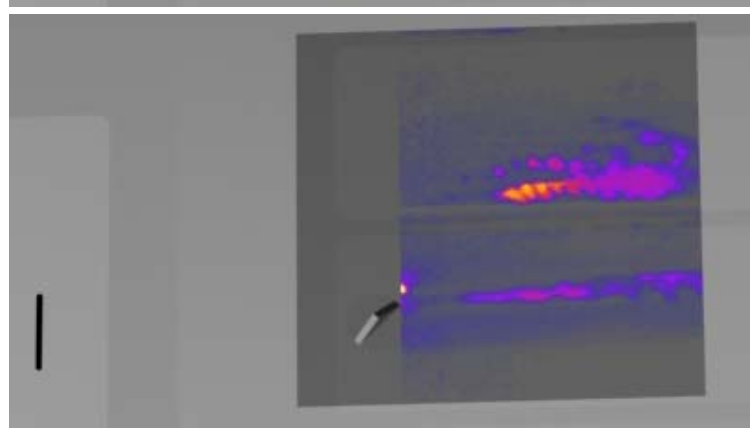

Figure A15: Test 463, Run 18, $2 \mathrm{~mm}$ tall x $8 \mathrm{~mm}$ wide triangular trip at $45^{\circ}$ on a flat plate, plate angle $=20^{\circ}, 11-\mathrm{mm}$ wide slot seeding, $\dot{m}=300 \mathrm{sccm}, \mathrm{P}_{0}=9.33 \mathrm{MPa}$, sheet position $=3.0 \mathrm{~mm}$ above surface, framing rate $=500 \mathrm{kHz}$. 


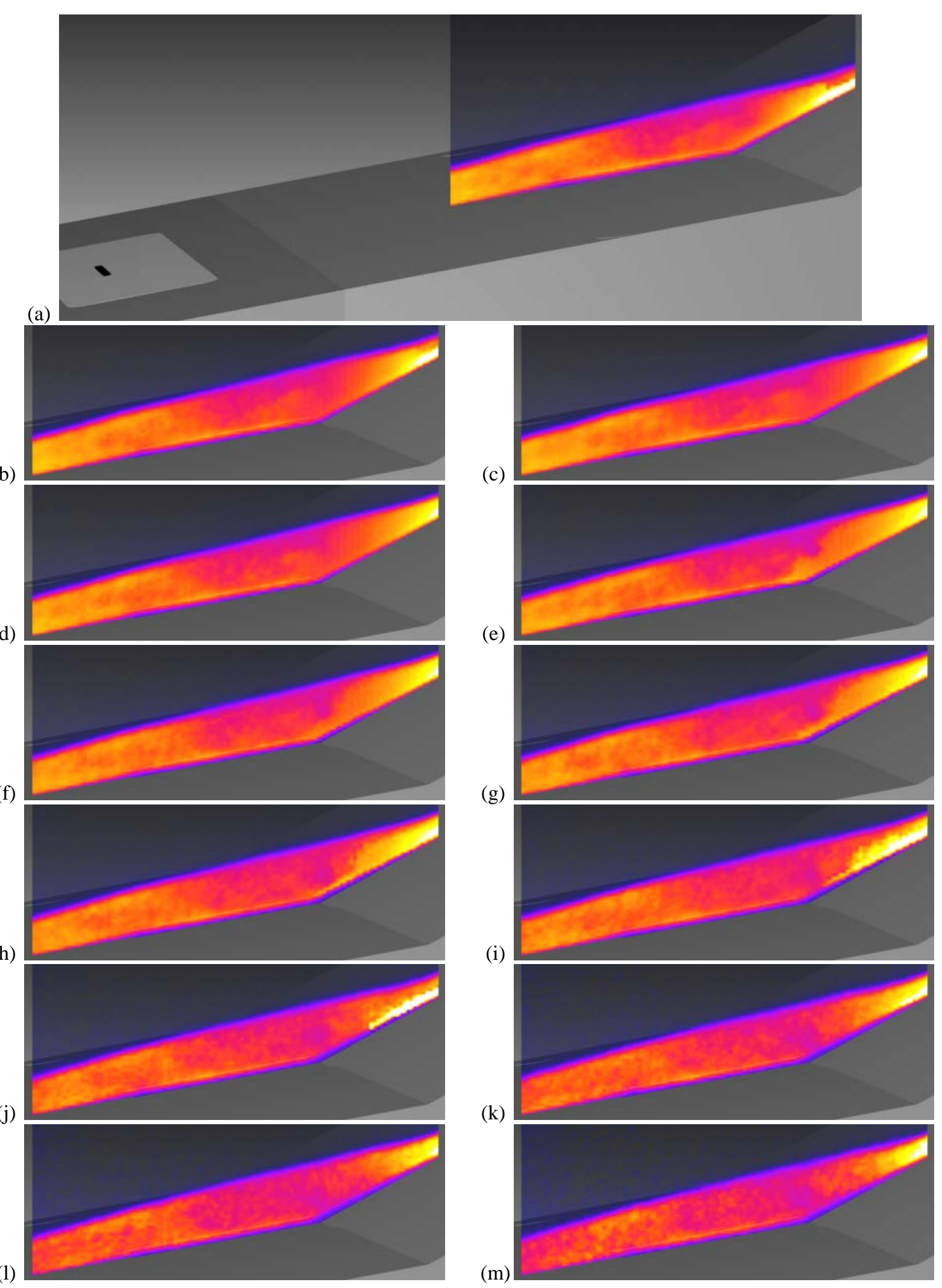

Figure A16: Test 463 , Run $19,20^{\circ}$ compression corner, plate angle $=10^{\circ}, 11$-mm wide slot seeding, $\dot{m}=300 \mathrm{sccm}$, $\mathrm{P}_{0}=4.97 \mathrm{MPa}$, framing rate $=100 \mathrm{kHz}$. 


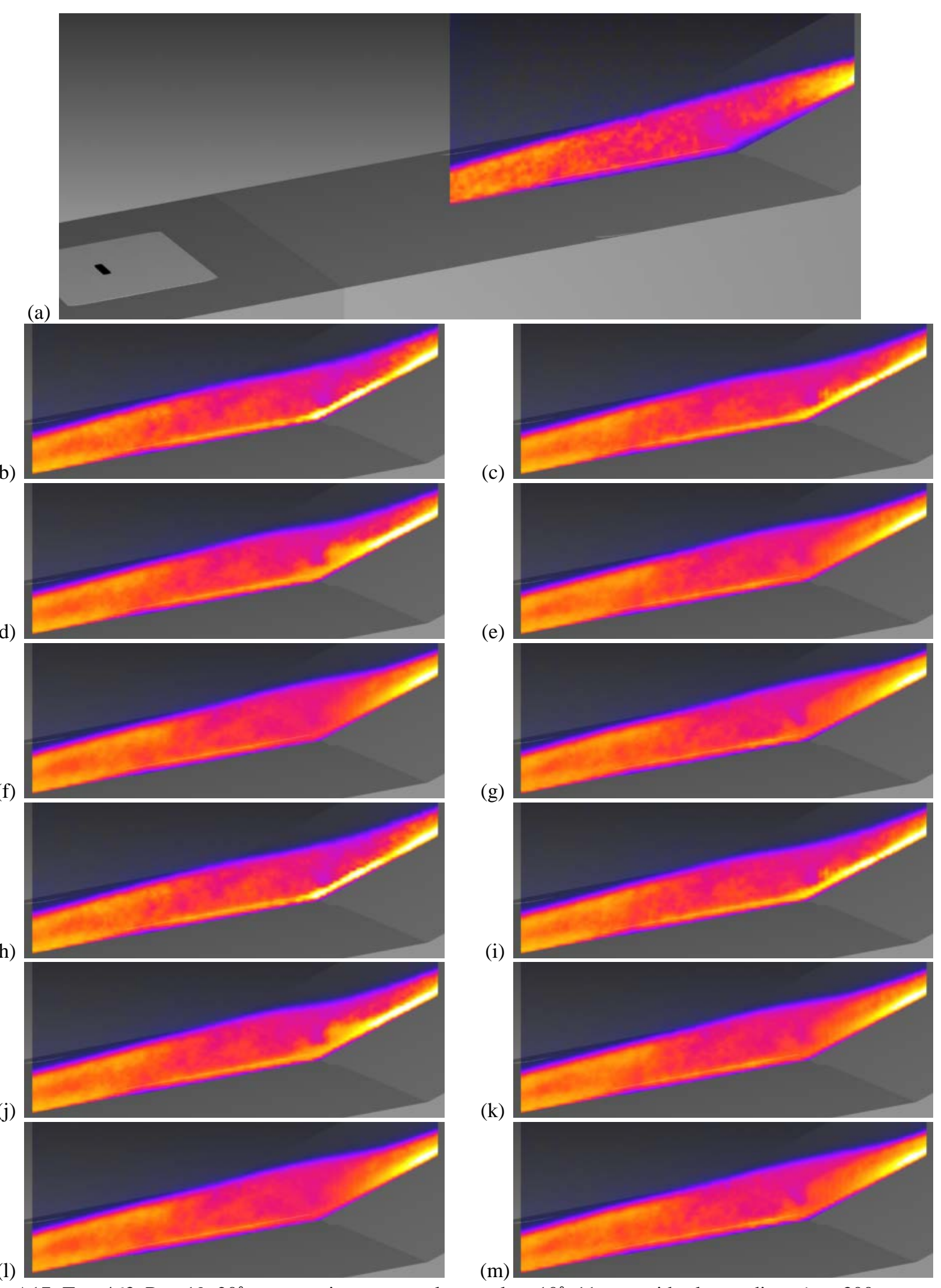

Figure A17: Test 463, Run 19, $20^{\circ}$ compression corner, plate angle $=10^{\circ}$, 11 -mm wide slot seeding, $\dot{m}=300$ sccm, $\mathrm{P}_{0}=4.97 \mathrm{MPa}$, framing rate $=100 \mathrm{kHz}$. 


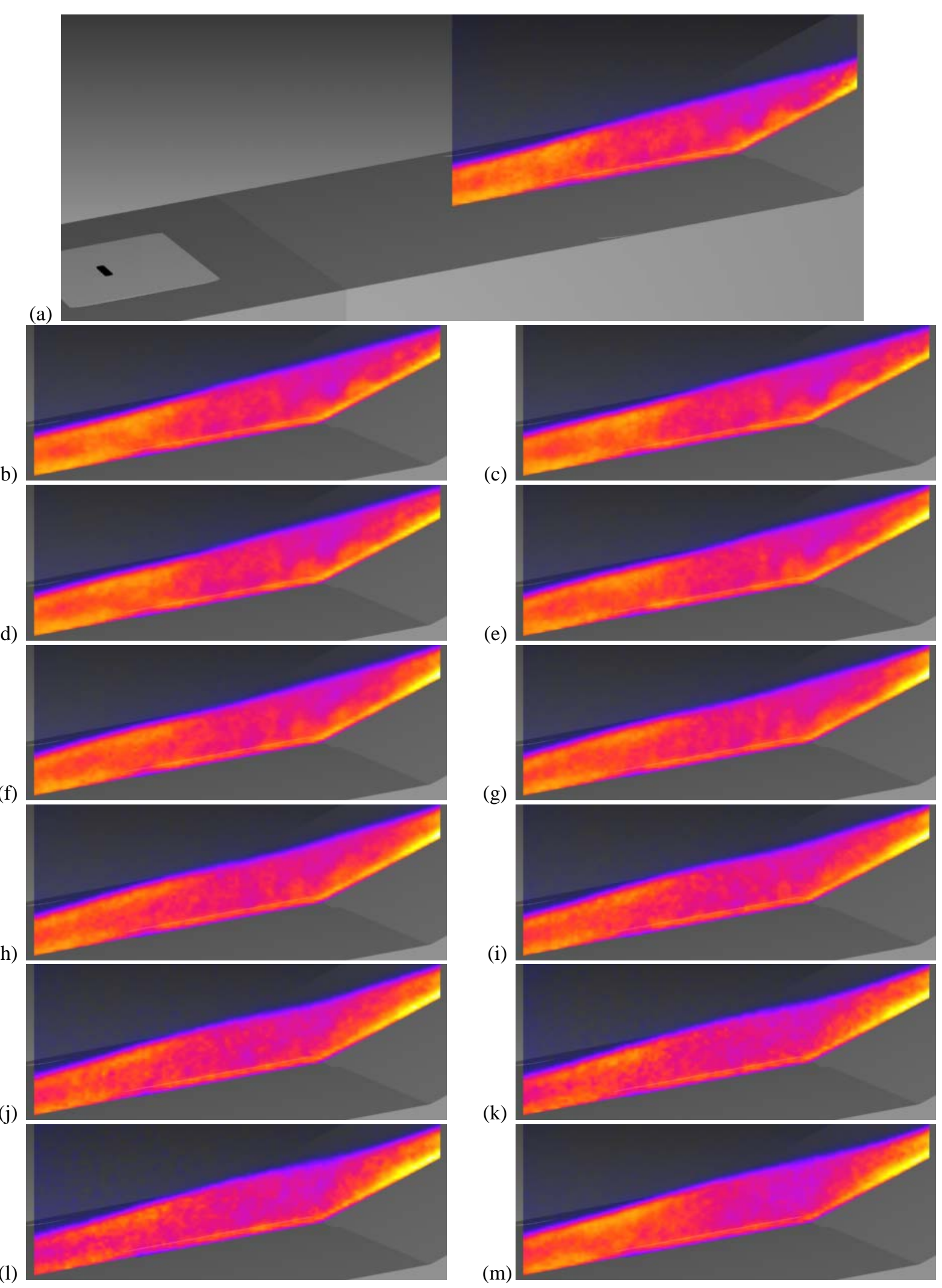

Figure A18: Test 463 , Run $19,20^{\circ}$ compression corner, plate angle $=10^{\circ}$, 11 -mm wide slot seeding, $\dot{m}=300$ sccm, $\mathrm{P}_{0}=4.97 \mathrm{MPa}$, framing rate $=100 \mathrm{kHz}$. 


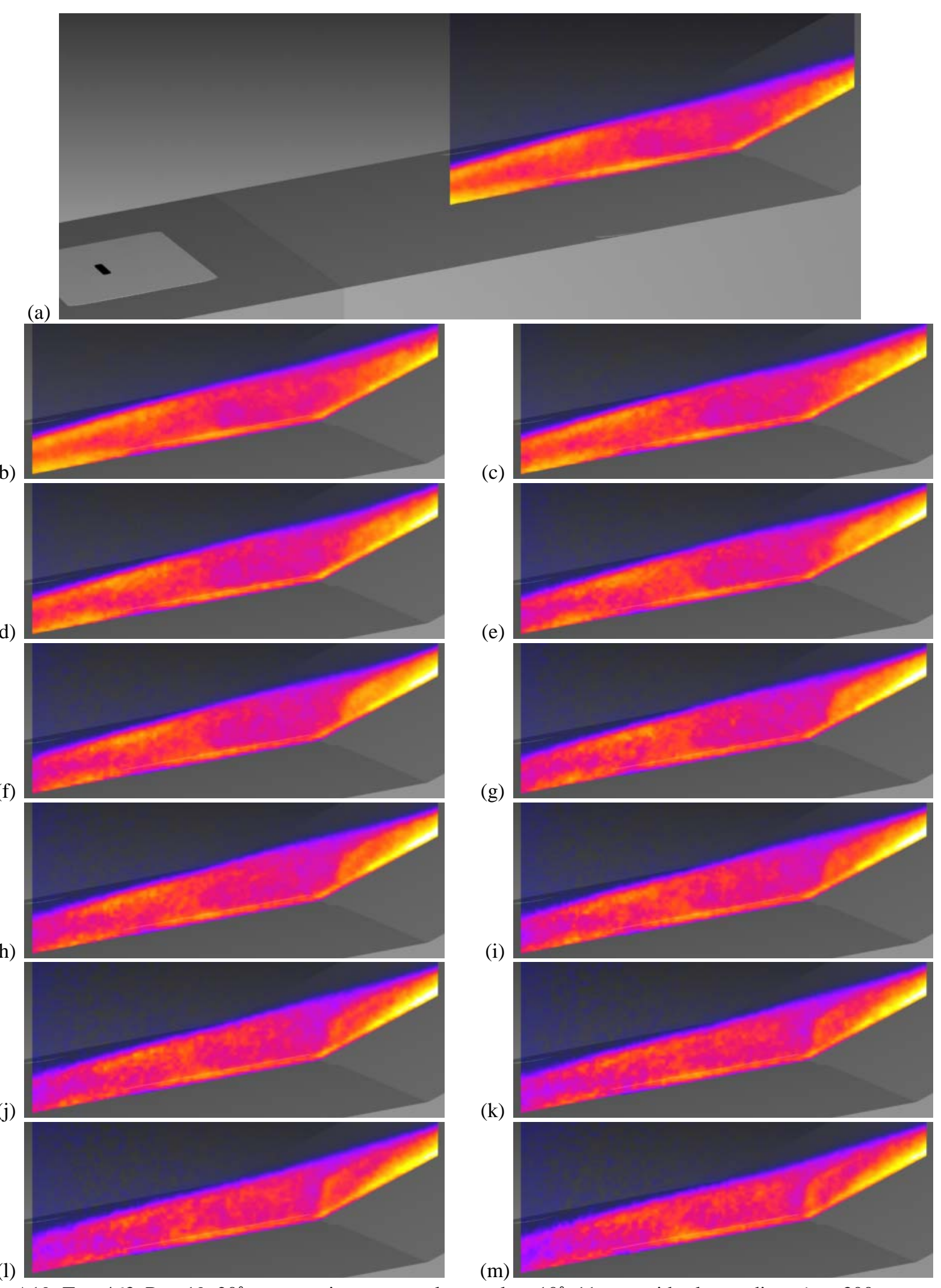

Figure A19: Test 463 , Run $19,20^{\circ}$ compression corner, plate angle $=10^{\circ}$, 11 -mm wide slot seeding, $\dot{m}=300$ sccm, $\mathrm{P}_{0}=4.97 \mathrm{MPa}$, framing rate $=100 \mathrm{kHz}$. 
(a)

(b)

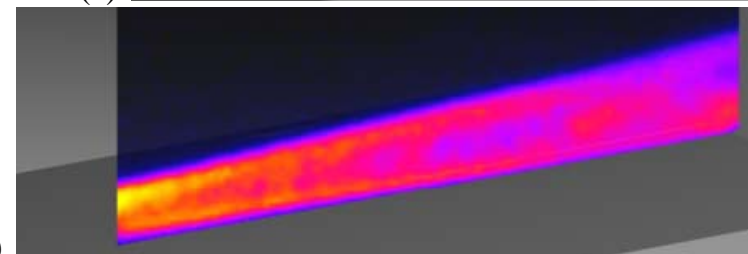

(d)

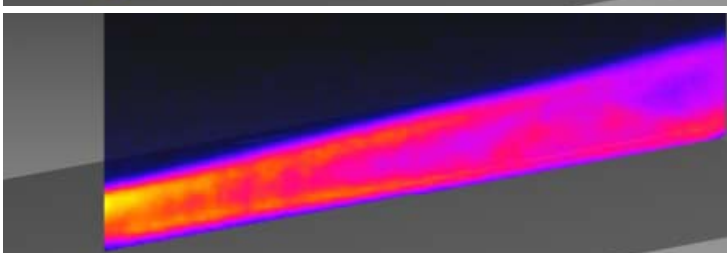

(f)

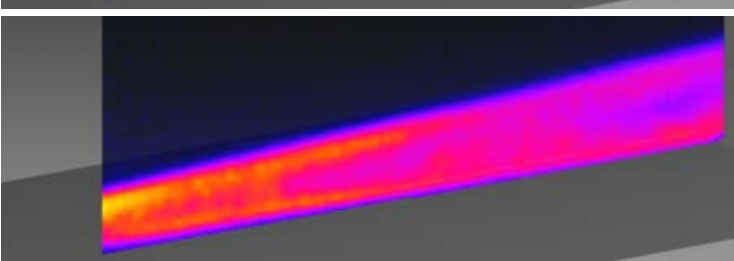

(h)
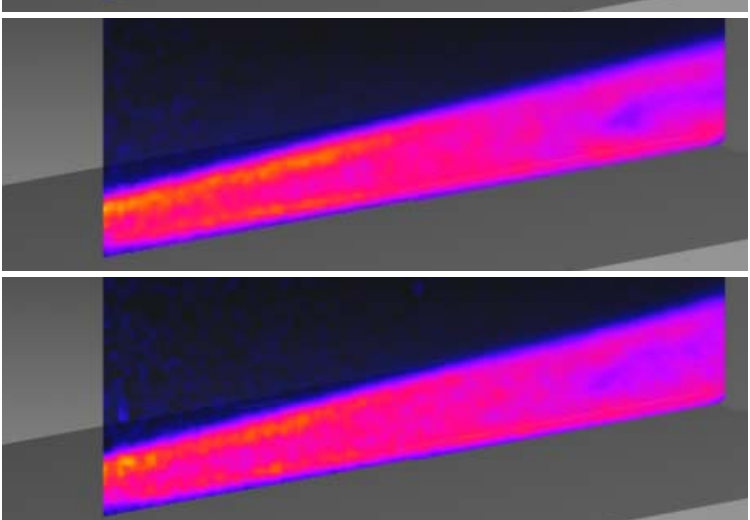

(j)

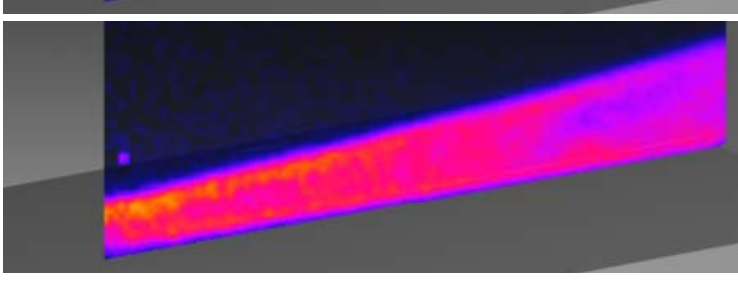

(c)

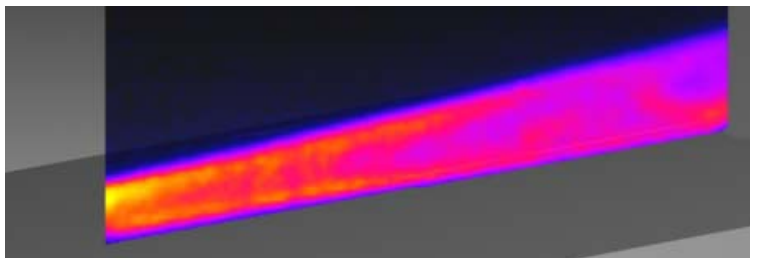

(e)

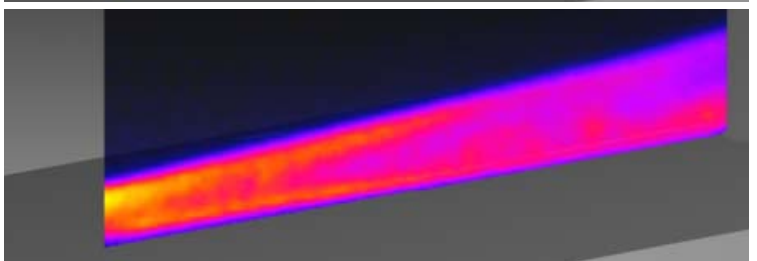

(g)

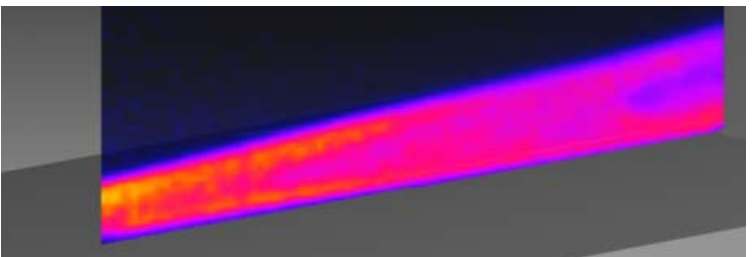

(i)

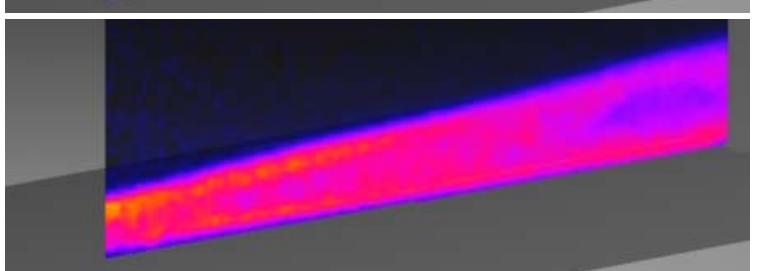

(k)

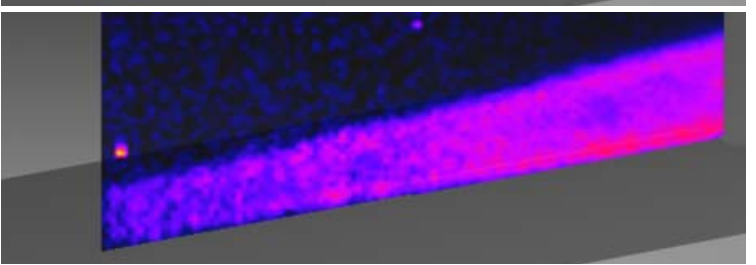

(m)

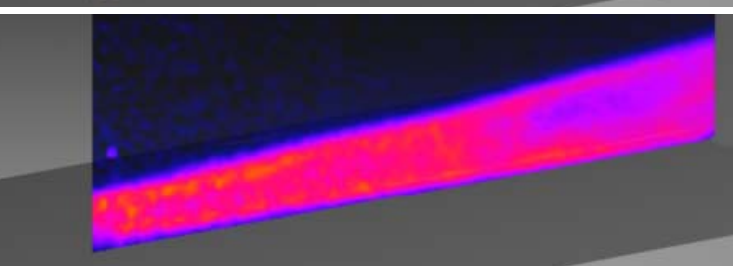

Figure A20: Test 463, Run 20, $20^{\circ}$ compression corner, plate angle $=10^{\circ}$, 11 -mm wide slot seeding, $\dot{m}=300 \mathrm{sccm}$, $\mathrm{P}_{0}=4.97 \mathrm{MPa}$, framing rate $=100 \mathrm{kHz}$. 
(a)

(b)

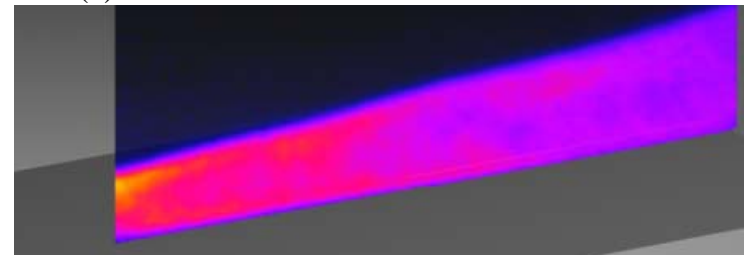

(d)

(f)

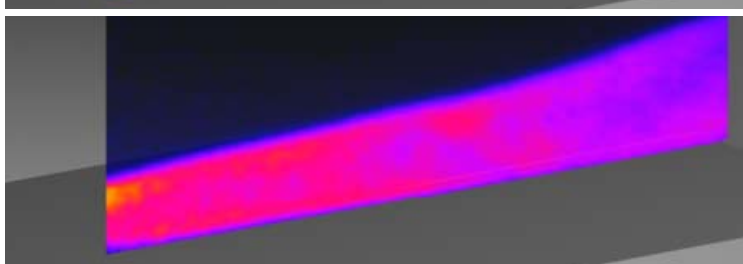

(h)
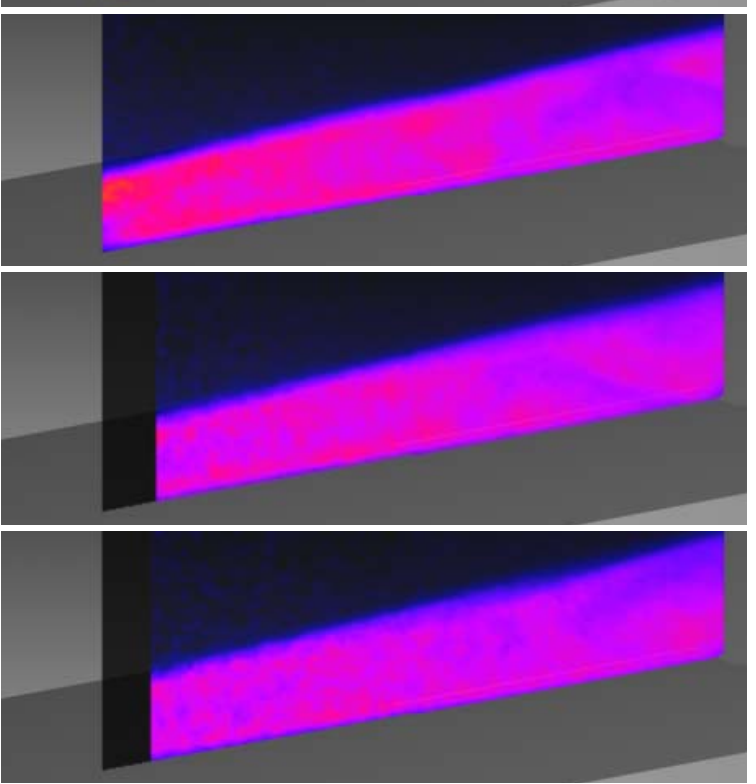

(j)

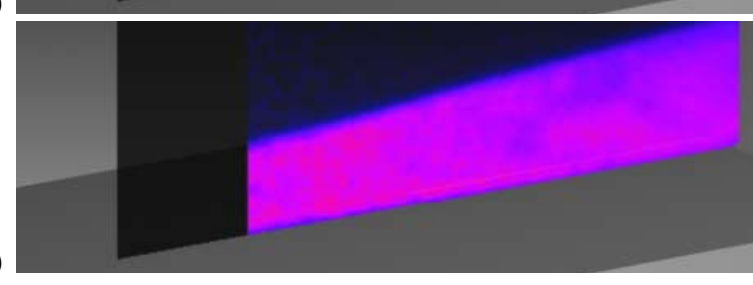

(c)

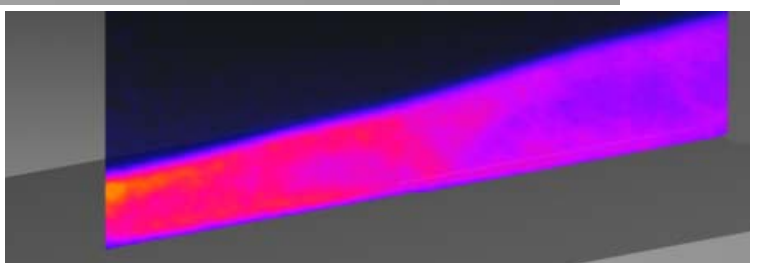

(e)

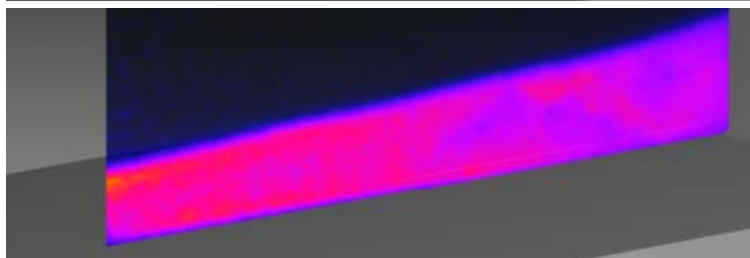

(g)

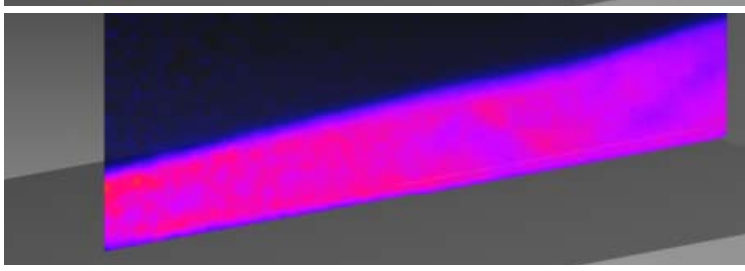

(i)

(k)

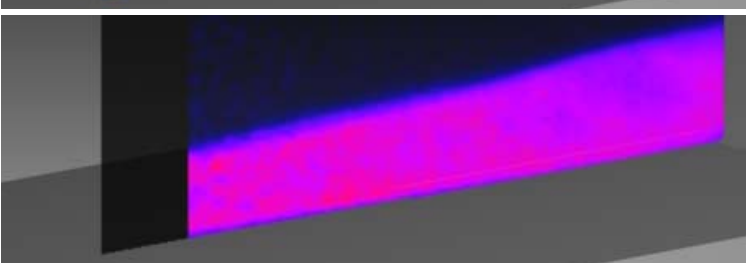

(m)
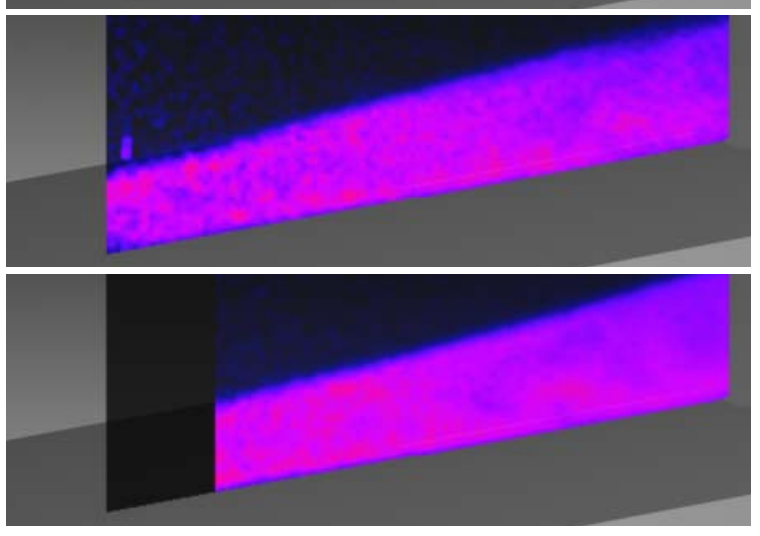

Figure A21: Test 463, Run 20, $20^{\circ}$ compression corner, plate angle $=10^{\circ}$, 11 -mm wide slot seeding, $\dot{m}=1000 \mathrm{sccm}$, $\mathrm{P}_{0}=4.97 \mathrm{MPa}$, framing rate $=100 \mathrm{kHz}$. 
(a)

(b)

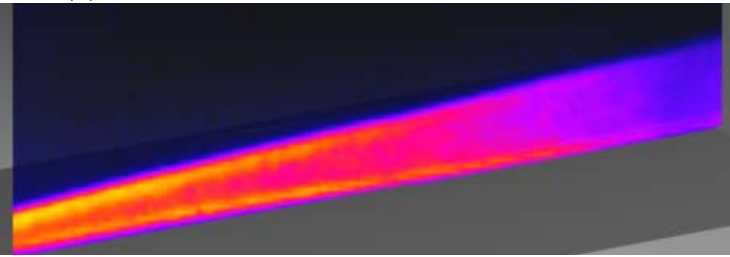

(d)

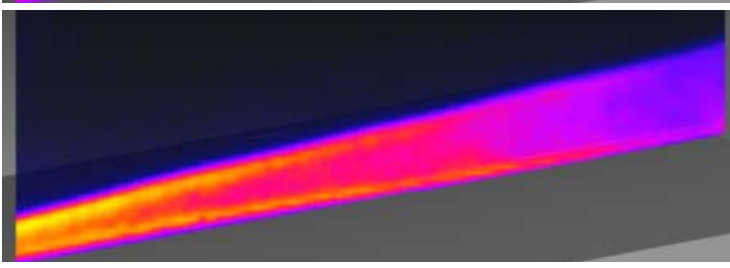

(f)

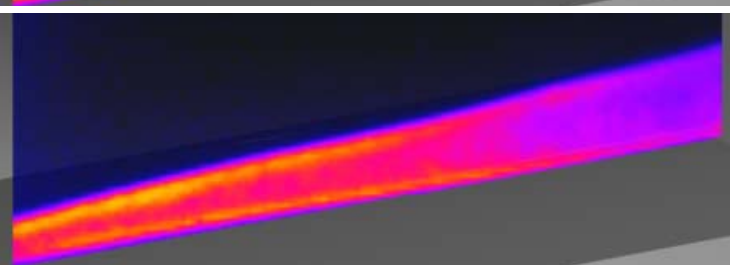

(h)
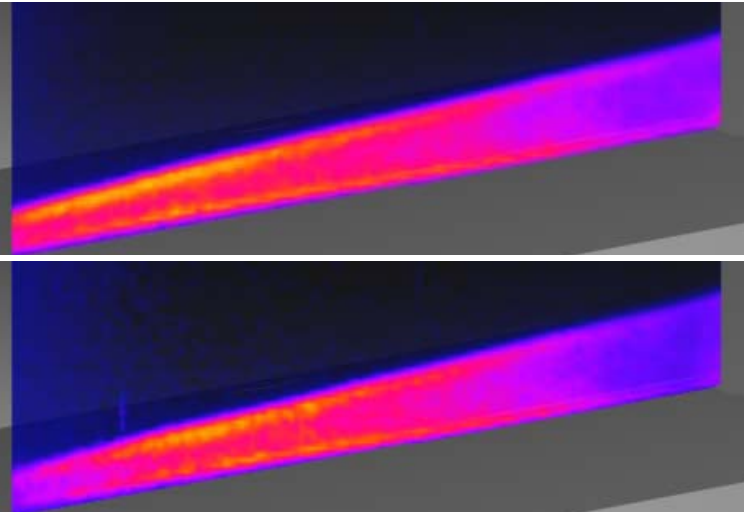

(j)

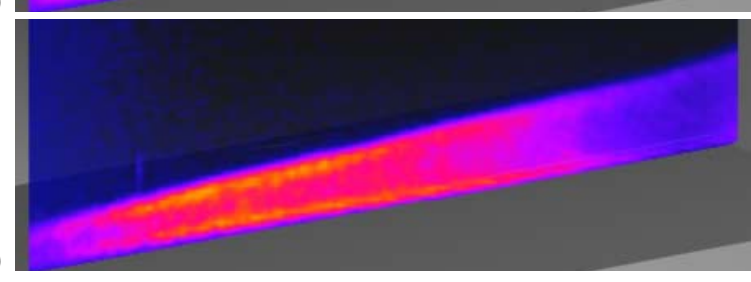

(c)

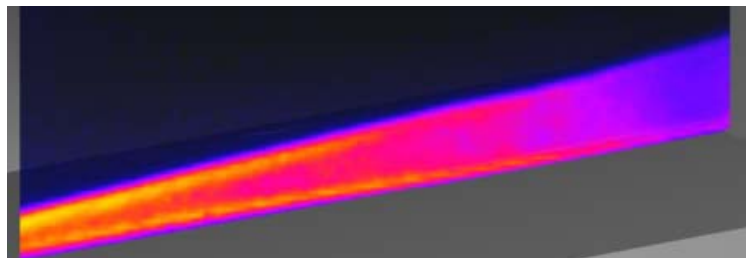

(e)

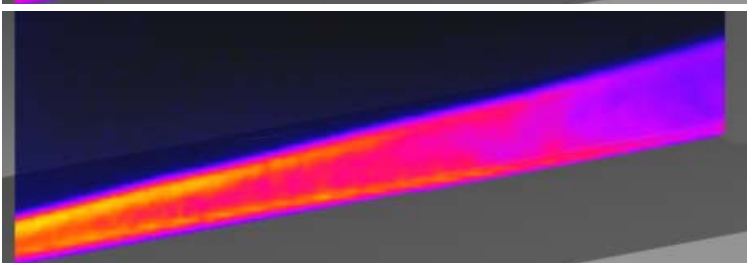

(g)

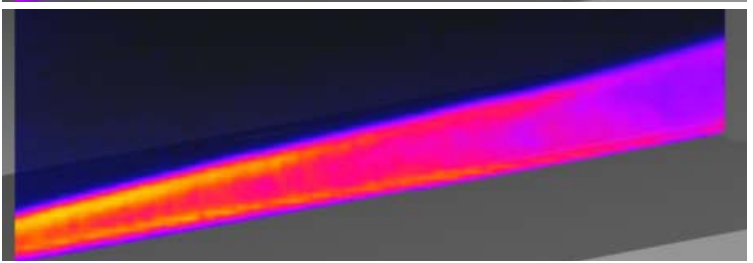

(i)

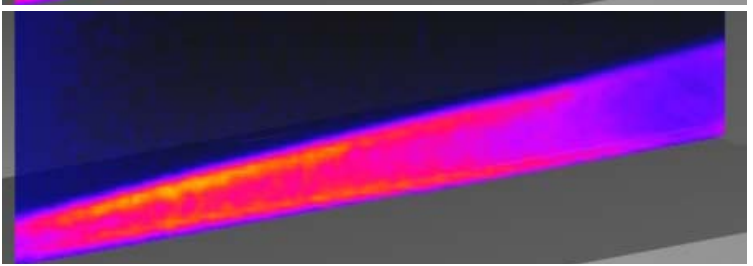

(k)

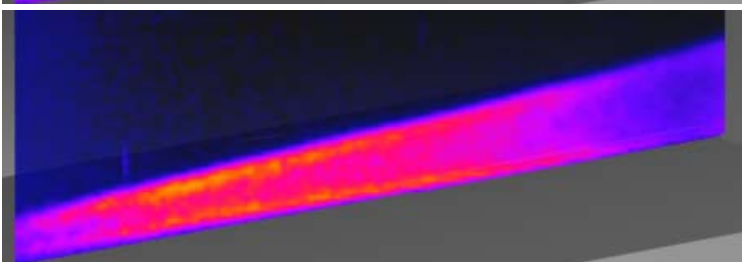

(m)

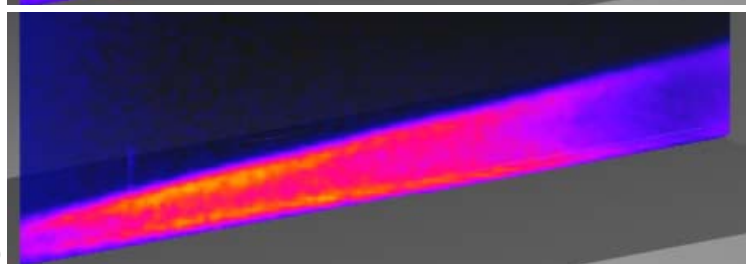

Figure A22: Test 463 , Run $21,20^{\circ}$ compression corner, plate angle $=10^{\circ}$, 11 -mm wide slot seeding, $\dot{m}=300 \mathrm{sccm}$, $\mathrm{P}_{0}=9.34 \mathrm{MPa}$, framing rate $=100 \mathrm{kHz}$. 
(a)

(b)

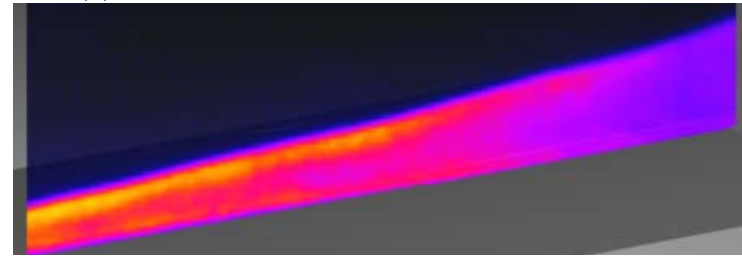

(d)

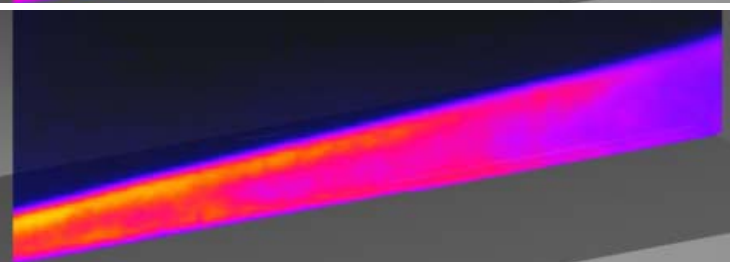

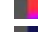

(f)

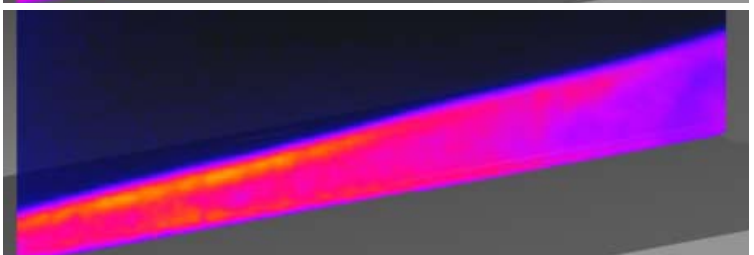

()

(h)

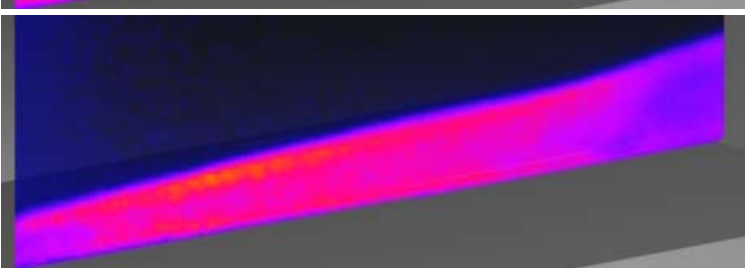

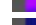

(j)

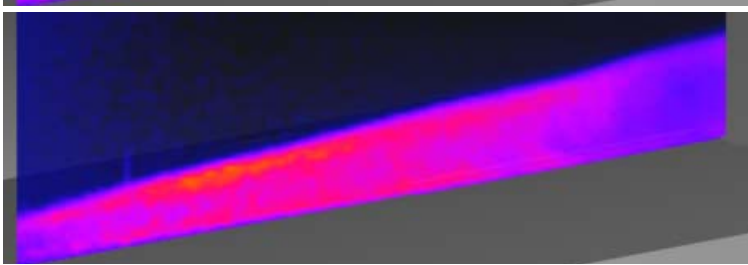

)

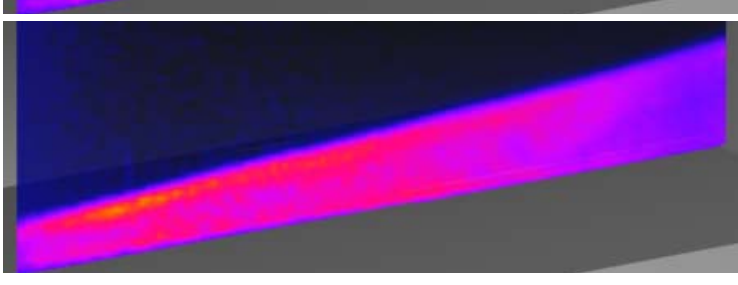

(c)

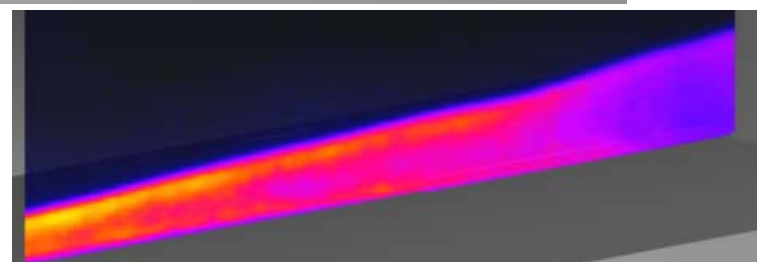

(e)

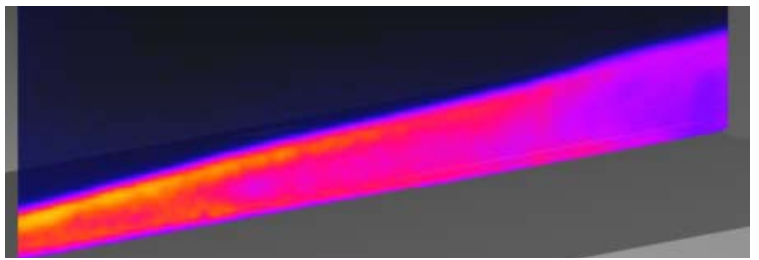

(g)

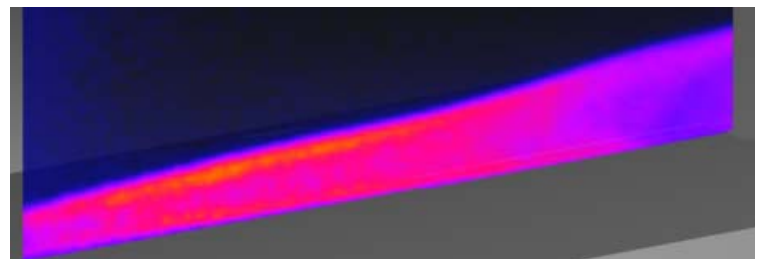

(i)

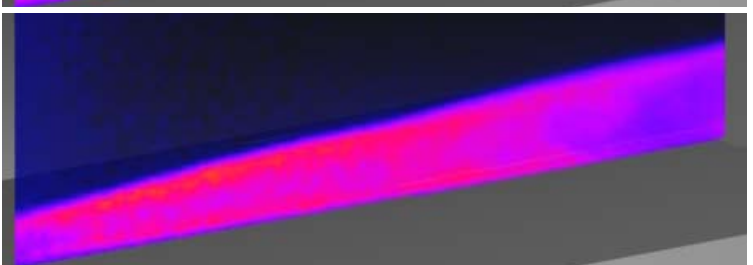

(k)

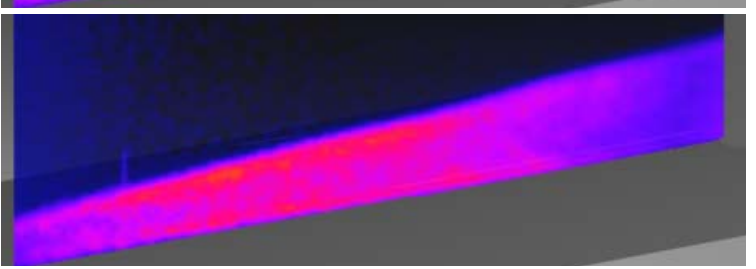

(m)

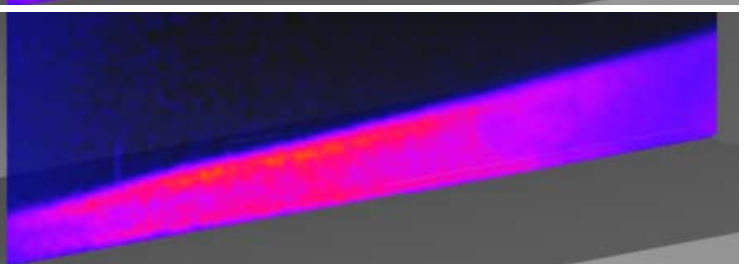

Figure A23: Test 463, Run 21, $20^{\circ}$ compression corner, plate angle $=10^{\circ}$, 11 -mm wide slot seeding, $\dot{m}=0-1000$ sccm, $\mathrm{P}_{0}=9.34 \mathrm{MPa}$, framing rate $=100 \mathrm{kHz}$. 
(a)

(b)

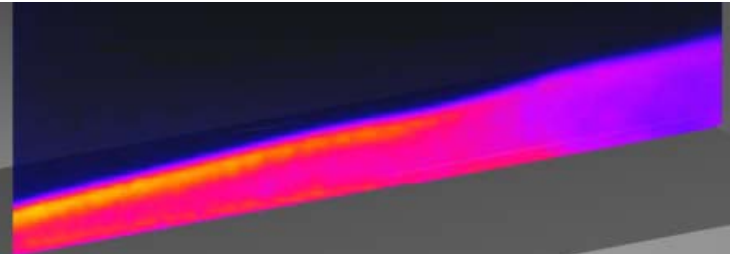

(d)

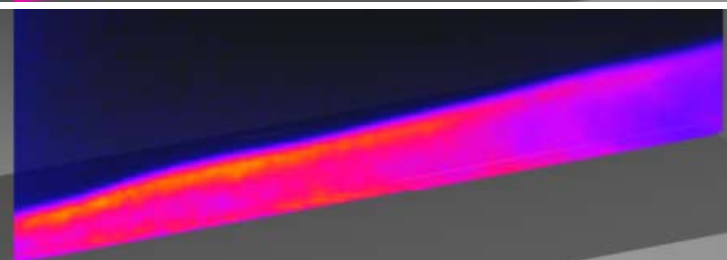

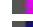

(f)

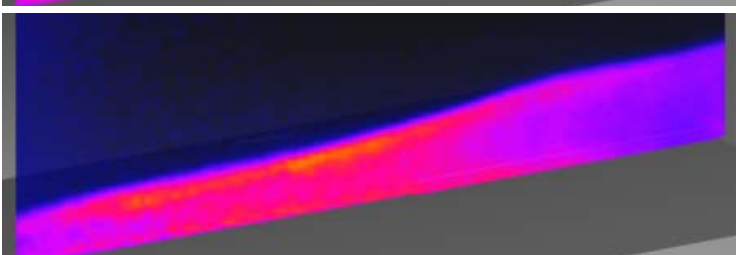

.

(h)

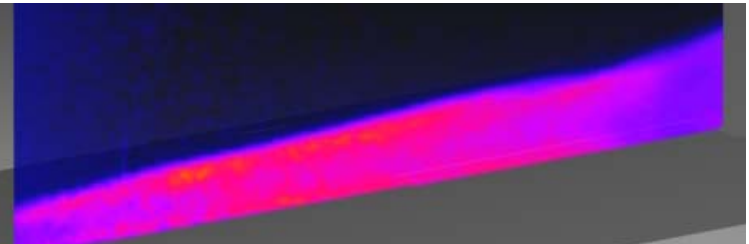

-

(j)

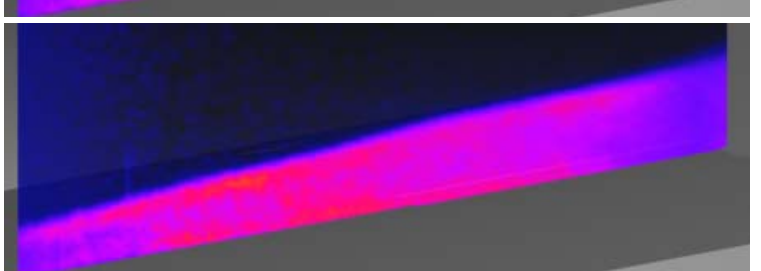

)

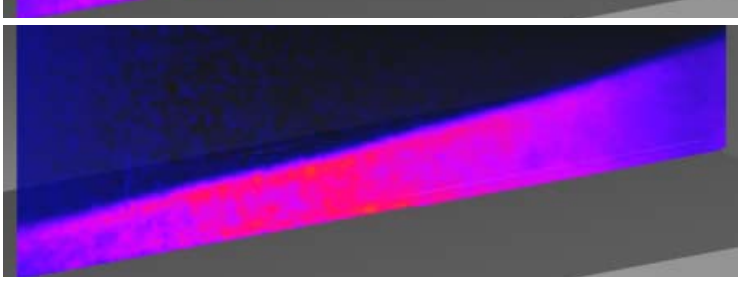

(c)

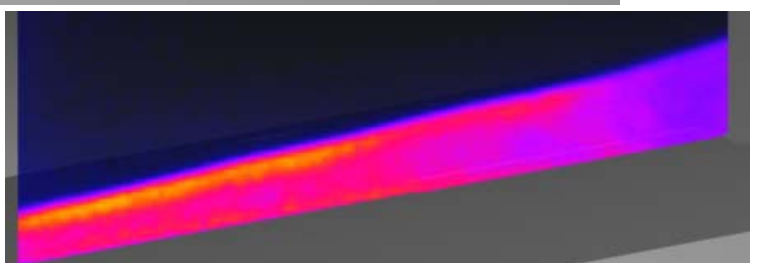

(e)

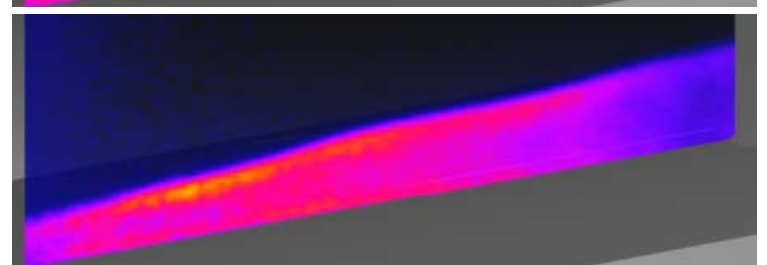

(g)

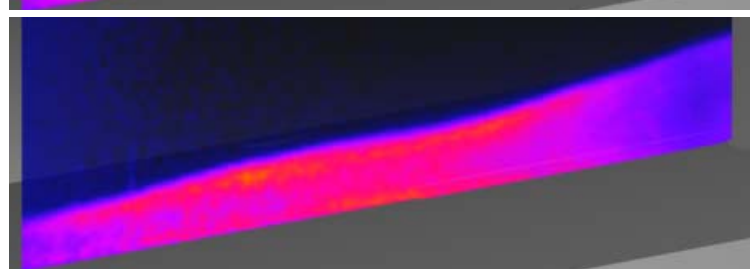

(i)

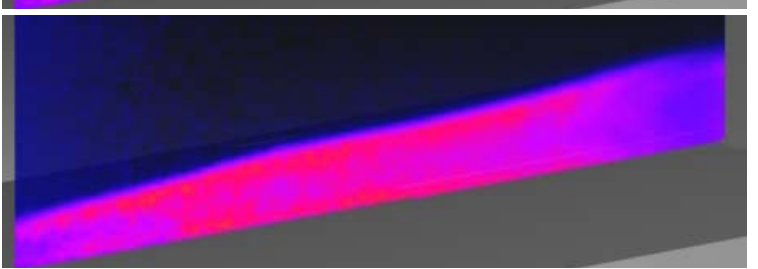

(k)

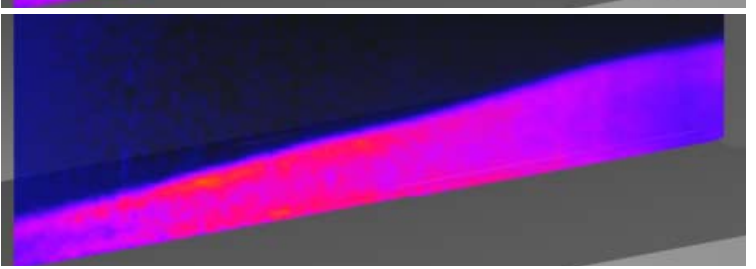

(m)

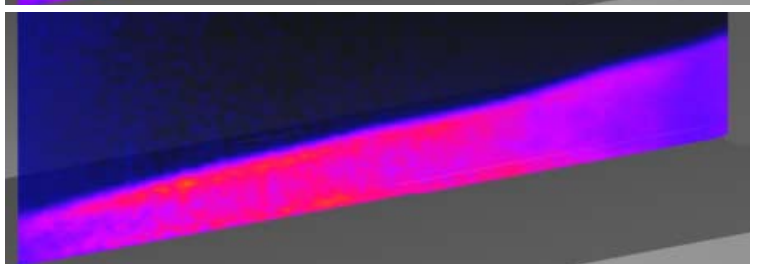

Figure A24: Test 463, Run 21, $20^{\circ}$ compression corner, plate angle $=10^{\circ}$, 11 -mm wide slot seeding, $\dot{m}=0-1000$ sccm, $\mathrm{P}_{0}=9.34 \mathrm{MPa}$, framing rate $=100 \mathrm{kHz}$. 